Prepared as part of a Technical Assistance Agreement with Sound Transit

\title{
Results of Hydrologic Monitoring on Landslide-Prone Coastal Bluffs Near Mukilteo, Washington
}

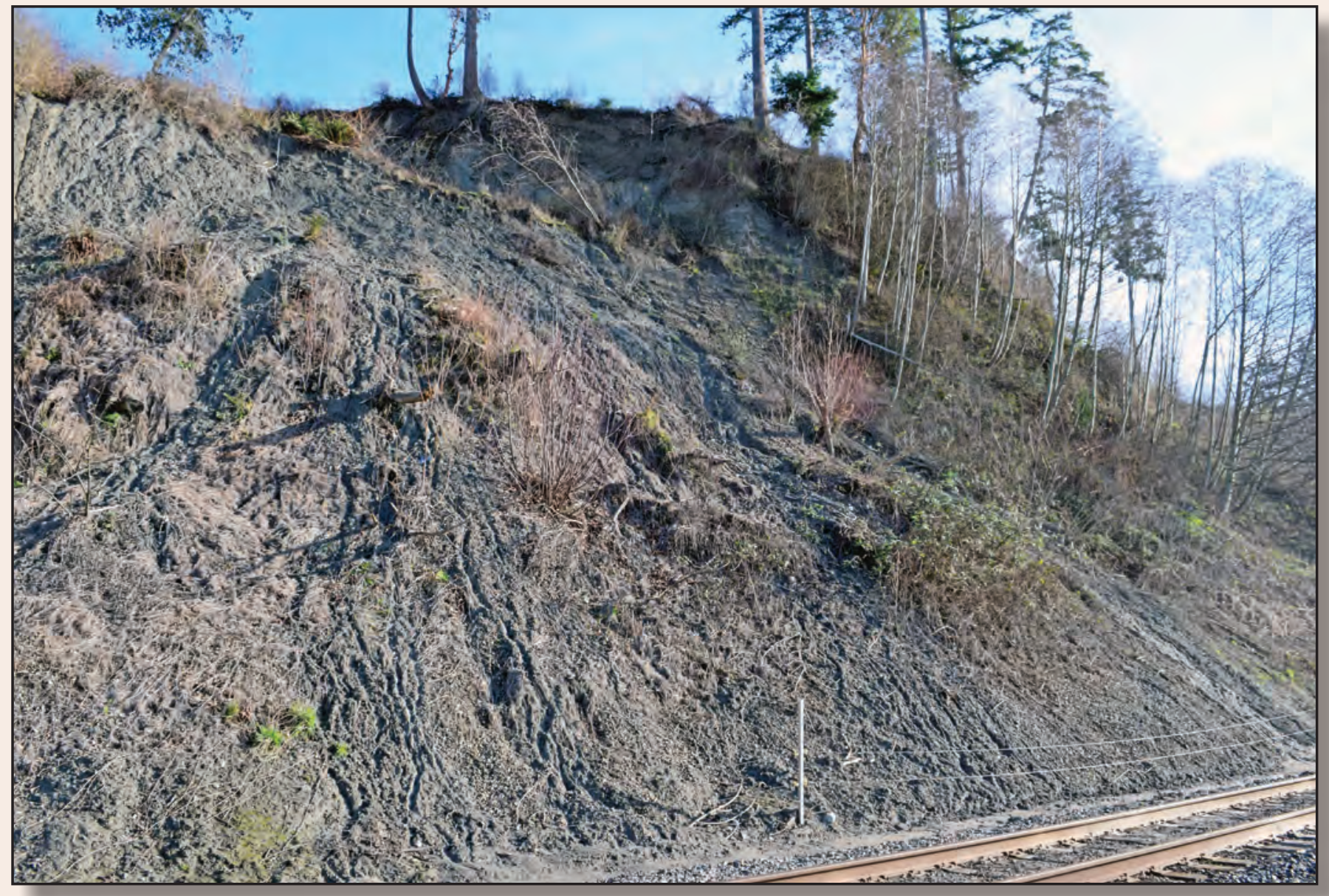

Open-File Report 2017-1095

U.S. Department of the Interior

U.S. Geological Survey 
Cover. A monitored landslide on the eastern coast of the Puget Sound, near Mukilteo, Washington. The toe beneath the mid-bluff bench and a southern portion of the landslide's headscarp and crown can be seen in the photo. Evidence of recent water and material flow were found during a site visit, February 2016, when this photo was taken. Burlington Northern-Santa Fe railroad tracks can be seen in the foreground. 


\section{Results of Hydrologic Monitoring on Landslide-Prone Coastal Bluffs Near Mukilteo, Washington}

By Joel B. Smith, Rex L. Baum, Benjamin B. Mirus, Abigail R. Michel, and Ben Stark

Prepared as part of a Technical Assistance Agreement with Sound Transit

Open-File Report 2017-1095 


\title{
U.S. Department of the Interior \\ RYAN K. ZINKE, Secretary
}

\section{U.S. Geological Survey William H. Werkheiser, Acting Director}

\author{
U.S. Geological Survey, Reston, Virginia: 2017
}

For more information on the USGS - the Federal source for science about the Earth, its natural and living resources, natural hazards, and the environment—visit http://www.usgs.gov or call 1-888-ASK-USGS.

For an overview of USGS information products, including maps, imagery, and publications, visit http://store.usgs.gov.

Any use of trade, firm, or product names is for descriptive purposes only and does not imply endorsement by the U.S. Government.

Although this information product, for the most part, is in the public domain, it also may contain copyrighted materials as noted in the text. Permission to reproduce copyrighted items must be secured from the copyright owner.

Suggested citation:

Smith, J.B., Baum, R.L., Mirus, B.B., Michel, A.R., and Stark, B., 2017, Results of hydrologic monitoring on landslideprone coastal bluffs near Mukilteo, Washington: U.S. Geological Survey Open-File Report 2017-1095, 48 p. https://doi.org/10.3133/ofr20171095.

ISSN 2331-1258 (online) 


\section{Preface}

The work described in this report was undertaken as part of a Technical Assistance Agreement between the U.S. Geological Survey and Sound Transit to investigate landslide hazards affecting the railway corridor along the eastern shore of Puget Sound between Seattle and Everett, Washington. This report describes a hydrologic monitoring system installed along this corridor near Mukilteo, Wash., and presents preliminary results from this system. The long-term objectives of this work are to improve understanding of the linkages between rainfall characteristics and hydrologically induced landslide initiation processes, and to inform the development of a prototype near real-time landslide hazard assessment system along the railway corridor. This report builds on companion work presented in U.S. Geological Survey Open-File Report 2016-1082 (https://doi.org/10.3133/ofr20161082) regarding the geologic site characterization of the Mukilteo monitoring site. 


\section{Acknowledgments}

This report was prepared through a Technical Assistance Agreement with Sound Transit, Seattle, Washington, under agreement \#15WNTAASNDTRNST_00. All equipment was installed on the City of Mukilteo's property with permission and access to the monitoring sites established through Temporary Right of Entry and License Agreements with the City of Mukilteo and the Home Owners Associations of One Club House Lane Sector 12 and Waterton at Harbour Pointe. Logistical support for site access and equipment procurement was provided by Jeff Chou of Sound Transit. The authors are grateful for the helpful review comments and suggestions on an earlier version of this work from U.S. Geological Survey colleagues Brian Collins and Francis Rengers. 


\section{Contents}

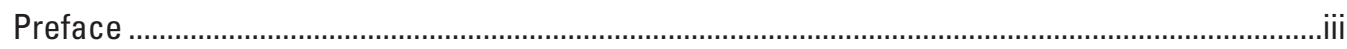

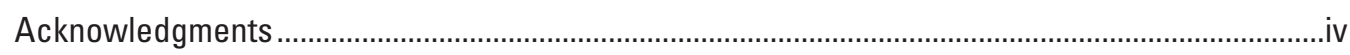

Abstract

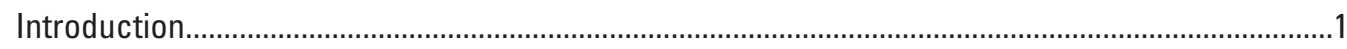

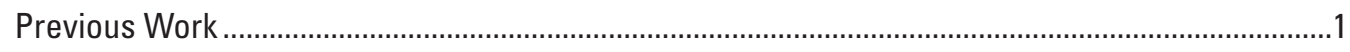

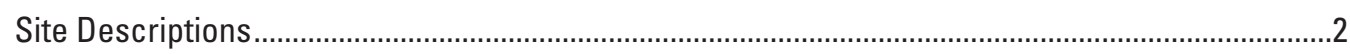

Hydrologic Monitoring Sites ...............................................................................................

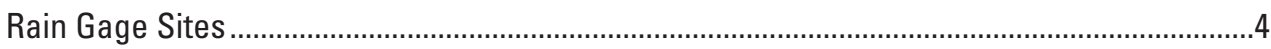

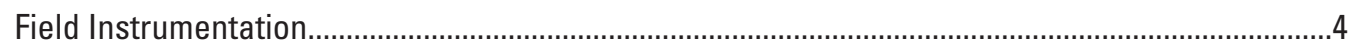

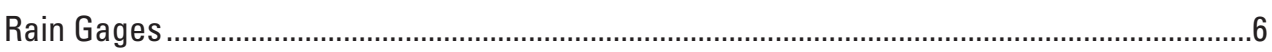

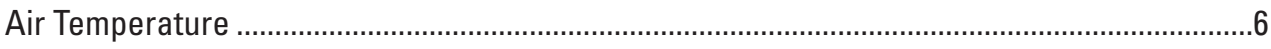

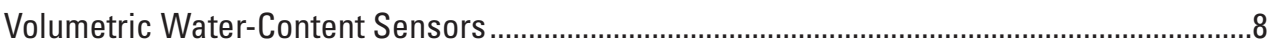

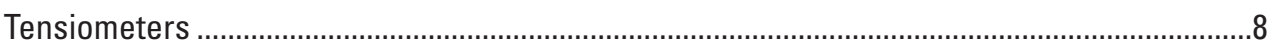

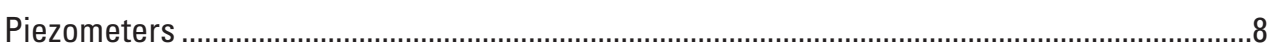

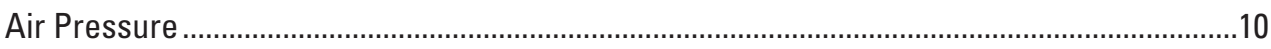

System Reliability and Recommended Improvements .................................................................10

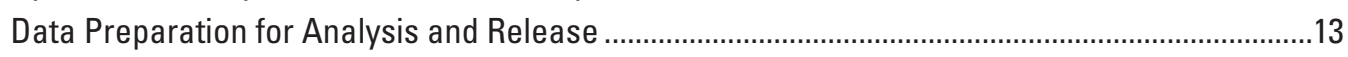

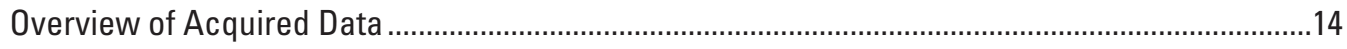

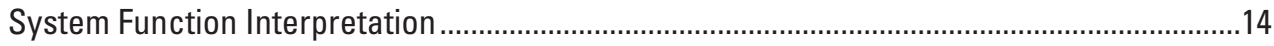

Rain Gage Data Interpretation...................................................................................... 14

Vegetated Hillslope Site Data Interpretation .................................................................14

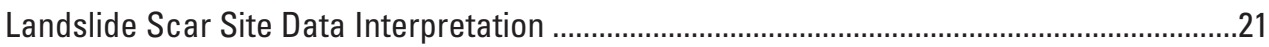

Conditions During Slide Initiation or Reactivation ..................................................................21

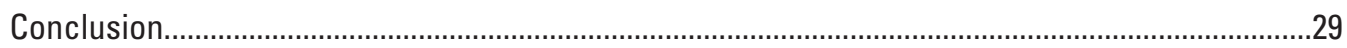

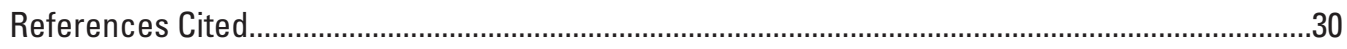

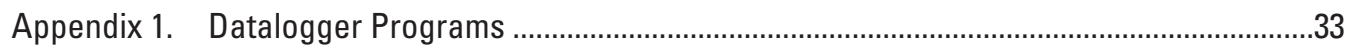

\section{Figures}

1. Map of the central Puget Sound area showing the relative locations of the four monitoring sites at Mukilteo Lighthouse Park, Landslide Scar, Mukilteo Water and Wastewater District Water Treatment Plant, and Vegetated Hillslope.

2. Cross-sectional view of instrument cluster elevations at the Vegetated Hillslope (VH) and Landslide Scar (LS) monitoring sites and plan views of the VH and LS monitoring sites ............................................................................................

3. Photo of typical rain gage installation showing datalogger enclosure and air temperature sensor assembly 5

4. Photo of typical volumetric water-content sensor installation and piezometer

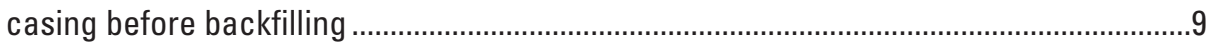

5. Photo of typical tensiometer and volumetric water-content sensor installation .............11

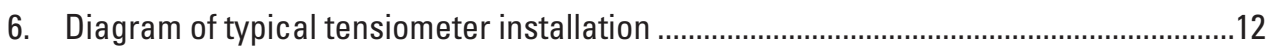

7. Diagram showing the operating characteristics of a tensiometer ..................................12 
8. Timeline of instrument installation and operating status

9. Graphs showing hourly and cumulative rainfall amounts recorded the Vegetated Hillslope, Landslide Scar, Mukilteo Water and Wastewater District Water Treatment Plant, and Mukilteo Lighthouse Park sites for the monitoring period.

10. Graph showing average monthly rainfall statistics for Everett, Washington, for 1915-2016

11. Bar graph showing yearly rainfall totals recorded in Everett, Washington, between 1915 and 2016.

12. Graphs showing volumetric water-content values for each instrument cluster at, and a rainfall plot for, the Vegetated Hillslope site for the complete monitoring period.

13. Graph comparing the relative volumetric water-content measurements taken at each instrument cluster at, and a rainfall plot for, the Vegetated Hillslope site from November 2015 through January 2016

14. Graphs showing pore-water pressure (soil-water potential) values for the Vegetated Hillslope (VH) site from both vibrating-wire piezometers (VH1 and $\mathrm{VH} 5$ ) and tensiometers (VH2, VH3, and $\mathrm{VH} 5)$, and a rainfall plot for the $\mathrm{VH}$ site, over the complete monitoring period

15. Graphs showing volumetric water-content values for each instrument cluster at, and a rainfall plot for, the Landslide Scar site for the complete monitoring period.

16. Graphs showing pore-water pressure (soil-water potential) values for the Landslide Scar (LS) site from both vibrating-wire piezometers (LS1 and LS5) and tensiometers (LS2, LS3, and LS4), and a rainfall plot for the LS site, for the complete monitoring period

17. Graphs showing volumetric water-content conditions and rainfall quantities leading up to landslide reactivation at the Landslide Scar site.

18. Graphs showing pore-water pressure conditions and rainfall quantities leading up to landslide reactivation at the Landslide Scar site.....

19. Graphs showing volumetric water-content and rainfall at the Vegetated Hillslope site during confirmed times of increased landslide hazard.

20. Graphs showing pore-water pressure and rainfall at the Vegetated Hillslope site during confirmed times of increased landslide hazard

\section{Tables}

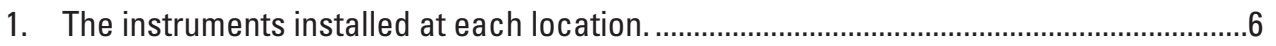

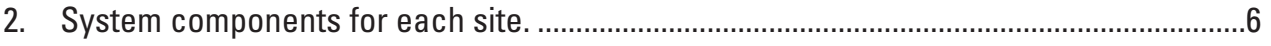

3. Installation depths of volumetric water-content sensors.............................................10

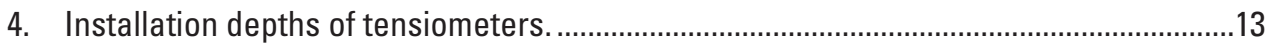

5. Installation depths of the vibrating-wire piezometers....................................................13 


\section{Conversion Factors}

International System of Units to U.S. customary units

\begin{tabular}{lll}
\hline \multicolumn{1}{c}{ Multiply } & By & \multicolumn{1}{c}{ To obtain } \\
\hline centimeter $(\mathrm{cm})$ & Length & inch (in.) \\
millimeter $(\mathrm{mm})$ & 0.3937 & inch (in.) \\
meter $(\mathrm{m})$ & 0.03937 & foot $(\mathrm{ft})$ \\
kilometer $(\mathrm{km})$ & 3.281 & mile (mi) \\
\hline & 0.6214 & \\
\hline cubic centimeter $\left(\mathrm{cm}^{3}\right)$ & Volume & cubic inch $\left(\mathrm{in}^{3}\right)$ \\
liter $(\mathrm{l})$ & 0.06102 & cubic inch $\left(\mathrm{in}^{3}\right)$ \\
\hline & 61.02 & \\
\hline kilopascal $(\mathrm{kPa})$ & Pressure & atmosphere, standard $(\mathrm{atm})$ \\
kilopascal $(\mathrm{kPa})$ & 0.009869 & bar \\
kilopascal $(\mathrm{kPa})$ & 0.01 & inch of mercury at $60{ }^{\circ} \mathrm{F}(\mathrm{in} \mathrm{Hg})$ \\
kilopascal $(\mathrm{kPa})$ & 0.2961 & pound-force per inch $(\mathrm{lbf} / \mathrm{in})$ \\
kilopascal $(\mathrm{kPa})$ & 0.1450 & pound per square foot $\left(\mathrm{lb} / \mathrm{ft}^{2}\right)$ \\
kilopascal $(\mathrm{kPa})$ & 20.88 & pound per square inch $\left(\mathrm{lb} / \mathrm{ft}^{2}\right)$ \\
\hline
\end{tabular}

Temperature in degrees Celsius $\left({ }^{\circ} \mathrm{C}\right)$ may be converted to degrees Fahrenheit $\left({ }^{\circ} \mathrm{F}\right)$ as follows:

$$
{ }^{\circ} \mathrm{F}=\left(1.8 \times{ }^{\circ} \mathrm{C}\right)+32
$$

\section{Datum}

Vertical coordinates are heights above mean sea level (meters) in the North American Vertical Datum of 1988 (NAVD 88).

Horizontal coordinates are Universal Transverse Mercator, Zone 10, meters.

Elevation, as used in this report, refers to distance above the vertical datum.

\section{Abbreviations}

LS Landslide Scar

MLP Mukilteo Lighthouse Park

MWWD Mukilteo Water and Wastewater District Water Treatment Plant

USGS U.S. Geological Survey

VH Vegetated Hillslope

VWC volumetric water content

VWP vibrating-wire piezometers 



\title{
Results of Hydrologic Monitoring on Landslide-Prone Coastal Bluffs Near Mukilteo, Washington
}

\author{
By Joel B. Smith, Rex L. Baum, Benjamin B. Mirus, Abigail R. Michel, and Ben Stark
}

\begin{abstract}
A hydrologic monitoring network was installed to investigate landslide hazards affecting the railway corridor along the eastern shore of Puget Sound between Seattle and Everett, near Mukilteo, Washington. During the summer of 2015, the U.S. Geological Survey installed monitoring equipment at four sites equipped with instrumentation to measure rainfall and air temperature every 15 minutes. Two of the four sites are installed on contrasting coastal bluffs, one landslide scarred and one vegetated. At these two sites, in addition to rainfall and air temperature, volumetric water content, pore pressure, soil suction, soil temperature, and barometric pressure were measured every 15 minutes. The instrumentation was designed to supplement landslide-rainfall thresholds developed by the U.S. Geological Survey with a long-term goal of advancing the understanding of the relationship between landslide potential and hydrologic forcing along the coastal bluffs. Additionally, the system was designed to function as a prototype monitoring system to evaluate criteria for site selection, instrument selection, and placement of instruments. The purpose of this report is to describe the monitoring system, present the data collected since installation, and describe significant events represented within the dataset, which is published as a separate data release. The findings provide insight for building and configuring larger, modular monitoring networks.
\end{abstract}

\section{Introduction}

Each winter, when soil moisture and groundwater levels are elevated due to long periods of continuous rainfall and infiltration, the coastal bluffs along Washington's Puget Sound are prone to rainfall-initiated shallow landsliding. Coastal-bluff landsliding has been documented along parts of Puget Sound since the construction of railroad tracks at the base of the coastal bluffs in the late 19th century (Laprade and others, 2000). The installation of the railroad tracks mandated construction techniques that limit wave erosion and consequently limit toe-slope recession. Although full-height bluff erosion has since been limited, bluff crests have continued to recede and the average slope-angle above the tracks has decreased (for example, Shipman, 2004). Although the bluffs are seemingly more stable, concentrated runoff over bluff crests caused by human activities and the presence of seeps and springs on the bluff face continue to cause mobilization of accumulated debris in the form of landslides. These landslides subsequently affect train operations on the railroad tracks located below the bluffs. Both cargo and passenger trains use the train tracks throughout the rainy winter season when operations are occasionally suspended due to landslide activity.

Threats to life due to landslides have motivated an interest in landslide forecasting and (or) warning systems in the greater Puget Sound area. This, in turn, has led to a suite of research endeavors by the U.S. Geological Survey (USGS) regarding criteria for landslide prediction and warning (Chleborad, 2000, 2003; Coe and others, 2004; Baum and others, 2005; Godt and others, 2006; Chleborad and others, 2008; Godt and McKenna, 2008; Schulz and others, 2008). Building on previous research regarding regional landsliding, the USGS installed a network of monitoring systems along the bluffs in summer 2015 (for example, Mirus and others, 2016). The USGS expects that new monitoring and analysis techniques will provide novel ways to quantify hazard in near real time. This work was carried out in cooperation with Sound Transit, which aims to minimize service delays and maximize passenger safety. This report provides details of the monitoring instrumentation installations, as well as monitoring summaries, for the first year of data collection (July 11, 2015 to August 9, 2016).

\section{Previous Work}

Previous research on coastal-bluff landsliding in the Puget Sound area has been inspired by climatic events leading to widespread landslide damage. Some of this research serves as a basis for this project. Tubbs $(1974,1975)$ reported on landslides caused by storms in 1972. In those reports, 50 landslides previously recorded in Federal relief disaster records, which are biased toward large and (or) destructive events, were analyzed to identify general causes and attributes. Tubbs $(1974,1975)$ 
Results of Hydrologic Monitoring on Landslide-Prone Coastal Bluffs Near Mukilteo, Washington

identified the primary control as intense rainfall, with a secondary control of greater-than-average rainfall total. The rainfall in February 1972 exceeded annual average rainfall totals by about 50 millimeters (mm), and in March 1972 exceeded average amounts by about $75 \mathrm{~mm}$. Subsequent landslides occurred on days with rainfall totals of $25-50 \mathrm{~mm}$. Although almost $50 \mathrm{~mm}$ of rain fell on January 20, 1972, no landslides were recorded presumably because the moisture content and pore-water pressure levels of the susceptible ground had not yet reached a critical threshold. Thus, Tubbs' work indicated that rainfall-induced bluff landslides, in general, occurred primarily when intense rainfall fell when groundwater levels were already elevated.

Following four severe storm events during 1996-97 that caused major landsliding in the Puget Sound area (Baum and others, 2000), and building on the work of Tubbs (1974), Chleborad (2000) proposed the use of a precipitation-threshold based approach to predictively identify time periods of greater than normal landslide susceptibility. Chleborad based this threshold on a local historical landslide database (Laprade and others, 2000) that identified the timing and associated climatic conditions of 187 rainfall-induced landslide events. The work relied on cumulative 18-day rainfall totals and demonstrated an empirical relationship between the most recent 3-day rainfall amount necessary to initiate landsliding and the antecedent 15-day rainfall needed for steep slopes to be sufficiently susceptible to failure. Additionally, because snowmelt played a significant role in the events of 1996-97, Chleborad proposed an air-temperature index. Chleborad (2000) also suggested that a distinction be made between the various types of landslide events that might be predicted with this method and pointed out that rotational and translational slides respond differently to rainfall, with rotational slides occurring more gradually than translational slides. The bluffs are susceptible to both varieties of slides (Tubbs, 1975).

To more fully understand the role of groundwater in bluff landsliding, Baum and others (2005) installed two monitoring sites in Edmonds and Everett to investigate the hydrological conditions leading to landslide susceptibility. A variety of different instrumentation, including rain gages, soil moisture sensors, pressure transducers, and soil-water potential sensors, were installed at the two sites. Notably, this work also considered landslide timing and frequency information during the monitoring period, which was originally compiled in part by Chleborad (2003). This timing information provided useful evidence of the relationship between landslides and hydrological conditions. Given the timing relationship, the monitoring activities helped to clarify the roles of antecedent wetness and subsequent rainfall intensity that was consistent with Chleborad's (2000) threshold work. Baum and others (2005) concluded that (1) soil-wetness monitoring could reliably indicate when the upper 1-2 meters (m) of soil were sufficiently wet for slope instability and (2) continuous monitoring of precipitation could be used to forecast landsliding after antecedent conditions are met.

In preparation for the instrumentation installation described in this report, Mirus and others (2016) performed a geologic site characterization for the hydrologic monitoring sites. The specimens collected for analysis exhibited material and hydrologic properties that are consistent with previously reported values for bluff materials in the Seattle area (Savage and others, 2000; Godt and McKenna, 2008). Material properties determined by laboratory testing can be used in conjunction with monitoring-site data for a more complete understanding of material behavior under conditions that lead to a loss of mechanical stability. Additionally, Mirus and others (2016) provide information regarding the project background and bluff geology.

\section{Site Descriptions}

The monitoring network presented herein consists of four sites (fig. 1). Two sites are located on coastal bluffs and are outfitted with a suite of surface and subsurface instrumentation (Hydrologic Monitoring Sites). The other two sites are located on nearby, climatically representative settings and outfitted only with rain gages and temperature sensors (Rain Gage Sites).

\section{Hydrologic Monitoring Sites}

The two sites installed on coastal bluffs include surface and subsurface instrumentation to record precipitation, air temperature, barometric pressure, volumetric water content (VWC), soil-water potential, and pore-water pressure. The bluffs within the area are, generally, subhorizontally bedded deposits of glaciolacustrine and glaciomarine materials (Minard, 1983). This subhorizontal bedding contributes to lateral flow that often appears as springs and seeps on the bluff face and is believed to be a contributor to slope instability during periods of heavy rainfall (for example, Mirus and others, 2016). The sites are located within City of Mukilteo open-space areas and site access requires permission from adjacent property owners. The southernmost site, referred to herein as the "Vegetated Hillslope" (VH), is located on a bluff area that has not experienced any significant slope failures in the near past, inferred by the presence of mature vegetation. The land immediately above the crest of the bluff is relatively undeveloped.

The second hydrologic monitoring site, herein referred to as the "Landslide Scar" (LS), is located about 0.6 kilometers $(\mathrm{km})$ north of VH (fig. 1). Although geologically similar to the VH site (Mirus and others, 2016), LS experienced a slope failure during winter 2013. Consequently, site vegetation and tree canopy are immature or absent at LS. The landslide failure at the 


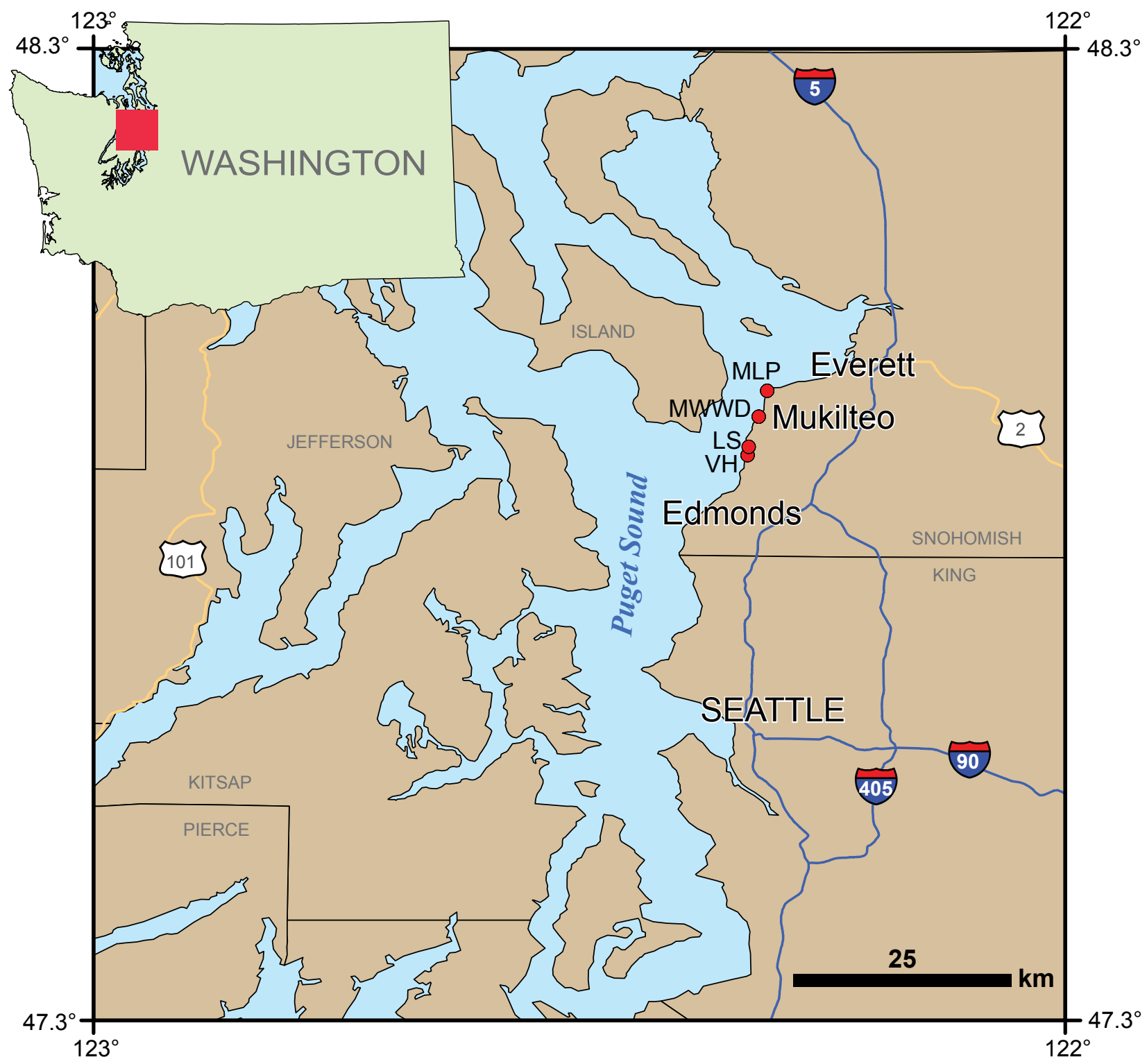

Figure 1. Map of the central Puget Sound area showing the relative locations of the four monitoring sites at Mukilteo Lighthouse Park (MLP), Landslide Scar (LS), Mukilteo Water and Wastewater District Water Treatment Plant (MWWD), and Vegetated Hillslope (VH). Nearby city center and county names are also shown.

site was a rotational earth slide (following the terminology of Varnes, 1978). Using local terminology (Thorsen, 1987), the failure can be described as an "upper bluff slump." This type of failure is generally thought to be caused by a buildup of porewater pressure at the contact of relatively permeable sand deposits located above lower-permeability clay units (see for example, Tubbs, 1974; Baum and others; 2000; Harp and others, 2006). However, Schulz and others (2008) indicate that only about 29 percent of similar historical landslides in the Puget Sound area fail under this type of seepage mechanism, with an additional 64 percent of similar historical failures seemingly independent of a local seepage zone and associated impermeable sand-clay contact. According to Thorsen (1987), following an initial failure, a steep, unsupported, arcuate scarp is left below the landslide crown that transitions into a hummocky, sag-pond like, mid-bluff bench. In many cases, the portion of the bluff below the bench can be very steep, and although veneered in landslide deposits, usually contributes to unchecked material translation towards the foot of the slope (and subsequently to the train tracks). After an initial slide occurs, the disturbed material is increasingly susceptible to other types of smaller mass movements. In a map of landslides that occurred during the 1996-97 storms, about two-thirds of the newly mapped landslides occurred within the bounds of previously mapped landslides, and this correlation suggests that reactivation of previous slides may be significant (Baum and others, 2000). 
Monitoring operations at LS were impacted by secondary debris flows originating from mobilization of the saturated toe (or bench deposits) from the depletion zone, as well as retrogressive headscarp failures in the form of composite slides or topples. It was confirmed during winter 2016 site visits that several remobilization and retrogressive mass movements disturbed the monitoring equipment. At least one covered the train tracks.

\section{Rain Gage Sites}

Two rain gage monitoring sites, consisting only of rain gages and air temperature sensors, were installed to provide auxiliary data regarding the spatial variability of rainfall in the area. One site is located at Mukilteo Lighthouse Park (MLP) and the other site is located about $4 \mathrm{~km}$ south of MLP and $1.4 \mathrm{~km}$ north of LS at the Mukilteo Water and Wastewater District Water Treatment Plant (MWWD) (fig. 1). These specific locations were chosen due to their proximity to the bluffs, ease of site accessibility, and lack of topographical features, trees, or other structures that might block, intercept, or otherwise influence measured rainfall quantities.

\section{Field Instrumentation}

Previous research (Tubbs, 1974; Baum and others, 2005) has demonstrated that rainfall-induced landslide initiation in the Puget Sound area is dependent on the combination of accumulated soil moisture and intense rainfall, which leads to high pore-water pressure. Thus, a suite of instruments was selected for installation that is capable of measuring these types of signals. Other factors considered in instrumentation design were ease of signal interpretation, power usage requirements of a solarpowered system, instrument familiarity, and the feasibility of system scalability (for example, future installations of multiple duplicate systems by operational staff).

A systematic approach to determining the instrument location points was devised before the specific field sites were identified. Ideally, the best observations would be made at sites where the topography and corresponding hydrologic measurements give an accurate indication of slope failure vulnerability. For example, the optimal location to install sensors would be along a known plane of instability. Unfortunately, these ideal measurement points are only identified (if they exist) after slope failure, requiring either extensive post-failure geological testing or "lucky" instrument placement. Furthermore, although the soil stratigraphy lies in a somewhat orderly fashion along the bluffs (with roughly horizontal bedding planes), the layer elevations can vary locally due to nonuniform deposition, surface discontinuities, and previous erosional events. We sought to address this spatial variability by placing instruments at each bluff site in a systematic manner at five locations oriented along a generalized sectional line (fig. 2). The depth of instrumentation installation was selected during onsite field investigations, and spatial-depth variability at the LS site was partially addressed by the use of paired instruments.

Each monitoring system uses a Campbell Scientific datalogger for instrument and peripheral control, data acquisition, and telemetry. Additionally, each of the four sites has a duty-cycled cellular modem used in conjunction with the datalogger. The cellular modem transmits data in near real-time to USGS offices in Golden, Colorado, and Sound Transit offices in Seattle, Washington. The rain gage station modems are powered for the first 10 minutes of every hour, and the hydrologic station modems are powered the first half of every hour. A normally closed relay (Crydom DC60S3-B) controls the modem power state and provides a communications fail safe in case of logger malfunction or relay failure.

The instrumentation at VH and LS are similar (table 1) and were installed using identical methods as described below. The instrumentation at each site consists of a rain gage, soil moisture sensors, vibrating-wire water pressure transducers, and soil-suction tensiometers placed along five instrumented areas along the bluff transects. At the VH site (fig. 2), the instrument clusters are labeled as VH1throughVH5; VH1 is located near the top of the VH bluff and VH5 near its base. At the LS site (fig. 2), the instrument clusters are labeled LS1 through LS5; LS1 is the instrumented area nearest to the crown of the landslide and LS5 is near the base of the LS bluff. A notable difference between the site configurations is that subsurface instruments are installed in pairs at LS (table 1) whereas only single instruments were installed at VH. In some cases, the "second" of each variety of sensor at the LS site was colocated with a similar sensor at a greater depth. The instrument clusters are denoted as "a" and "b" for shallow and deep installations, respectively. The LS site uses two Campbell Scientific CR1000 dataloggers running in parallel to accommodate the additional sensors, whereas $\mathrm{VH}$ only uses a single CR1000. The datalogger programs running at the hydrological monitoring sites are provided in appendix 1. Long runs from the datalogger to the instruments were accomplished using Belden 8723 cables pulled through 0.75 -inch flexible aluminum conduit with splice points located directly outside the installation pits.

The rain gage sites use Campbell Scientific, Inc., CR200x dataloggers. Rain gage and temperature probe specifications are detailed in their corresponding sections below. The program running on the CR200x dataloggers is provided in appendix 1. 

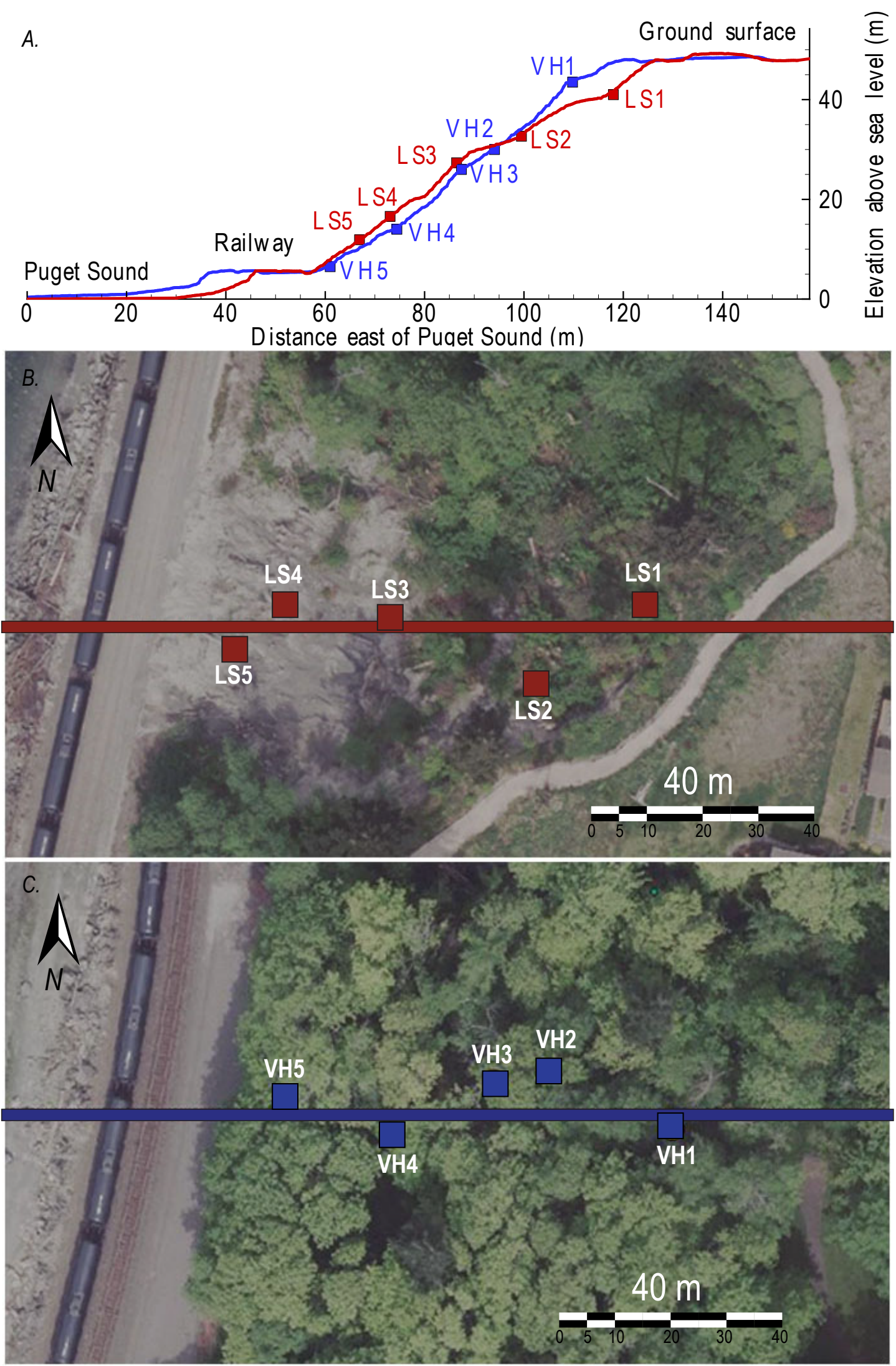

Figure 2. A, Cross-sectional view of instrument cluster elevations at the Vegetated Hillslope (VH) and Landslide Scar (LS) monitoring sites. $B$, Plan view of the VH monitoring site. $C$, Plan view of the LS monitoring site. ( $\mathrm{m}$, meter) 
Each of the sites is solar powered with sealed lead-acid batteries providing power during times with limited solar input. The VH site uses a pair of solar panels ( 50 watt and 20 watt), a 38 ampere-hour battery, and a dedicated charge controller. The LS site uses dual 50-watt solar panels, dual 38 ampere-hour batteries, and a dedicated charge controller (table 2). The rain-gage power systems consist of 20-watt solar panels, datalogger integrated charge controllers, and 7 ampere-hour batteries.

\section{Rain Gages}

Each site uses a Hydrological Services, PTY TB-4 rain gage for measuring both rainfall intensity and rainfall totals. This 200 - $\mathrm{mm}$ siphoning rain gage provides \pm 2 percent accuracy at rainfall rates between 0 and $250 \mathrm{~mm}$ per hour. The gages are post mounted about $1 \mathrm{~m}$ above the ground surface. The LS, MLP, and MWWD gages are placed in an open area free of interfering landforms or objects. Conversely, the VH gage was intentionally placed under the vegetative canopy to examine the effects of rainfall interception. The gages are fitted with a leaf filter to prohibit foreign material from settling in the measuring buckets. These leaf filters require periodic cleaning to ensure that the funnel continues to drain into the tipping buckets as intended.

\section{Air Temperature}

Each site is equipped with an air temperature sensing assembly made up of a Met One 064-2 temperature sensor (with accuracy of \pm 0.1 degree Celsius) mounted inside a Met One 5980 6-panel radiation shield (fig. 3). Due to differences between the CR1000 and CR200x dataloggers at the hydrologic and rain gage sites, respectively, the air temperature sensor is measured against a 1-volt reference at the hydrologic monitoring sites (CR1000) and against a 2.5-volt reference at the rain gage sites (CR200x). Both reference measurements are made through a $23.1 \mathrm{k}$-ohm resistor. The sensor assembly was mounted so that it would be as shaded as possible (for example, on the north side of the logger enclosure) to minimize solar radiation heating effects.

Table 1. The instruments installed at each location.

[Ah, ampere hour]

\begin{tabular}{|c|c|c|c|c|}
\hline Site location & $\begin{array}{c}\text { CR1000 } \\
\text { datalogger }\end{array}$ & $\begin{array}{c}\text { CR200x } \\
\text { datalogger }\end{array}$ & $\begin{array}{c}\text { Battery } \\
\text { capacity } \\
\text { (Ah) }\end{array}$ & $\begin{array}{l}\text { Maximum } \\
\text { solar output } \\
\text { (watts) }\end{array}$ \\
\hline Vegetated Hillslope (VH) & 1 & 0 & 38 & 70 \\
\hline Mukilteo Lighthouse Park (MLP) & 0 & 1 & 7 & 20 \\
\hline Mukilteo Water and Wastewater District Treatment Plant (MWWD) & 0 & 1 & 7 & 20 \\
\hline
\end{tabular}

Table 2. System components for each site.

[Gray shading indicates not applicable]

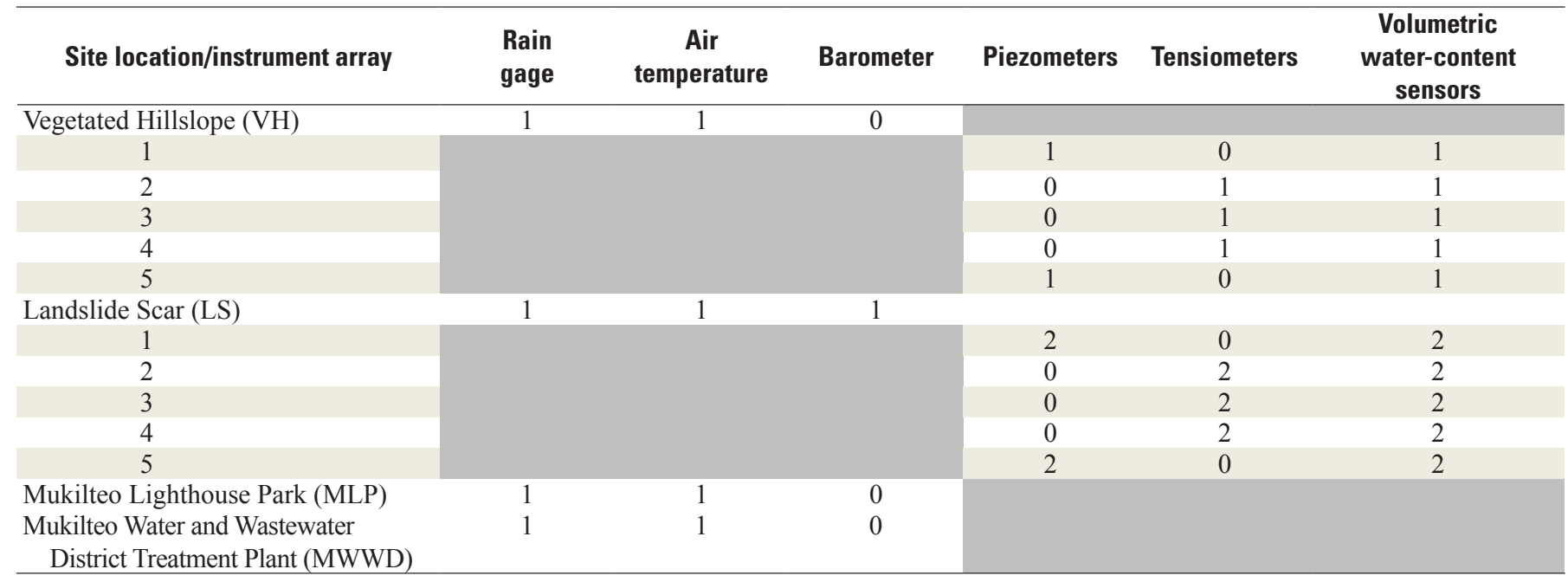




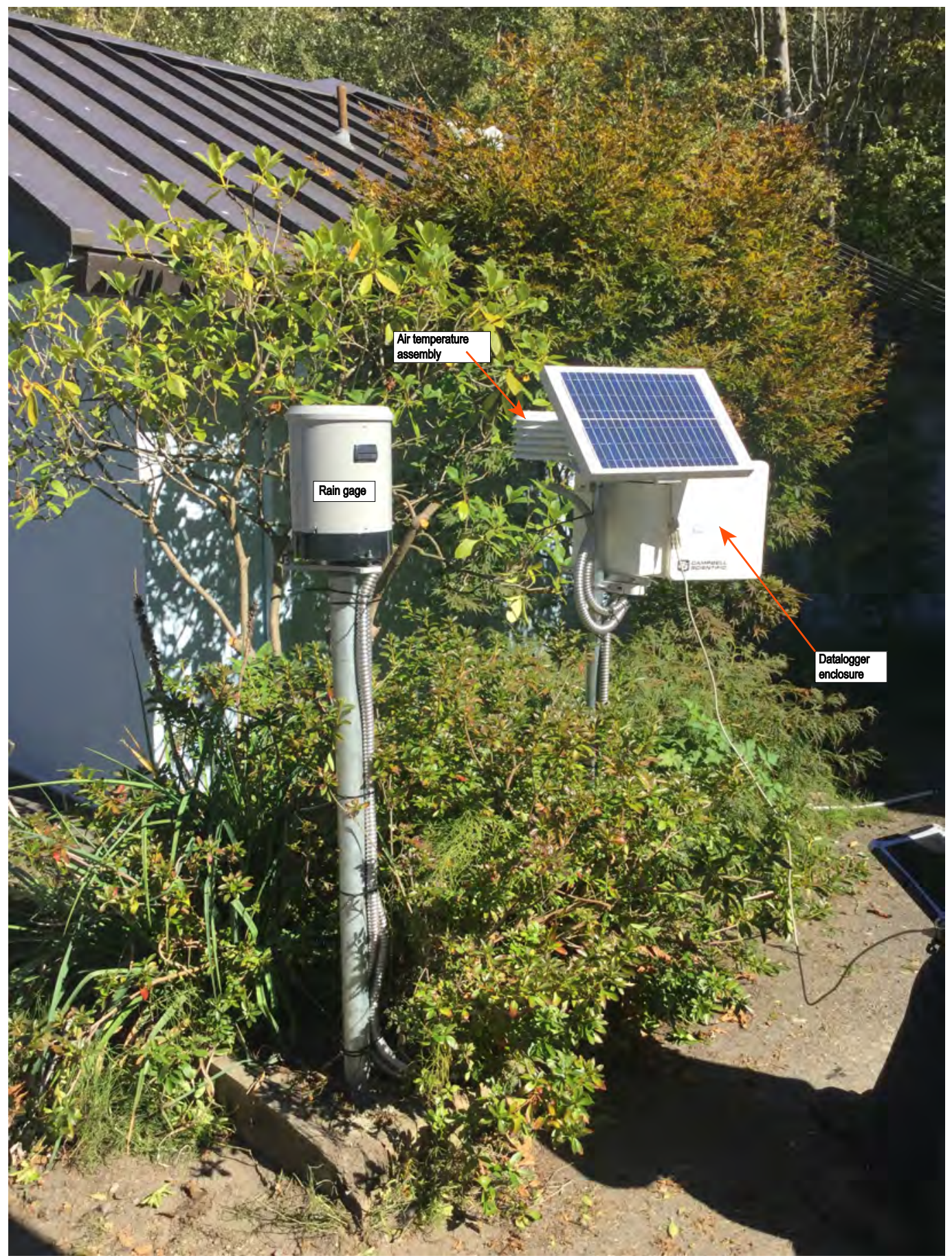

Figure 3. Photo of typical rain gage installation showing datalogger enclosure and air temperature sensor assembly. 


\section{Volumetric Water-Content Sensors}

Decagon Devices' EC-5 soil moisture sensors are used for VWC measurements. The sensor is a 5-centimeter (cm) long, electrical-conductivity (capacitive) sensor that indirectly measures the percentage of water in the surrounding 0.24 liters of soil by correlating the dielectric constant (that is, the relative permittivity) of water (which is about 80 from 0-20 degrees Celsius) to the dielectric constant of the soil media (about 1-5) (for example, Kizito and others, 2008). A calibration equation provides a measure of water content that is accurate to about 2 percent for a broad range of soils. The sensors are sensitive to temperature effects but relatively small temperature changes underground nullify the need for correction. The devices were installed (1) on edge (smallest dimension facing vertically) to minimize water ponding on the sensor and (2) in the back face of the excavated soil pits to provide realistic readings of undisturbed soil moisture response (fig. 4; see also Mirus and others, 2016). Installation depths for all sensors are provided in table 3.

Despite the stated accuracy of the VWC sensors, it is unlikely that the sensors provide an accurate measure of volumetric soil moisture because of the variability in readings caused by different soil textures and salinity properties. For example, stones near a sensor reduce the available pore space and thereby reduce the sensor's effective range. Although the sensors likely provide a reliable measure of relative soil moisture conditions, care should be taken in evaluating the data to not rely on the actual values. Comparison of the VWC values to lab measurements provided by Mirus and others (2016) should better constrain this variability. Also, for the same reason, multiple years of data from a particular sensor can assist in interpretation.

\section{Tensiometers}

Field-refillable T8 tensiometers by Umwelt-Monitoring-Systeme were installed at the midslope locations (VH2, LS2, VH3, LS3, VH4, and LS4) at both the hydrologic monitoring sites (figs. 2, 5, 6, 7 and table 4). The sensors indirectly measure soilwater potential over a range of pressures from -85 kilopascals ( $\mathrm{kPa}$ ) (unsaturated suction) to $100 \mathrm{kPa}$ (pore-water pressure) with an accuracy and resolution of $0.05 \mathrm{kPa}$. These tensiometers operate using a pressure transducer housed within a semipermeable ceramic cup located at the installation end of the instrument. The cup makes direct contact with the soil at the bottom of a 2.54-cm diameter hand-augured boring (fig. 6). Under saturated conditions, water is pushed into the cup causing the pressure within the system to increase to positive values. Under dry season conditions, water is pulled from the cup by soil tension causing negative pressure (suction) to occur within the system. After extended dry periods, this suction will ultimately cause the tensiometer to cavitate, or lose vacuum, as air enters the system. Small amounts of air entering the system result in a reduction of both response time and the operating range. A fully cavitated sensor will completely lose the ability to measure soil-water potential, and the tensiometer must be manually refilled with degassed water to resume normal operational characteristics. This is achieved in the field using dedicated tensiometer refill tubes (figs. 5 and 6) and refilling is typically performed one or more times each year depending on climatic conditions. For example, the sensor will not report actual values during periods of prolonged dryness when suction values are outside the measurement range of the instrument (for example, soil-water potential is far less than $-85 \mathrm{kPa}$ ). In these cases, tensiometer refilling should be postponed until the end of the dry season when the soil-water potential has increased to be within the tensiometer's normal operating range.

The tensiometer signals need little postprocessing for conversion to engineering units because the tensiometer has a built-in temperature probe that measures the temperature of the water in the cup and applies a temperature adjustment before outputting an analog signal. In addition, there is no need to compensate for air pressure fluctuations because the tensiometer's pressure transducer is vented through a semipermeable membrane located on the aboveground cable jacket, which makes the actual measurement reflective only of soil-water pressures rather than atmospheric pressures. To compensate for voltage drop over the wire run from the instrument to the datalogger, the tensiometer generates a differential voltage reading that is applied when the measurement is taken. The reported pressure is affected by the plunge of the instrument and varies between $0 \mathrm{kPa}$ and $0.5 \mathrm{kPa}$ between horizontal and vertical installations, respectively. These offsets have been applied to the time-series data.

\section{Piezometers}

Sealed vibrating-wire piezometers (VWP) from Durham Geo Slope Indicator are used at the hydrologic monitoring sites to measure shallow groundwater fluctuations. These devices use the fundamental resonant frequency of an enclosed, tensioned wire to indirectly measure the pressure of water against a diaphragm. The diaphragm is exposed to the environment (ideally groundwater) on the exterior of the sensor and directly coupled to the vibrating wire sensor within the instrument housing. The installed sensors can measure pressures up to $345 \mathrm{kPa}$ with an accuracy of about $\pm 0.35 \mathrm{kPa}$ and a resolution of about $0.5 \mathrm{kPa}$. The VWPs installed at the sites apparently read suction values to a limited extent as values as low as about $-5 \mathrm{kPa}$ are seen during the wet season, but only immediately after positive pressures are present. As the pressure continues to decrease, the apparent pressures increase as the sensor loses its hydraulic connection (similar to tensiometer cavitation). A built-in transducer converts 


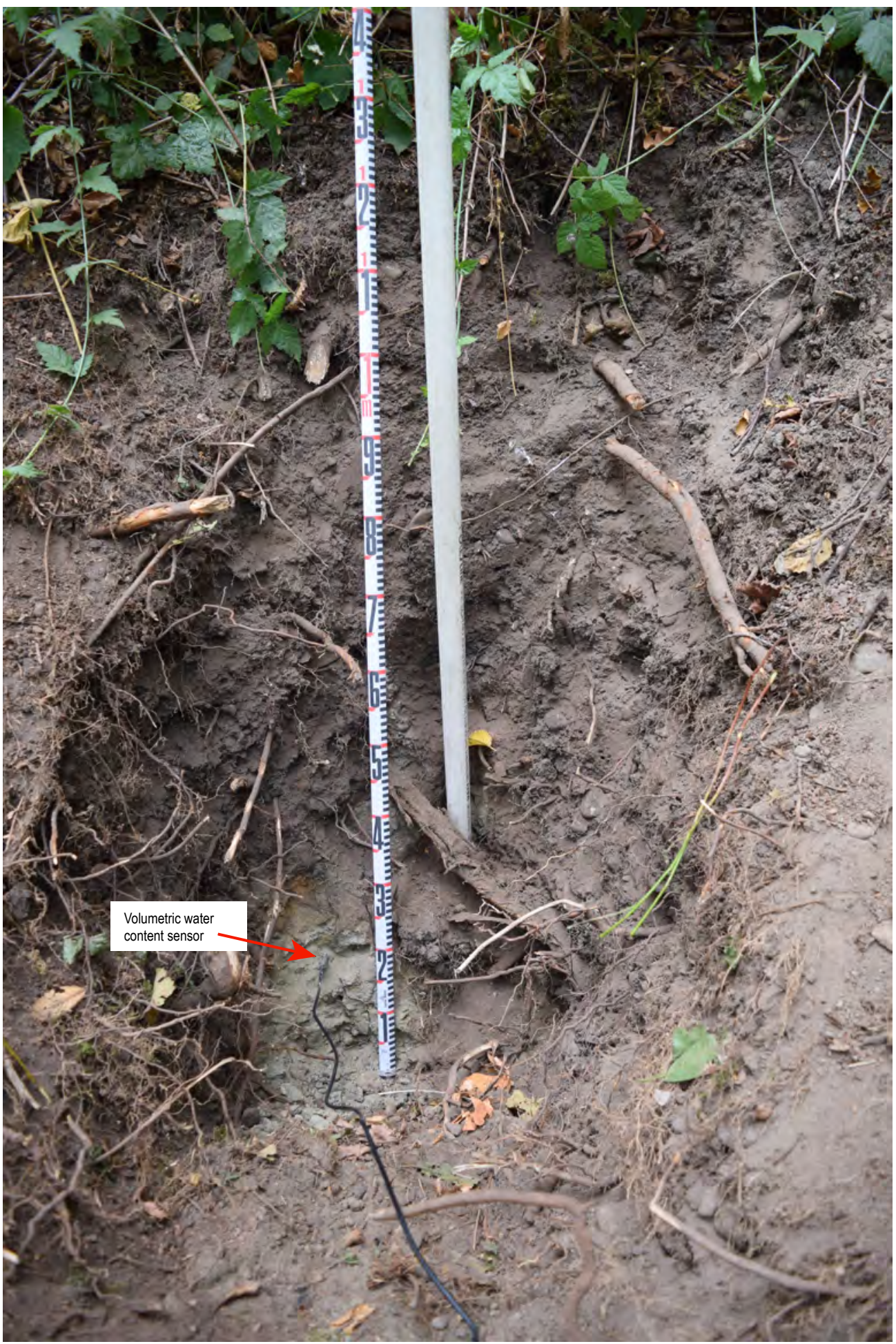

Figure 4. Photo of typical volumetric water-content sensor installation and piezometer casing before backfilling. 
Table 3. Installation depths of volumetric water-content sensors.

[cm, centimeter; VH, Vegetated Hillslope; LS, Landslide Scar]

\begin{tabular}{|cc}
\hline Location & Installation depth $\mathbf{( c m )}$ \\
\hline VH1 & 110 \\
VH2 & 110 \\
VH3 & 100 \\
VH4 & 130 \\
VH5 & 100 \\
LS1a & $20^{\mathrm{a}}$ \\
LS1b & 100 \\
LS2a & $20^{\mathrm{b}}$ \\
LS2b & $20^{\mathrm{c}}$ \\
LS3a & 80 \\
LS3b & 115 \\
LS4a & 80 \\
LS4b & 115 \\
LS5a & 95 \\
LS5b & 120 \\
\hline
\end{tabular}

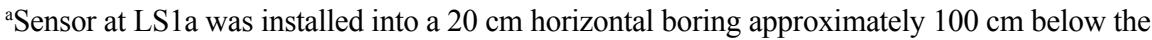
crown of the headscarp.

${ }^{\mathrm{b}}$ Sensor LS2a was installed in a $20 \mathrm{~cm}$ horizontal boring approximately $200 \mathrm{~cm}$ below the rim of the southern flank.

'Sensor LS2b was installed in a $20 \mathrm{~cm}$ horizontal boring approximately $500 \mathrm{~cm}$ below the rim of the southern flank.

the vibrations from the electrically swept (or plucked) wire into a voltage signal that is transmitted to a vibrating-wire interface. The monitoring systems use Campbell Scientific AVW200 interfaces that perform spectral analysis on the signals to determine the dominant frequency of the signal. This frequency is related to pressure through a sensor-specific conversion equation. The Campbell CR1000 datalogger queries the AVW200 digitally and returns the processed data for logging. The VWPs are sensitive to temperature fluctuations and include a thermal resistor that is used to measure temperature. Temperature correction is integrated into the equation used for conversion to engineering units immediately during signal postprocessing.

The VWPs are installed in near-vertical, hand-augered, and cased boreholes (fig. 4). The casing is 2.54 -cm polyvinyl chloride pipe slotted and screened along the bottom-most $30 \mathrm{~cm}$. The depth of the borehole and piezometer installation (table 5) was dictated by the technical limitations of the hand-augering equipment, either shaft length or interfering material (for example, clasts or bedrock). The sensors are lowered into the casing and easily removable for repair or replacement. Although the casings are capped, the VWPs are susceptible to atmospheric pressure fluctuations and require a correction.

\section{Air Pressure}

A barometer (Vaisala PTB110) was installed within the datalogger enclosure at the LS site to provide atmospheric pressure measurement corrections for the sealed VWPs. Given the nearness of the hydrologic monitoring sites, and the relatively slow scan rate of the VWPs, only one barometer was installed to make pressure corrections for both sites. The barometer measures pressure over a range of $50-110 \mathrm{kPa}$, has a temperature dependent accuracy of about $\pm 0.1 \mathrm{kPa}$ under the temperatures found at the monitoring site, and is specified to drift less than $0.01 \mathrm{kPa}$ annually.

\section{System Reliability and Recommended Improvements}

Since the installation of the monitoring system in 2015, the initial year of data shows that, under most conditions, these systems operate reliably with a minimal amount of maintenance. The sites at VH, MLP, and MWWD have operated continuously and delivered all data as anticipated with no issues. The LS site has also been reliable except that ground deformations have disturbed (and destroyed) some of the instruments, and there is a high probability that additional damage will occur in the future. Presumably, the only way to avoid this would be to avoid installing instruments at susceptible areas, but that solution 


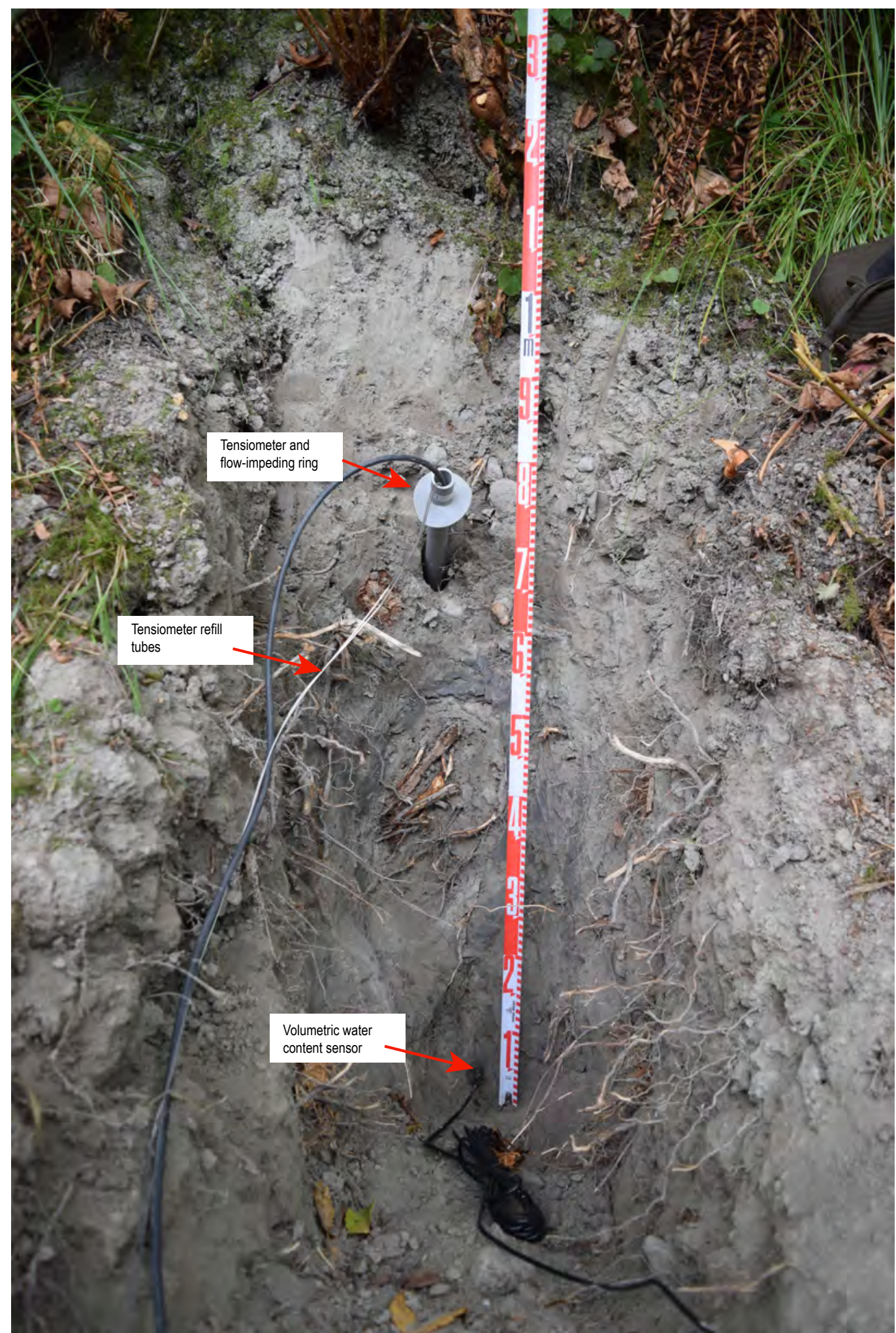

Figure 5. Photo of typical tensiometer and volumetric water-content sensor installation. Notice refill tubes and flow-impeding ring. 


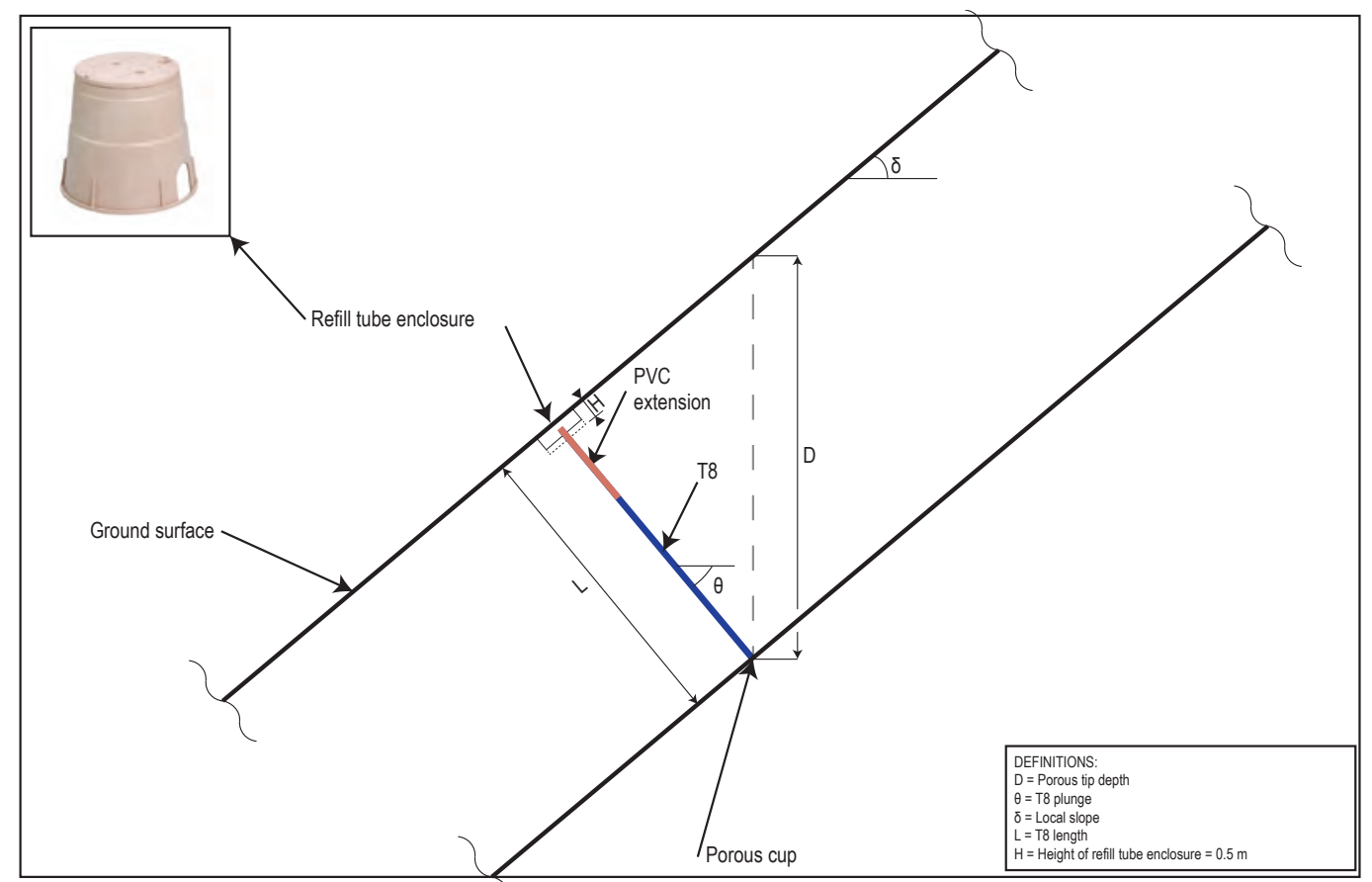

Figure 6. Diagram of typical tensiometer installation. The polyvinyl chloride pipe (PVC) extension length is variable depending on the desired installation depth. The depths presented in table 4 represent depth $\mathrm{D}$.

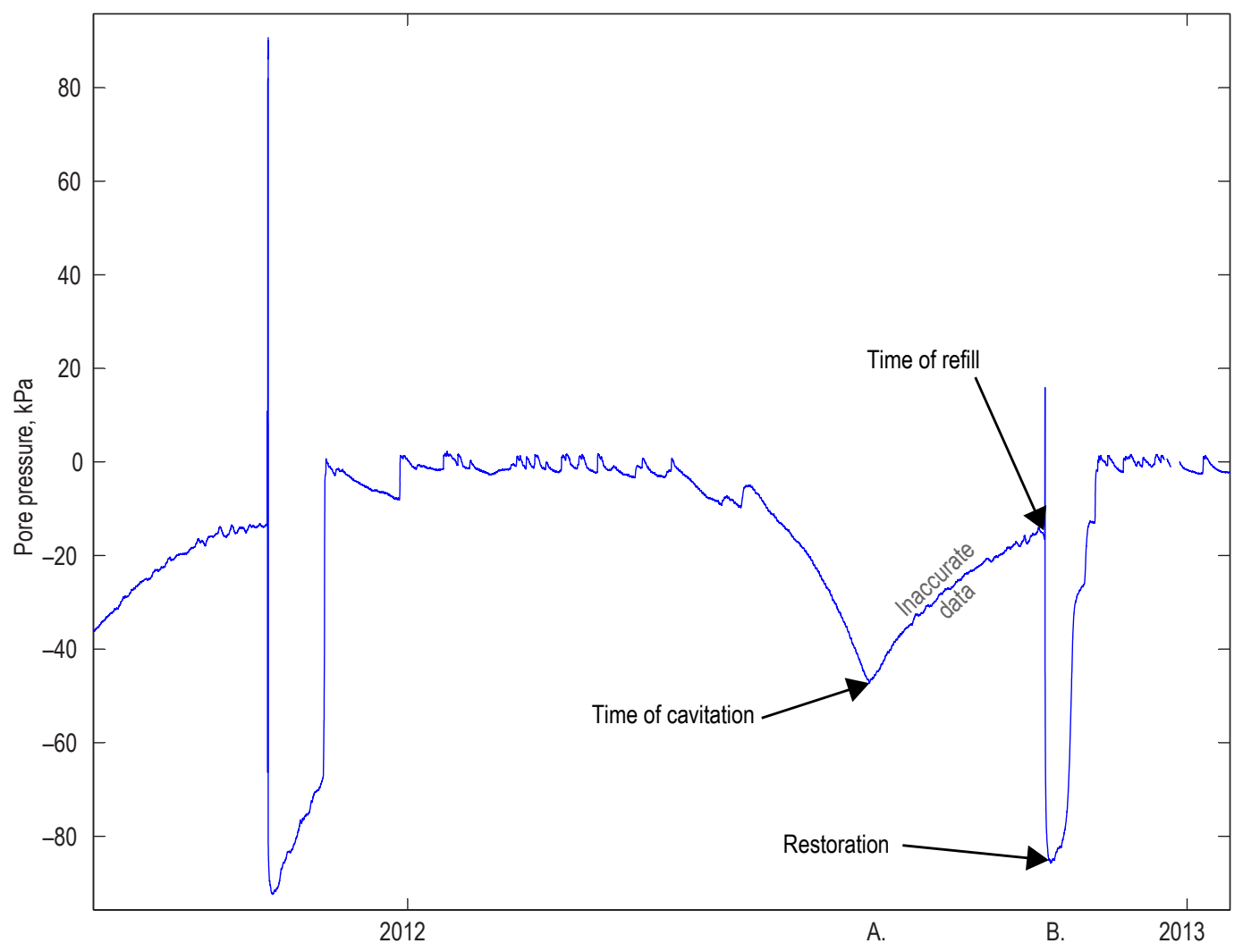

Figure 7. Diagram showing the operating characteristics of a tensiometer. Point A shows an apparent inflection point in the tensiometer pressure reading caused by system cavitation. Point $B$ shows the time of refill followed by restoration of the normal operating range of the instrument. ( $\mathrm{PPa}$, kilopascal) 
Table 4. Installation depths of tensiometers.

[cm, centimeter; VH, Vegetated Hillslope; LS, Landslide Scar]

\begin{tabular}{ccccc}
\hline Location & Effective depth $(\mathbf{c m})$ & Local slope, $\boldsymbol{\delta}$ & Plunge, $\boldsymbol{\theta}$ & $\begin{array}{c}\text { Instrument length } \\
\text { (cm) }\end{array}$ \\
\hline VH2 & 0 & 35 & 55 & 100 \\
VH3 & 0 & 35 & 55 & 100 \\
VH4 & 0 & 35 & 55 & 100 \\
LS2a & 0 & 60 & 3 & 110 \\
LS2b & 0 & 60 & 2 & 108 \\
LS3a & 0 & 35 & 55 & 110 \\
LS3b & 0 & 35 & 55 & 170 \\
LS4a & 0 & 35 & 55 & 114 \\
LS4b & 0 & 35 & 55 & 177 \\
\hline
\end{tabular}

Table 5. Installation depths of the vibrating-wire piezometers.

[cm, centimeter; VH, Vegetated Hillslope; LS, Landslide Scar]

\begin{tabular}{cc}
\hline Location & Installation depth $(\mathbf{c m})$ \\
\hline VH1 & 300 \\
VH5 & 300 \\
LS1a & 300 \\
LS1b & 300 \\
LS5a & 150 \\
LS5b & 300 \\
\hline
\end{tabular}

would limit a potential source of valuable data. A wireless system might help to mitigate issues associated with systems installed in actively deforming locations. Such wireless stations would not be totally safe from landslide-related ground deformation, but the benefit would be derived from the independence of each station. In contrast, the wired systems have demonstrated large interdependencies due to the long runs of wiring that transmit strain as a result of ground deformation, erosion, and deposition of sediments. The independence of an upgraded wireless system, however, comes with higher cost and system complexity.

An opportunity for improvement was recognized in the datalogger program running at the hydrologic monitoring stations. The resolution of the VWP measurements can be improved by recording (and transmitting) their frequency measurements in a different format. The data currently use a two-byte floating point (FP2) only capable of representing four significant digits. The VWP, however, has the ability to measure at a higher accuracy than can be resolved by this data type. The two-byte floating point (FP2) format could be changed to a four-byte floating point (IEEE4) data type in a future revision of the program so that current resolution of $\pm 0.5 \mathrm{kPa}$ can be made smaller than the instrument accuracy of $\pm 0.35 \mathrm{kPa}$.

\section{Data Preparation for Analysis and Release}

Both Sound Transit and USGS computers query the field modems hourly for raw data. Software (Python2.x) scripts convert data into engineering units and generate plots for viewing data (for example, Baum and others, 2017). The USGS displays these plots on the USGS Landslide Hazards Program web site (http://landslides.usgs.gov/monitoring/seattle/rtd/bluff_hydrology.php).

The dataset created for this report was compiled using MATLAB technical computing software to analyze the raw source data. The dataset is published as a separate data release (Smith and others, 2017). This software was used for all subsequent data conversion, plotting, and the creation of a site-combined, comma-separated values file containing the converted (engineering unit) data. The conversion equations used on the data for this report are the same as those used for the USGS web site visualizations. Although not transmitted, the dataloggers use the similar conversion equations to create "field accessible" engineering-unit values to aid in maintenance and instrument troubleshooting. Thus, the conversion equations from raw to engineering units can be found within the datalogger programs included in appendix 1 . There are only some minor differences in data conversion. For example, the dataloggers do not apply the barometric pressure correction to the VWP measurements as these correction values are not available to the loggers in real time. 


\section{Overview of Acquired Data}

\section{System Function Interpretation}

Figure 8 shows the dates of installation of all of the instruments and provides a summary of the operational status of the instruments over the monitoring period. Instrumental status is defined as "functional," "questionable," "out-of-range," or "nonfunctional." For example, all of the VH tensiometers showed readings outside of their operating range (range is -85 to $100 \mathrm{kPa}$, reading was $-90 \mathrm{kPa}$ ) due to the "dry season" pore pressures. In this "out-of-range" case, the readings can be assumed to be less than the indicated value but not actually the indicated value (for example, less than, but not equal to, $-85 \mathrm{kPa}$ ). Similarly, the VWP cannot reliably measure below $0 \mathrm{kPa}$ pressure, so readings at or around $0 \mathrm{kPa}$ should be interpreted as less than zero (except where noted otherwise). Furthermore, the LS site experienced several confirmed landslide events throughout the winter, and as the ground moved around and over the sensors, the readings exhibited signal excursions that were possibly spurious. Although the readings still seem reasonable in some cases, the affected instruments and time periods are indicated as "questionable." Lastly, some instruments were confirmed damaged and (or) excavated from their emplacement, and these instruments and time periods are labeled "non-operational."

\section{Rain Gage Data Interpretation}

Figure 9 shows the rainfall recorded at each site over the monitoring period, August 2015 through August 2016 (October 2015 through August 2016 for MWWD). The 15-minute rainfall totals are summed into hourly values in these plots for ease of interpretation. The plots show that the majority of the seasonal rainfall fell between November and March. Longer periods without rainfall occur between April and October, although during these periods, rainfall intensity appears to be greater during storms of shorter duration. These recorded rainfall quantities are consistent with regional rainfall patterns (fig. 10) based on data from Everett, Wash., which is located about $11 \mathrm{~km}$ northeast of the MLP site.

Yearly rainfall totals for the monitoring period were slightly higher than historical averages seen in this region. The VH, MWWD, and MLP sites recorded about $900 \mathrm{~mm}$ of rain, while the LS site gaged about 1,200 $\mathrm{mm}$ rainfall. Assuming that the MWWD site received similar rainfall amounts as recorded at the MLP and VH sites for the same time period, the cumulative rainfall recorded at MWWD is understated by about $\pm 100 \mathrm{~mm}$ because it was installed later than the others (fig. 8),. For comparison, the cumulative annual rainfall average in nearby Everett beginning in 1916 to 2015 is $889 \mathrm{~mm}$ (fig. 11). However, it should be noted that high precipitation years at the Everett rain gage do not necessarily correspond to high landslide incidence. For example, years with greater than average early-season rain may not exhibit widespread landslide occurrence if substantial amounts of the year's above average rainfall fell on dry soil.

\section{Vegetated Hillslope Site Data Interpretation}

The monitoring sites provide a detailed record of rainfall and the hydrologic response to rainfall infiltration and seepage. Figure 12 shows an overview of the VWC conditions recorded at VH for the monitoring period. At the VH1 location, VWC seemed to be most sensitive to early season rainfall, with a 15 percent increase in water content occurring after the apparent onset of the rainy season in late August. This uppermost location transitioned to its "wet-season" level before the other sites, and although its baseline reading increased throughout the rainy season, it showed the lowest overall VWC levels of any VH location. The persistently lower VWC values at VH1 are consistent with lab testing results (as measured by Mirus and others, 2016) showing this material has a saturated hydraulic conductivity at least an order of magnitude higher than the other VH locations. In addition, the site never reached a saturated VWC value (as measured by Mirus and others, 2016), and the dry-season VWC measurements of 11 percent compare closely to lab-measured VWC values of 9 percent, suggesting that the readings are valid. The downslope VH sites (VH4 and VH5) showed greater moisture content during the middle of the wet season and VH5, in particular, demonstrated clear differences between partially saturated field capacity values and fully saturated conditions before and after storm events (fig. 13). Based on figure 12, it appears that rainy-season steady-baseline soil-moisture conditions were met about the first week of December 2015 and persisted through April 2016. Although the moisture-drainage component of the annual soil moisture cycle is quite linear (as opposed to stepped), an exact time where VWC drains below the rainy-season moisture threshold is unclear. For our purposes here, the background level of soil moisture maintained between storms during much of the rainy season defines the rainy-season steady-baseline soil-moisture conditions. These conditions correspond to high landslide susceptibility characterized by a high degree of soil saturation (greater than about 33 percent in the case of VH5 [fig. 13]), and relatively rapid response of pore pressure and soil moisture to additional rainfall. Just as the upper sites responded first to early season rainfall, the drainage and drying component of the soil moisture wet-dry cycle is shown to lead at the head of the bluff and lag at the base. 
pwp_VH1_178cm_kPa pwp_VH5_297cm_kPa swp VH2 $122 \mathrm{~cm} \mathrm{kPa}$ swp_VH3_122cm_kPa swp_VH4_122cm_kPa VwC_VH1_110cm vwc_VH2_110cm vwc_VH3_100 cm vwc VH4 $130 \mathrm{~cm}$ vwc_VH5_100cm precip_VH_mm panelTemp_VH_degC airTemp VH degC systemVoltage_VH_V

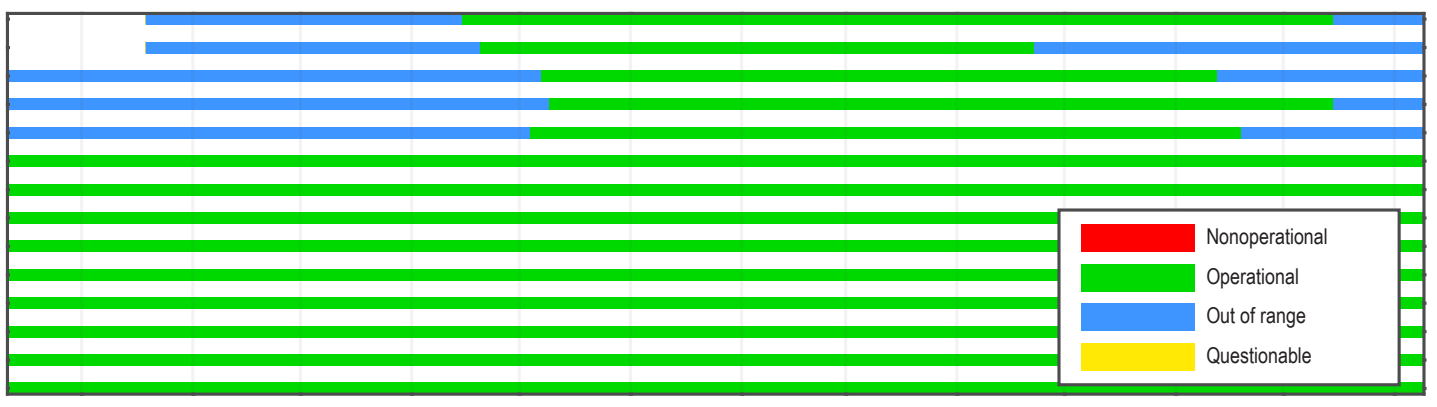

pwp_LS1a_300cm_kPa pwp LS1b $300 \mathrm{~cm}$ kPa pwp_LS5a_300cm_kPa pwp_LS5b_175cm_kPa swp_LS2a $196 \mathrm{~cm} \mathrm{kPa}$

swp_LS2b_110cm swp_LS3a_134cm_kPa swp_LS3b_208cm_kPa swp LS4a $139 \mathrm{~cm} \mathrm{kPa}$ swp_LS4b_216cm_kPa vwc_LS1a_20 cm vwc LS1b $100 \mathrm{~cm}$ vwc_LS2a_20cm vwc_LS2b_20cm vwc_LS3a_80 cm vwc_LS3b_115cm vwc_LS4a_80cm vwc LS4b $115 \mathrm{~cm}$ vwc LS5a $95 \mathrm{~cm}$ vwc_LS5b_120cm precip LS mm barometricPressure $\mathrm{kPa}$ panelTemp_LSa_degC panelTemp_LSb_degC airTemp_LS_degC systemVoltage_LSa_V systemVoltage_LSb_V

precip_MLP_mm airTemp_MLP_degC systemVoltage_MLP_V

precip_MWWD_mm airTemp_MWWD_degC systemVoltage_MWWD_V
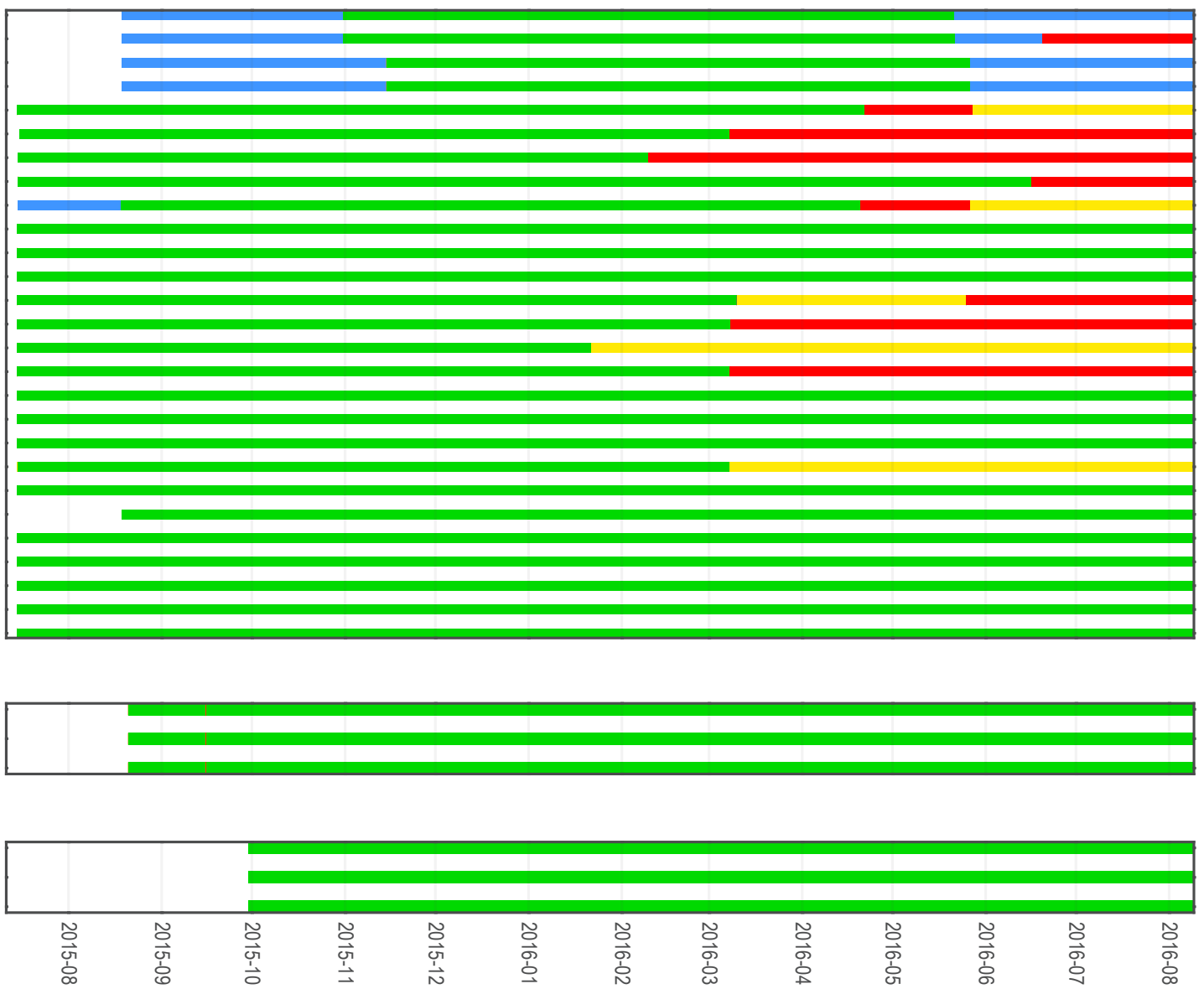

Figure 8. Timeline of instrument installation and operating status. (pwp, pore-water pressure; VH, Vegetated Hillslope; $\mathrm{cm}$, centimeter; $\mathrm{kPa}$, kilopascal; swp, soil-water potential; vwc, volumetric water content; precip, precipitation; $\mathrm{mm}$, millimeter; panelTemp, wiring panel temperature; airTemp, air temperature, degC, degrees Celsius; V, volts; LS, Landslide Scar; MLP, Mukilteo Lighthouse Park; MWWD, Mukilteo Water and Wastewater District Water Treatment Plant) 

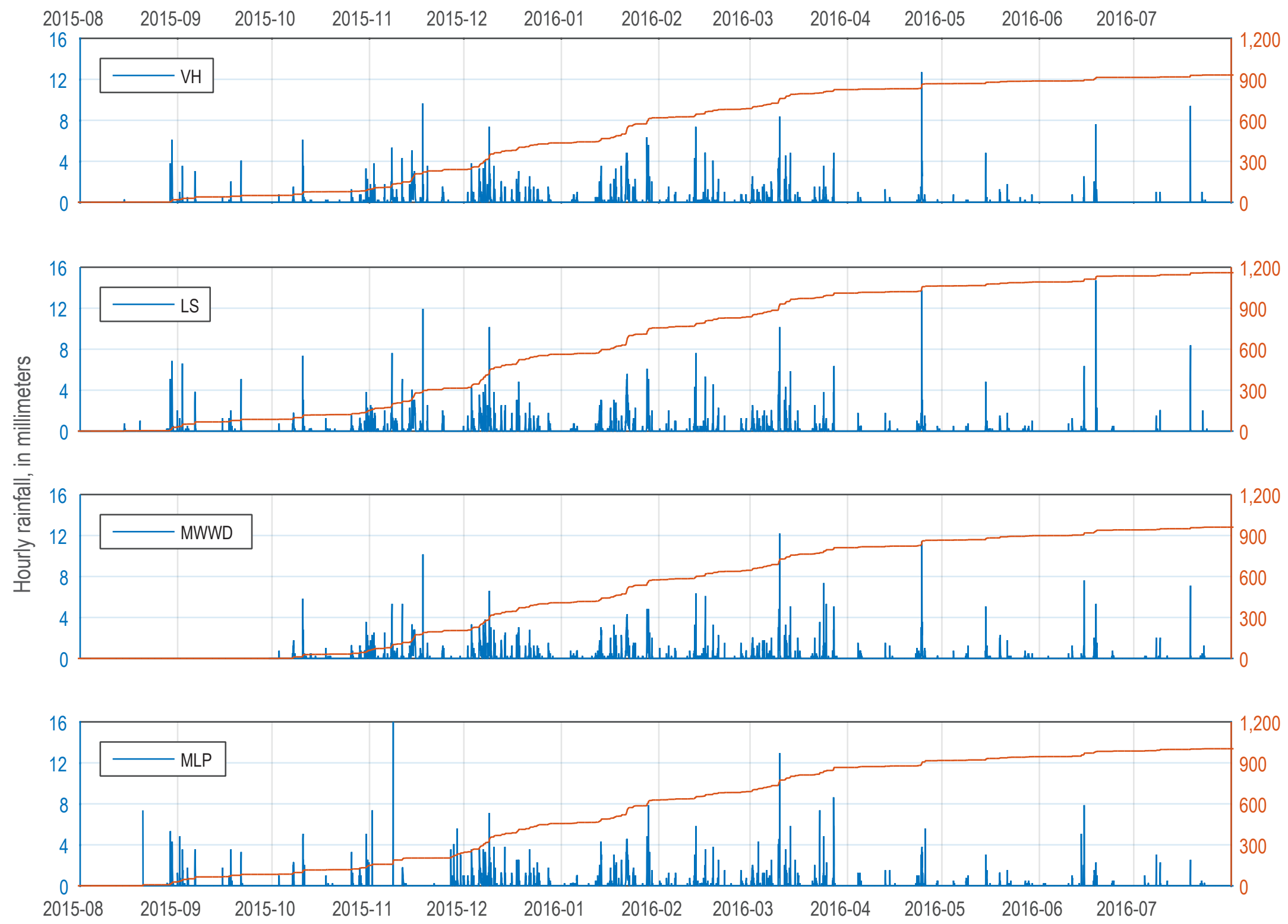

Figure 9. Graphs showing hourly (in blue) and cumulative (in red) rainfall amounts recorded at the Vegetated Hillslope (VH), Landslide Scar (LS), Mukilteo Water and Wastewater District Water Treatment Plant (MWWD), and Mukilteo Lighthouse Park (MLP) sites for the monitoring period. 


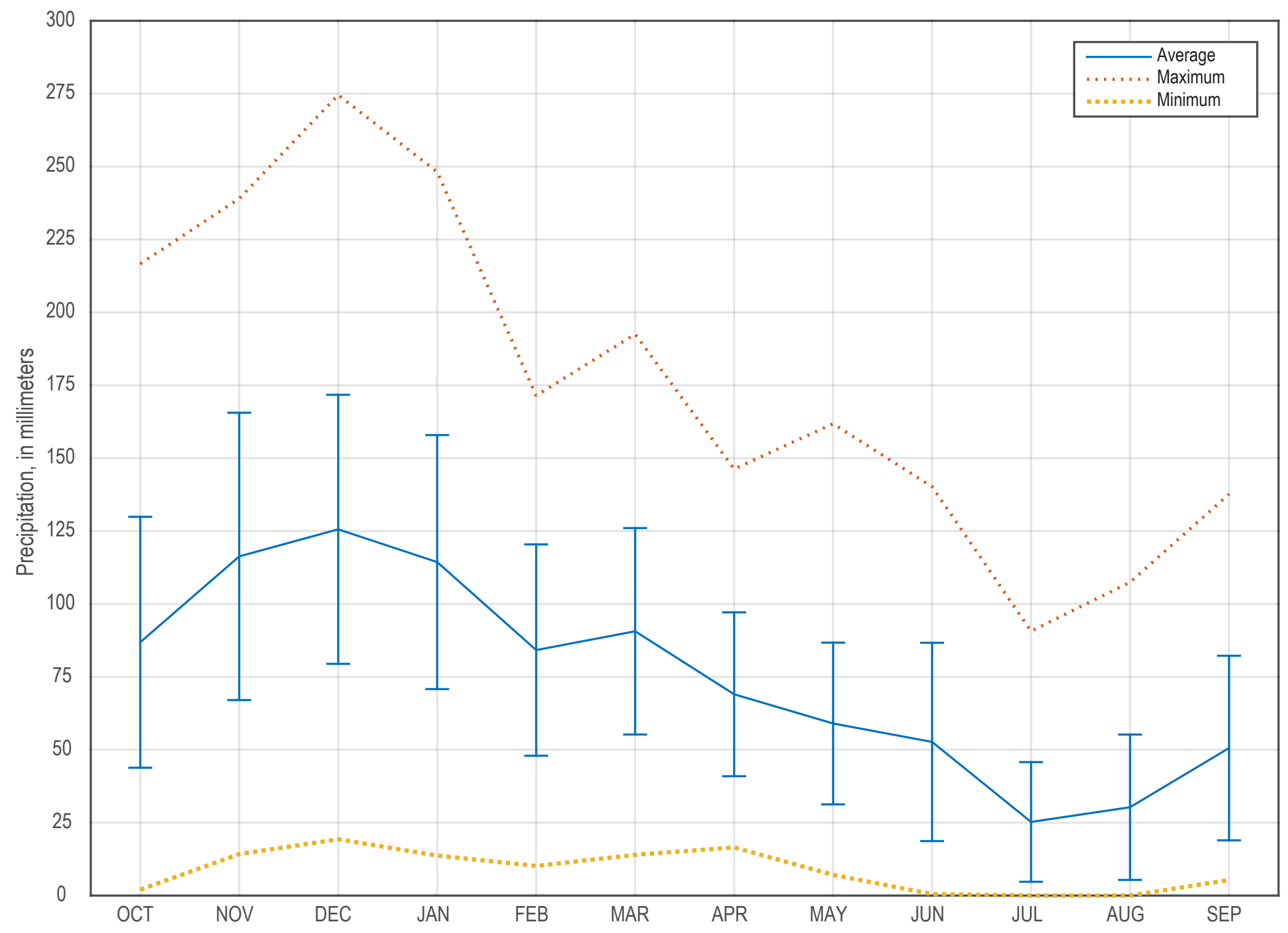

Figure 10. Graph showing average monthly rainfall statistics for Everett, Washington, for 1915-2016 (National Weather Service ID EVEW1). The plot shows average monthly rainfall statistics, the range bars show \pm 1 standard deviation, and historical maximum and minimum are shown by the red and yellow traces, respectively. 


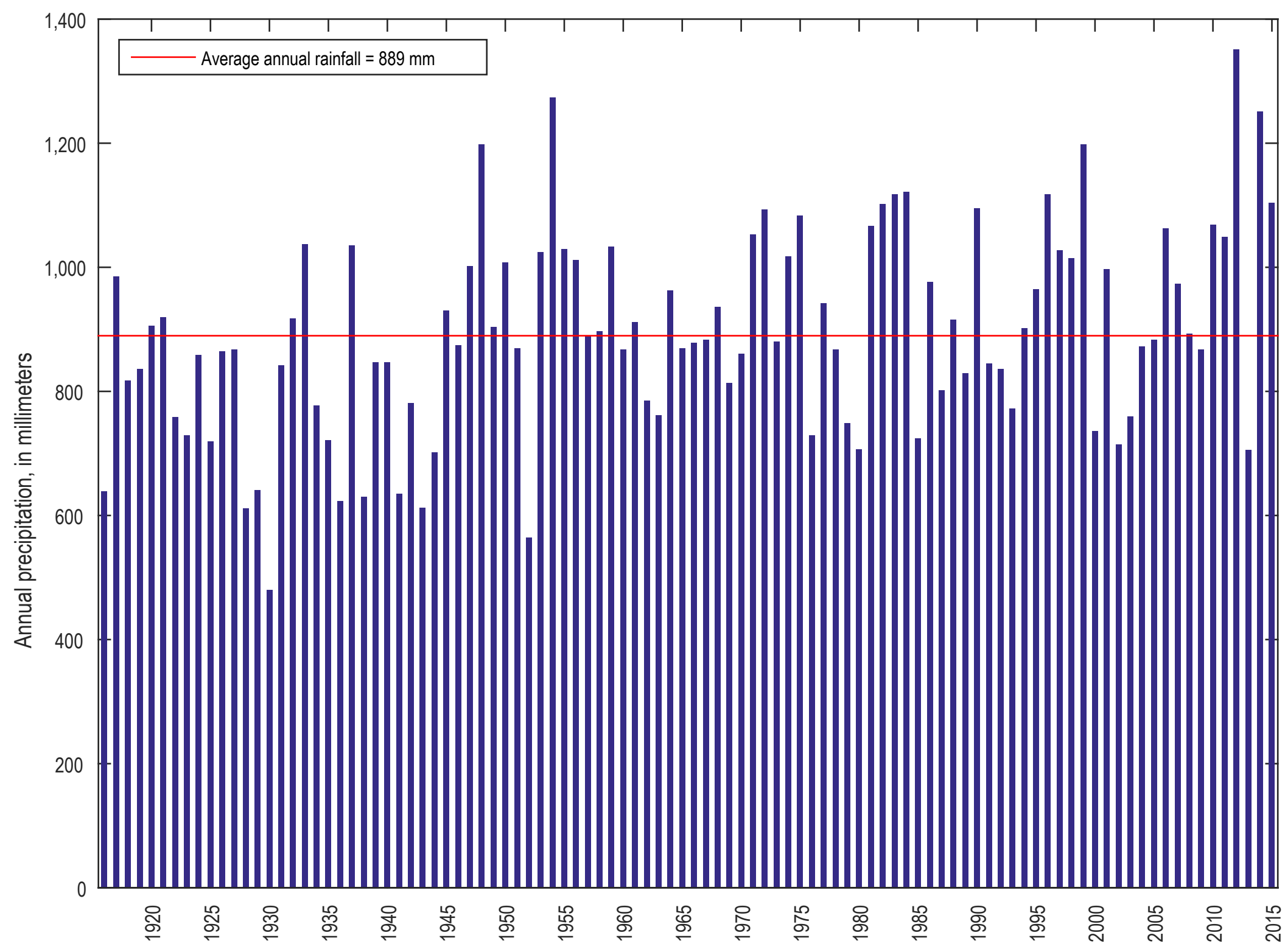

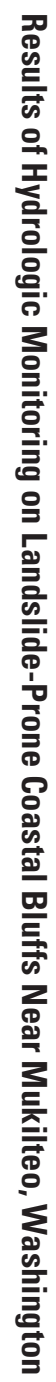

Figure 11. Bar graph showing yearly rainfall totals recorded in Everett, Washington, between 1915 and 2016. (mm, millimeters) 

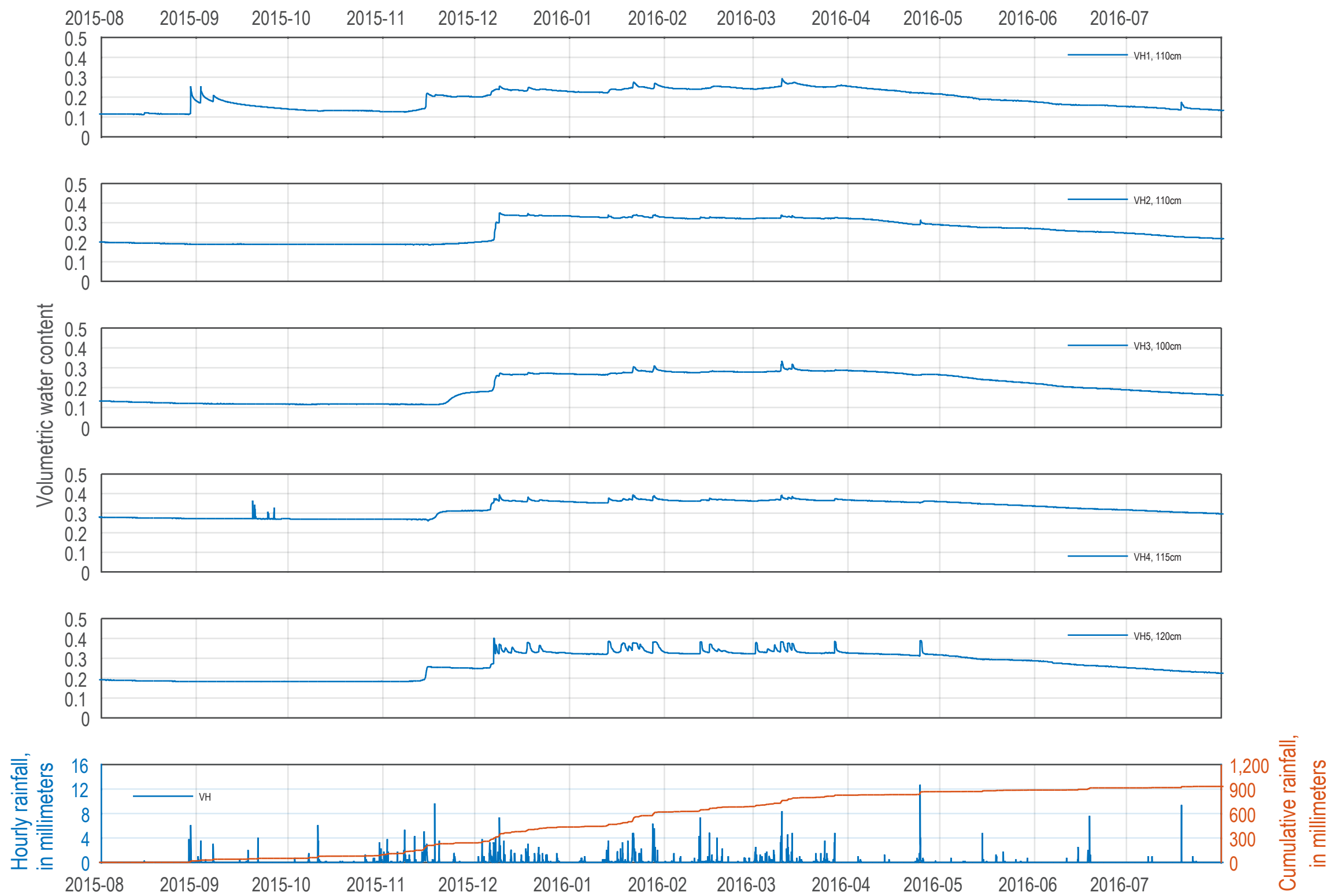

Figure 12. Graphs showing volumetric water-content values for each instrument cluster at, and a rainfall plot for, the Vegetated Hillslope (VH) site for the complete monitoring period. Sensor depth is shown in legend. (cm, centimeter) 

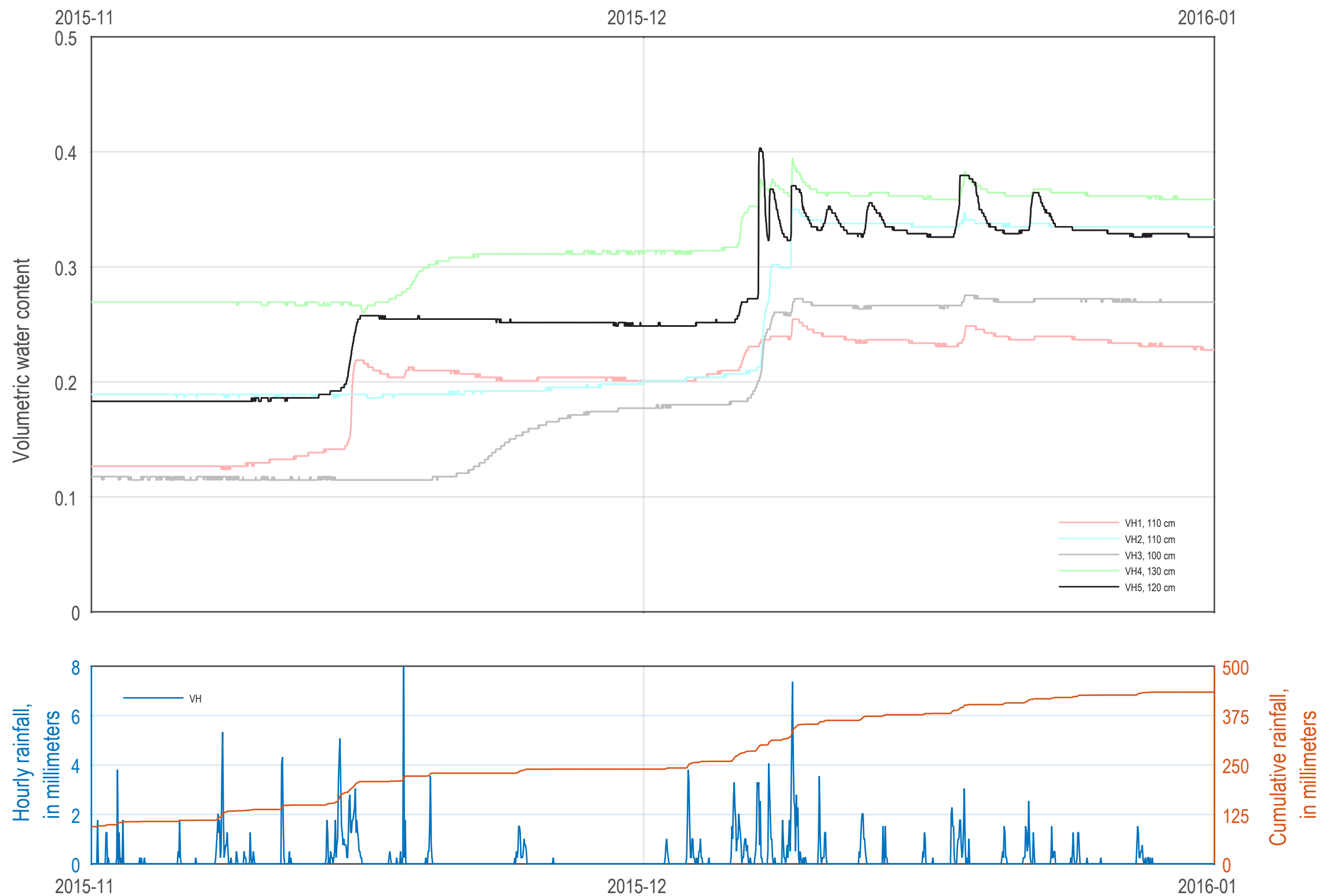

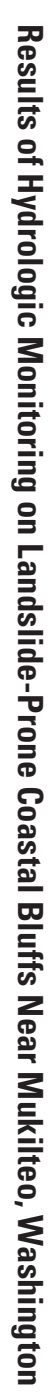

Figure 13. Graph comparing the relative volumetric water-content measurements taken at each instrument cluster at, and a rainfall plot for, the Vegetated Hillslope (VH) site from November 2015 through January 2016. The figure demonstrates bluff water contents in transition from dry- to rainy-season moisture conditions. The volumetric water-content instrument located at VH5 shows a clear response to rainfall events. (cm, centimeter) 
Figure 14 shows an overview of the piezometric and tensiometric pore-water pressure conditions at the VH site. The VWP instruments and tensiometers are shown at different scales to display the full operating range of the tensiometer. Although landslides do not generally occur at highly negative pore-water pressures, these "dry-season" pressures may contribute to a better understanding of the soil behavior across the full range of the wet and dry conditions that are common in the region. As can be seen in figure 14 (VH2, VH3, and VH4), a shift from high soil suction (less than $-100 \mathrm{kPa}$ ) to nearly neutral pore pressures occurred in the first week of December following about $300 \mathrm{~mm}$ of cumulative rainfall. Beginning in mid-April, the tensiometers display a decrease in pore pressure for about two months, after which cavitation occurs and the tensiometers no longer accurately measure pore-pressure values (for example, fig. 7). This dissipation of pressure, as compared to the much more gradual decay of VWC, is due to the water retention characteristics of the unsaturated soil. Because of its depth and (or) topographic position, the VWP at VH5 displays a significant increase in background pore pressure during about the last week of January before it drains and loses its hydraulic connection near the last week of April. Although hardly noticeable, a similar increase in background pressure at VH1 occurs during the first extended rain event in November and remains slightly elevated through May. As in the VWC at VH1, this instrumental record of the VWP at VH1 seems to indicate high conductivity as it does not develop elevated pore-water pressures.

\section{Landslide Scar Site Data Interpretation}

The LS monitoring site data record shows characteristics similar to the VH site. Figure 15 shows that the VWC instruments begin to display partially saturated values in mid-November that begin to subside in April. The instrument locations containing colocated sensors (LS3-LS5) show that the shallower of the paired sensors responds more quickly to rainfall infiltration, although almost negligibly, probably owing to the hydraulic conductivity. The LS1a sensor, which was installed $20 \mathrm{~cm}$ into the near-vertical face of the landslide headscarp, responds greatly to rainfall infiltration with spikes in VWC readings approaching a 20 percent water content increase above baseline wet-season values (for example, VWC increases from about 20 percent to about 40 percent).

Figure 16 shows the record of pore pressures at the LS site. The shallower tensiometers in LS2, LS3, and LS4 (LS2a, LS3a, LS4a, respectively) all respond to early season rainfall, with LS2 showing large pore-pressure transients that quickly dissipatesuggesting that the cliff face material surrounding the instrument drains quickly. The LS site received more rainfall than the VH site and reached $300 \mathrm{~mm}$ cumulative rainfall almost two weeks earlier, although it is unclear if the discrepancy in indicated rainfall is due to the spatial variability of rainfall, rainfall interception by the vegetation, or some other factor entirely. At this time, all of the instruments show that the soil reached a "moist" condition which persisted until June. All of the VWP instruments show a clear response to rainfall, with LS1a and LS5a also developing significantly elevated baseline pressures.

Slope movements in January, February, and March damaged instruments in LS2 and LS3, and data traces from damaged instruments are not displayed in the plots. Also, as confirmed by field visits, instruments in LS2, LS3, and LS4 were buried (or excavated) by landslide deposits in February and March and this can be seen by further elevation of VWC reported at LS2a and LS3a (fig. 15). The "fuzzy" line shown by LS5b was caused by the damaged wiring of a companion sensor sharing the same power source as LS5b. The removal of the companion instrument from the power source resolved the small signal excursions seen in the signal.

\section{Conditions During Slide Initiation or Reactivation}

A time-lapse camera, which was used to determine if slide reactivation occurred at the LS site over the monitoring period, identified five periods containing ground movements. Apparent slow and consistent slope-surface movements are seen during these periods, but there are also indications that this slow displacement indirectly triggered topples and debris-avalanche movements both upslope and downslope. The approximate sizes of topples and debris avalanches were on the order of $10^{5}-10^{7}$ cubic centimeters. The video captures slope movements during the time periods of December 8-9, 2015; January 21-30, 2016; and March 9-14, 2016. In addition, the video shows two seemingly "instantaneous" events on the nights of March 23 and March 26. Figures 17-20 show the rainfall and subsurface conditions from both monitoring sites leading up to the reactivation periods. The data from $\mathrm{VH}$ are shown here to further investigate the overall regional hydrologic response at times when landslide reactivation occurs. The time-lapse photos were taken three times during daylight hours (at $9 \mathrm{am}, 12 \mathrm{pm}$, and $4 \mathrm{pm}$ ) and stored onsite on a memory card, so the timing resolution and accuracy of the date ranges are expected to be within 17 hours. 

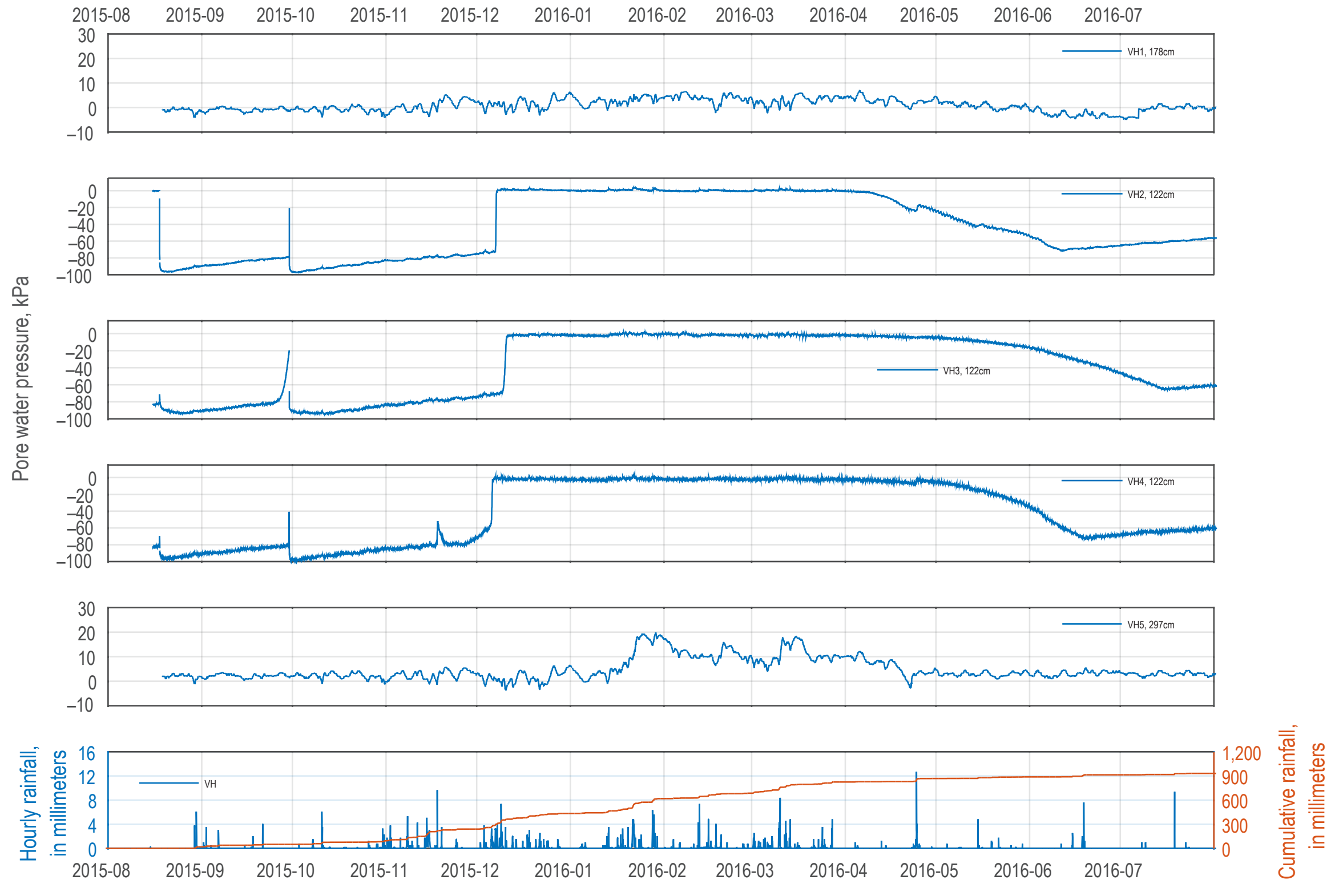

Figure 14. Graphs showing pore-water pressure (soil-water potential) values for the Vegetated Hillslope (VH) site from both vibrating-wire piezometers (VH1 and VH5) and tensiometers (VH2, VH3, and VH5), and a rainfall plot for the VH site, over the complete monitoring period. (kPa, kilopascal; cm, centimeter) 

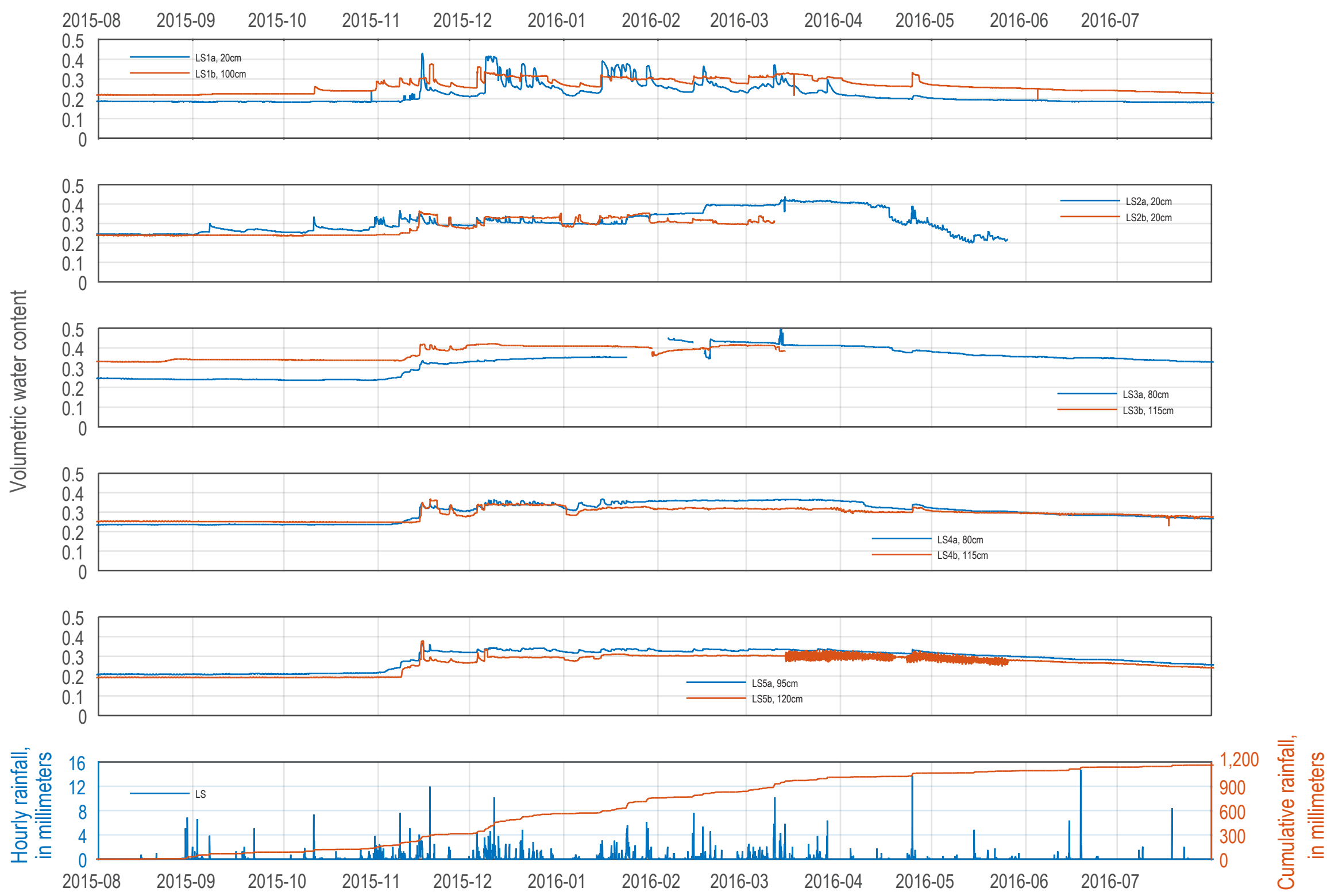

Figure 15. Graphs showing volumetric water-content values for each instrument cluster at, and a rainfall plot for, the Landslide Scar (LS) site for the complete monitoring period. The "fuzzy" line displayed by the LS5b instrument was initiated by ground movements, presumably after LS5 was buried by landslide deposits. This interference was eliminated after the removal of the damaged instruments with a shared power port. (cm, centimeter) 

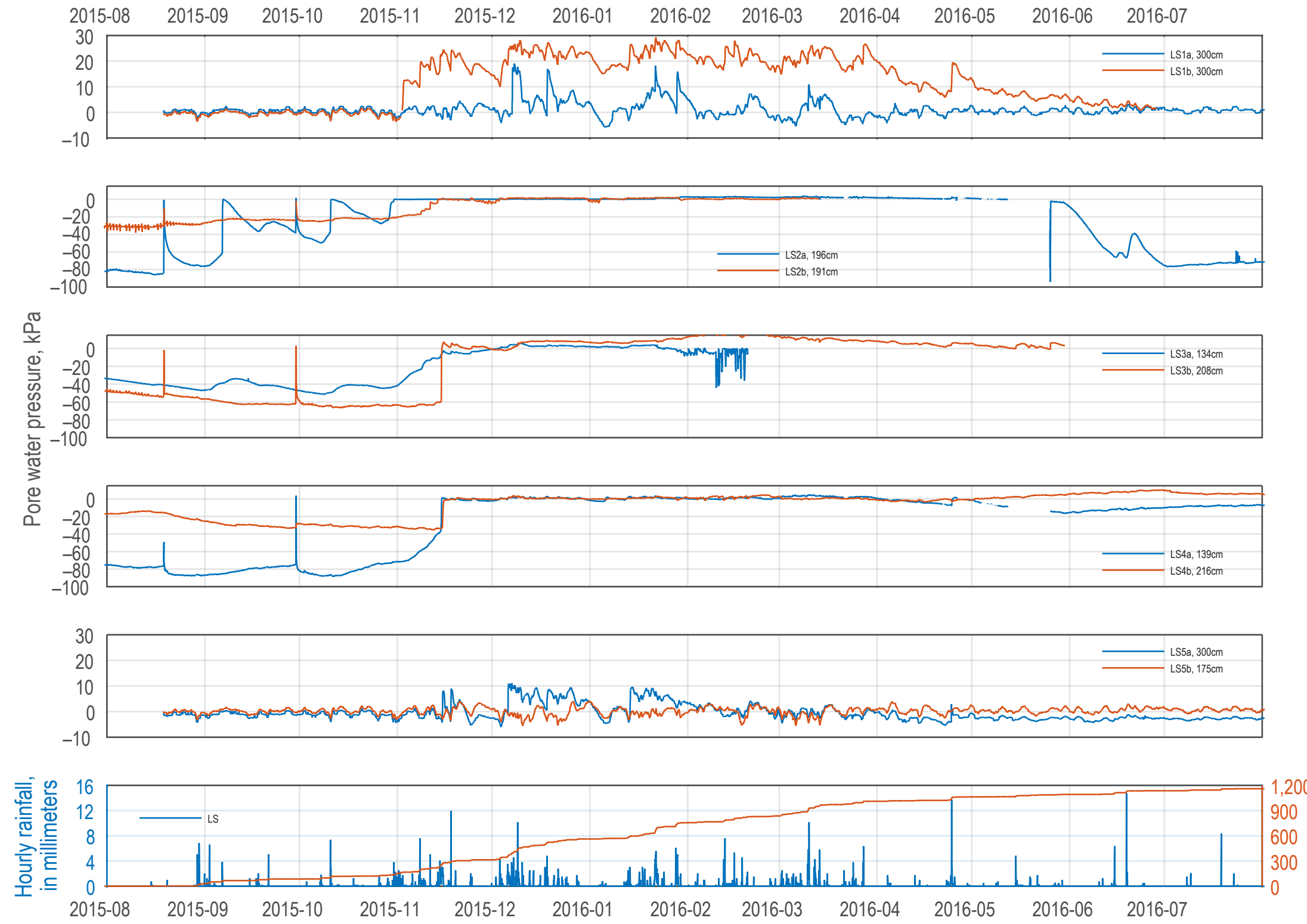

Figure 16. Graphs showing pore-water pressure (soil-water potential) values for the Landslide Scar (LS) site from both vibrating-wire piezometers (LS1 and LS5) and tensiometers (LS2, LS3, and LS4), and a rainfall plot for the LS site, for the complete monitoring period. (kPa, kilopascal; cm, centimeter) 

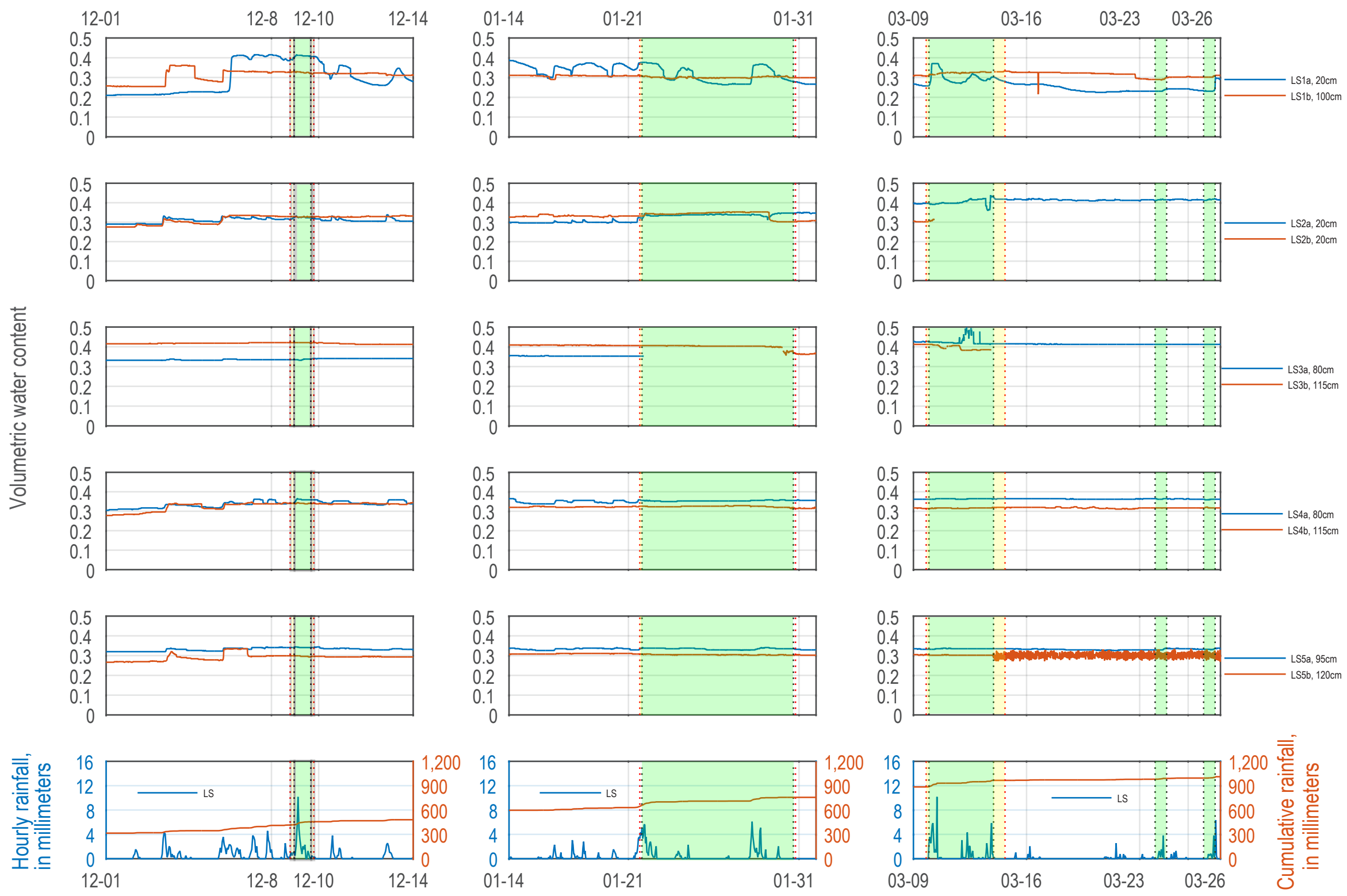

Figure 17. Graphs showing volumetric water-content conditions and rainfall quantities leading up to landslide reactivation at the Landslide Scar (LS) site. Timing of five landslide reactivation events is shown on three series of time synced plots. The date ranges shown on the x-axis show the time limits of the reactivation periods to a certainty of about 24 hours. The green shading indicates a high certainty of movement, and yellow shading represents a time period within which the transition from stationary to sliding (or viceversa) occurs. (cm, centimeter) 

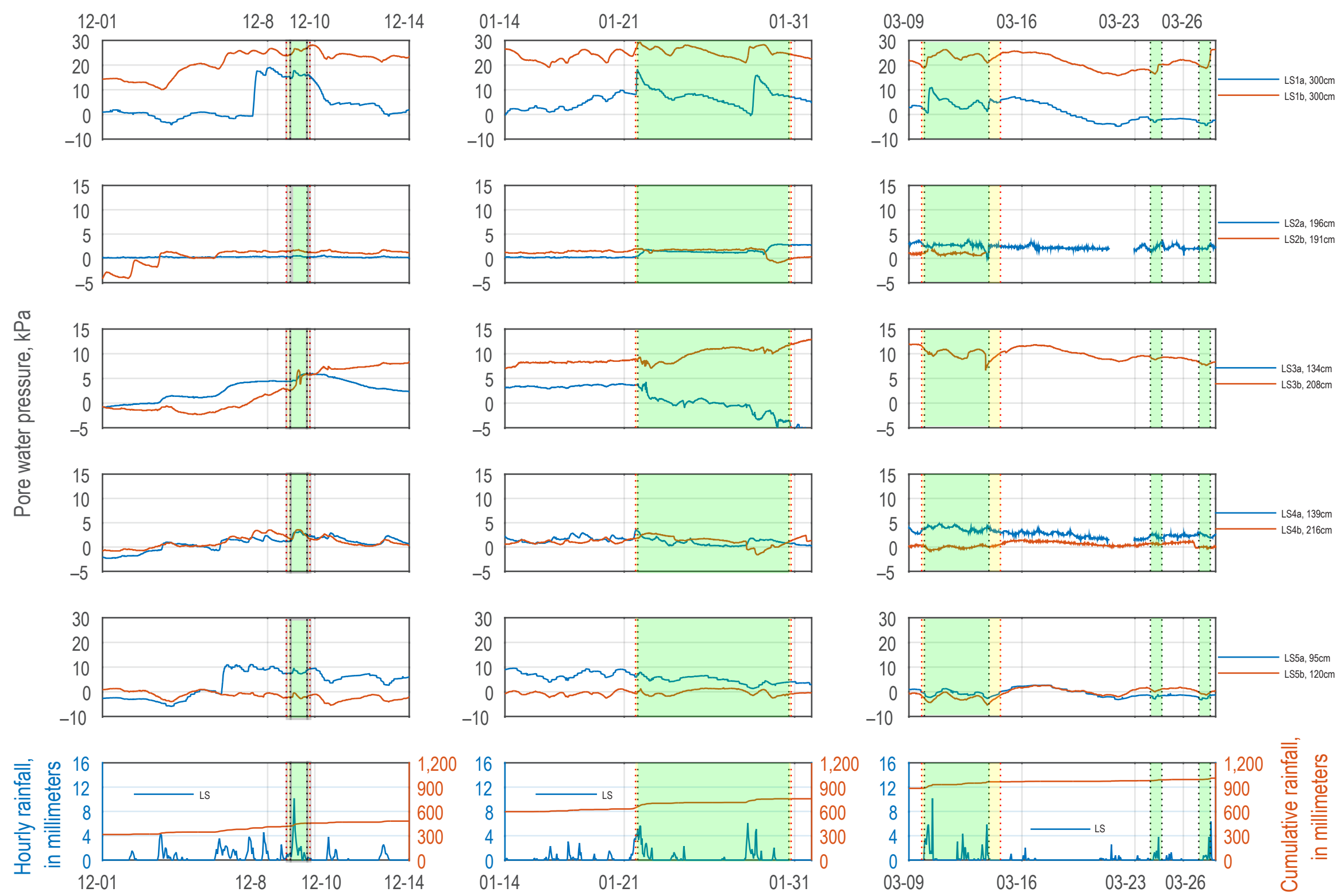

Figure 18. Graphs showing pore-water pressure conditions and rainfall quantities leading up to landslide reactivation at the Landslide Scar (LS) site. Timing of five landslide reactivation events is shown on three series of time synced plots. The date ranges shown on the x-axis show the time limits of the reactivation periods to a certainty of about 24 hours. The green shading indicates a high certainty of movement, and yellow shading represents a time period within which the transition from stationary to sliding (or viceversa) occurs. (kPa, kilopascal; cm, centimeter) 

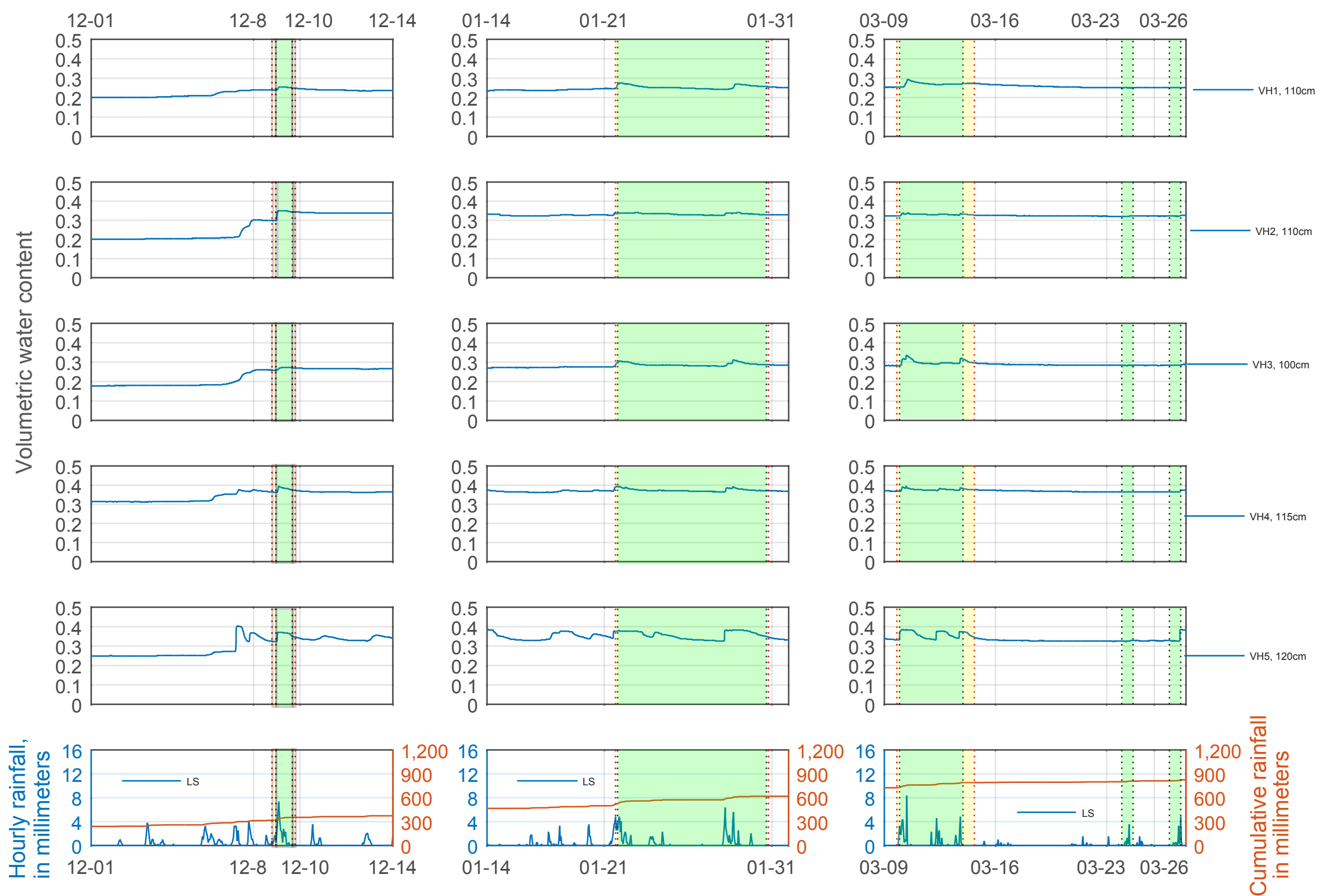

Figure 19. Graphs showing volumetric water-content and rainfall at the Vegetated Hillslope (VH) site during confirmed times of increased landslide hazard. Timing of five landslide reactivation events at the Landslide Scar site is superimposed on three series of time-synced plots. The date ranges shown on the x-axis show the time limits of Landslide Scar site slide reactivation periods to a certainty of about 24 hours. The green shading indicates a high certainty of movement, and yellow shading represents a time period within which the transition from stationary to sliding (or vice-versa) occurs. (cm, centimeter) 

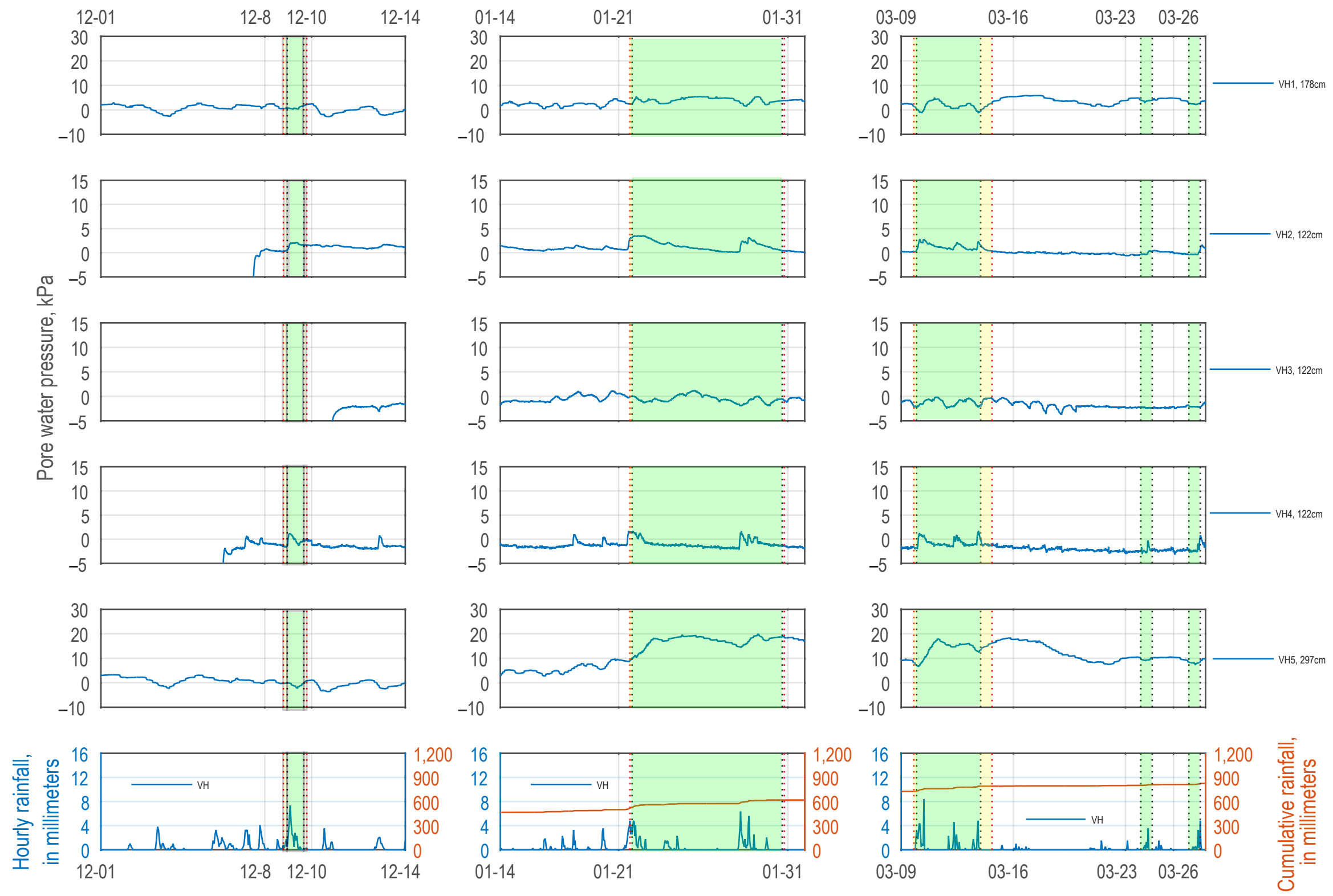

Figure 20. Graphs showing pore-water pressure and rainfall at the Vegetated Hillslope (VH) site during confirmed times of increased landslide hazard. Timing of five landslide reactivation events at the LS site is superimposed on three series of time-synced plots. The date ranges shown on the $\mathrm{x}$-axis show the time limits of Landslide Scar site slide reactivation periods to a certainty of about 24 hours. The green shading indicates a high certainty of movement, and yellow shading represents a time period within which the transition from stationary to sliding (or vice-versa) occurs. (kPa, kilopascal; $\mathrm{cm}$, centimeter) 
Data from a variety of sensors installed at LS show conditions leading up to the slide movements. It should be expected that the instrument readings at the location of movement should give some indication of conditions leading to movement, even if the signals (or sudden lack of signals) are induced by the actual ground displacements as opposed to rainfall. Occurring on or about December 6, 2015, VWC at LS1a (fig. 17) showed a signal spike in near-saturated VWC readings, preceding the first indications of slope movement by about two days. At about this same time, the VWP at LS1b and LS5a (fig. 18) showed large increases in pore-water pressure. The LS1b pressure increased to about $28 \mathrm{kPa}$, suggesting that the ground above the instrument was completely saturated because $28 \mathrm{kPa}$ is equivalent to about a $2.9-\mathrm{m}$ head (about the depth of the instrument). The VWP at LS1a (installed $1 \mathrm{~m}$ or so above LS1b within the face of the headscarp) responded to the infiltrating rainfall on the following day, hours before the reactivation of the slide material. The photos show an acceleration of the slide between the night of December 8 and morning of December 9 that correlates with an intense burst of rainfall that reached about $10 \mathrm{~mm}$ per hour. This burst of rain caused measurement spikes in many of the monitoring instruments above already elevated levels. The slide movement stopped before any of the sensors returned to their prestorm values, although all of the sensors showing a predictive response to this event also showed subsiding values over the following hours to days after the movement ceases.

Based on observed movements in the camera footage, the movements that occurred between January 21 and January 30 were much greater than the December movements in terms of total displacement. A large rain event on January 21 caused porepressure spikes at LS1a and LS1b above previously elevated background levels. Shortly thereafter, the tensiometers at LS3 began to rapidly depart from previously established value ranges, with the LS3a value declining and the LS3b sensor increasing. The VWC sensor at LS3a began to show large signal excursions at this same time. (For clarity, these erroneous data are not shown in figure 17 and have been removed from the dataset.) A trip to the field identified that the LS3a tensiometer had been pulled from its emplacement and its broken housing was protruding from a downhill landslide deposit, while the LS3b tensiometer was buried under additional deposited material. The change in effective water column height above these two sensors changed the pressures acting on them, leading to decreasing and increasing signals, respectively.

The final episode of definitive movement identified by the camera occurred between March 9 and March 14. Again, the movement followed pore-pressure responses of the LS1a and LS1b VWPs that were instigated by a large burst of rainfall. Additionally, the VWC at LS1a jumped about 10 percent following the onset of the initial storm pulse. The VWC instrument at LS2b began to show large signal excursions after this point, and was found to have been pulled from its emplacement during a field trip. A few days later, after another episode of rain, the tensiometer at LS2b, and the VWC instruments at LS3b and LS5b, began to exhibit questionable signals suggestive of nearby ground movements.

Two additional probable movements were identified from the time-lapse photography on the nights of March 23 and March 26. Although associated with rainfall, these movements were accompanied by comparatively small storm events and insignificant instrumental responses, suggesting that the failures might be of a different nature than those preceding them such as tree throw or some unidentified human activity.

The VH instruments showed storm responses similar to the LS site instruments for the time ranges, although there was no indication of slope movements at the VH site. Because there was no movement at the site, the traces should be free of confounding "displacement-induced" readings. Figures 19 and 20 show VWC and pore-water pressure levels, respectively, in transition from dry-season to wet-season levels before the December 2015 storm. Furthermore, the tensiometer at VH3 was still showing very low pore pressures until after the storm passed, and the VWP at VH1 and VH5 did not seem to respond to the event at all. This lack of pore-pressure response is consistent with low (or still increasing) soil moisture, which is reflected in the VWC plots.

The January and March storms produced similar instrument response at VH, except that the VWP at VH5 responded with elevated pore-water pressures in both cases. Each of the tensiometers showed positive pore-pressure responses to each storm episode during the susceptible time periods and coincide with VWC spikes moving from field conditions to saturated conditions.

\section{Conclusion}

Thoughtful interpretation of near real-time monitoring data provides a useful tool to aid in determining landslide susceptibility. The data show the transition from dry-season conditions to wet-season conditions-which are susceptible to movement with additional rainfall. Furthermore, these data show rapid increases in pore-water pressures and near-saturated volumetric water-content values after storm events that correlate with documented landslide movement events. As a result, the data can aid in determination of landslide susceptibility. However, the data also show that, regardless of hydrologic forcing, not all storm events cause ground movements. Used in conjunction with weather forecasts and rainfall thresholds, subsurface hydrologic observations provided by combined volumetric water-content sensors, vibrating-wire piezometers, and tensiometers help identify times when hillslopes are more susceptible to sliding. 


\section{References Cited}

Baum, R.L., Harp, E.L., and Hultman, W.A., 2000, Map showing recent and historic landslide activity on coastal bluffs of Puget Sound between Shilshole Bay and Everett, Washington: U.S. Geological Survey Miscellaneous Field Studies Map MF 2346, 1 sheet, scale 1:24,000, accessed September 9, 2016, at http://pubs.usgs.gov/mf $/ 2000 / \mathrm{mf}-2346 /$.

Baum, R.L., McKenna, J.P., Godt, J.W., Harp, E.L., and McMullen, S.R., 2005, Hydrologic monitoring of landslide-prone coastal bluffs near Edmonds and Everett, Washington, 2001-2004: U.S. Geological Survey Open-File Report 2005-1063, 42 p., accessed August 1, 2016, at https://pubs.er.usgs.gov/publication/ofr20051063.

Baum, R.L., Fischer, S.J., and Vigil, J.C., 2017, Thresh—Software for tracking rainfall thresholds for landslide and debris flow occurrence, Code Repository: U.S. Geological Survey Software Release, accessed July 13, 2017, at https://oi.org/10.5066/ F7Q23XR0.

Chleborad, A.F., 2000, Preliminary method for anticipating the occurrence of precipitation-induced landslides in Seattle, Washington: U.S. Geological Survey Open-File Report 00-469, 29 p., accessed August 1, 2016, at https://pubs.usgs.gov/ of/2000/0469/report.pdf.

Chleborad A.F., 2003, Preliminary evaluation of a precipitation threshold for anticipating the occurrence of landslides in the Seattle, Washington, Area: U.S. Geological Survey Open-File Report 03-463, 39 p., accessed August 12, 2016, at http://pubs.usgs.gov/ of/2003/ofr-03-463/ofr-03-0463.html.

Chleborad, A.F., Baum, R.L., and Godt, J.W., 2008, A prototype system for forecasting landslides in the Seattle, Washington, area, in Baum, R.L., Godt, J.W., and Highland, L.M., eds., Engineering geology and landslides of the Seattle, Washington, area: Geological Society of America Reviews in Engineering Geology, v. 20, p. 103-120, accessed September 19, 2016, at https://doi.org/10.1130/2008.4020(06).

Coe, J.A., Michael, J.A., Crovelli, R.A., Savage, W.Z., Laprade, W.T., and Nashem, W.D., 2004, Probabilistic assessment of precipitation-triggered landslides using historical records of landslide occurrence, Seattle, Washington: Environmental \& Engineering Geoscience, v. 10, p. 103-122.

Godt, J.W., Baum, R.L., and Chleborad, A.F., 2006, Rainfall characteristics for shallow landsliding in Seattle, Washington, USA: Earth Surface Processes and Landforms, v. 31, p 97-110.

Godt, J.W., and McKenna, J.P., 2008, Hydrological response of hillside materials to infiltration-Implications for shallow landsliding in the Seattle area, in Baum, R.L., Godt, J.W., and Highland, L.M., eds., Landslides and engineering geology of the Seattle, Washington, area: Geological Society of America Reviews in Engineering Geology, v. 20, p. 121-135.

Harp, E.L., Michael, J.A., and Laprade, W.T., 2006, Shallow-landslide hazard map of Seattle, Washington: U.S. Geological Survey Open-File Report 2006-1139, 23 p., 1 sheet, scale 1:25,000, accessed August 1, 2016, at https://pubs.usgs.gov/ of/2006/1139/.

Kizito, Fred, Campbell, C.S., Campbell, G.S., Cobos, D.R., Teare, B.L., Carter, B., and Hopmans, J.W., 2008, Frequency, electrical conductivity, and temperature analysis of a low-cost capacitance soil moisture sensor: Journal of Hydrology, v. 352, p. $367-378$.

Laprade, W.T., Kirkland, T.E., Nashem, W.D., and Robertson, C.A., 2000, Seattle landslide study: Shannon and Wilson, Inc. Internal Report W-7992-01, 164 p.

Minard, James P., 1983, Geologic map of the Edmonds East and part of the Edmonds West quadrangles, Washington: U.S. Geological Survey Miscellaneous Field Studies Map MF-1541, scale 1:24,000.

Mirus, B.B., Smith, J.B., Stark, Benjamin, Lewis, York, Michel, Abagail, and Baum, R.L., 2016, Assessing landslide potential on coastal bluffs near Mukilteo, Washington - Geologic site characterization for hydrologic monitoring: U.S. Geological Survey Open-File Report 2016-1082, 28 p., accessed September 6, 2016, at http://dx.doi.org/10.3133/ofr20161082.

Savage, W.Z., Morrissey, M.M., and Baum, R.L., 2000, Geotechnical properties for landslide-prone Seattle area glacial deposits: U.S. Geological Survey Open-File Report 2000-228, 5 p., accessed June 29, 2017, at https://pubs.usgs.gov/of/2000/0228/ report.pdf. 
Schulz, W.H., Lidke, D.J., and Godt, J.W., 2008, Modeling the spatial distribution of landslide-prone colluvium and shallow groundwater on hillslopes of Seattle, Washington: Earth Surface Processes and Landforms, v. 33, p. 123-141.

Shipman, Hugh, 2004, Coastal bluffs and sea cliffs on Puget Sound, Washington: U.S. Geological Survey Professional Paper 1693, p. 81-94.

Smith, J.B., Baum, R.L., Mirus, B.B., Michel, A.R., Stark, B., 2017, Results of hydrologic monitoring on landslide-prone coastal bluffs near Mukilteo, Washington: U.S. Geological Survey data release, https://doi.org/10.5066/F7NZ85WX.

Thorsen, Gerald W., 1987, Soil bluffs + rain = slide hazards: Washington Geologic Newsletter, v. 15, no. 3, p. 3-11.

Tubbs, D.W., 1974, Landslides in Seattle: State of Washington Department of Natural Resources, Division of Geology and Earth Sciences Information Circular No. 52, 15 p., accessed September 15, 2016, at http://file.dnr.wa.gov/publications/ ger_ic52_landslides_in_seattle.pdf.

Tubbs, D.W., 1975, Causes, mechanisms and prediction of landsliding in Seattle: Seattle, Wash., University of Washington, Ph.D. dissertation, $52 \mathrm{p}$.

Varnes, D.J., 1978, Slope movement types and processes, in Schuster, R.L., and Krizek, R.J., eds., Landslides-Analyses and control: Washington, D.C., Transportation Research Board, National Research Council Special Report 176, p. 11-33. 



\section{Appendix 1. Datalogger Programs}

Appendix 1 provides the datalogger programs that run at the monitoring sites. The rain gage sites both use the same program, which is named "rainfallTemp20150902.CR2." Because of unique calibrations for the vibrating-wire piezometers, and the inclusion of a barometer at the Landslide Scar site, each of the hydrologic monitoring sites uses a separate program. The programs are VH_20150817.CR1 for the Vegetated Hillslope site, and LSa_20150824.CR1 and LSb_20150817.CR1 for the Landslide Scar site. 


\section{STrainfallTemp20150902.CR2}

'Written by Smith, July 2015

'Modified by Smith on 9/2 to correct voltage to resistance conversion equation

'for airTempRs_ohms

'The underscore character ( ) at the end of a line continues a command to the following line

'The apostrophe character (') denotes comments

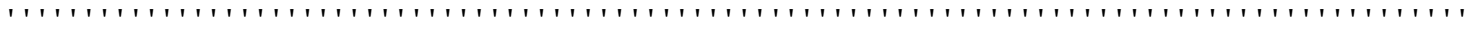

'Define variables

' ' ' ' ' ' ' ' ' ' ' ' ' ' ' ' '

Public battVolt_V

'battery voltage

'Rainfall variables

Public rain_tipcount 'tips measured by TB4 gage

Public rain $\mathrm{mm}$

'rain measured by TB4

Public rain $10 \mathrm{~mm}$

Public ilo_mm $\bar{P} e r h r$

Public cumRain mm

'rain in last $10-\mathrm{min}$

'10-min rainfall intensity (mm/hr)

Public cumRain $\bar{B} a c k 10$

cumulative Rainfall since start of program

'Air temperature variables

Public airTempRaw

Public airTempRs ohms

'cumulative Rainfall 10 records back

Public airTemp_degC

'temperature probe raw measurement, $23.1 \mathrm{k}$ completion resistor

'resistance of the thermistor

'resistance converted to degrees Celsius

'Clock Time variables for power cycling modem

'Power cycle modem hourly, on 10 off 50

Public rTime(8)

Alias rTime $(4)=$ Hour

Alias rTime (5) = Minute

Const minuteoff $=10$

Const minuteon $=0$

Public modemoff

'10 minutes past the hour

' 0 minutes past the hour

'Scan and Log rate variables

Const Rate $=5$

'switch for modem power

'Define Data Tables

'rawMeasurements_15m table provides raw (for example, non-converted) values

' for data acquisition, every 15 minutes

DataTable (rawData_15m,1,-1)

DataInterval $(0, \overline{1} 5, \mathrm{~min})$

Sample (1, battVolt V)

Totalize (1,rain_tipcount,False)

Sample (1, airTemp̄Raw)

EndTable

'physicalUnits $15 \mathrm{~m}$ table provides converted units for field verification

'of proper operation and troubleshooting, every 15 minutes

DataTable (physunits_5m, 1,20160)

DataInterval (0, Rate, min)

Sample (1, rain_mm)

Sample (1, cumRāin_mm)

Sample (1, il 0 mmPerhr)

Sample (1, airTemp_degC)

EndTable

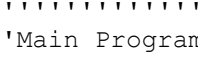

' ' ' ' ' ' ' ' '

'Initialize variables

cumRain_mm $=0$.

$\operatorname{rain} 10 \mathrm{~mm}=0$.

i10_mm $\bar{P}$ erhr $=0$.

'Turn on switched $12 \mathrm{~V}$ port for modem

modemoff $=0$

PortSet (2, modemoff)

'Begin scan

Scan (Rate, min) 


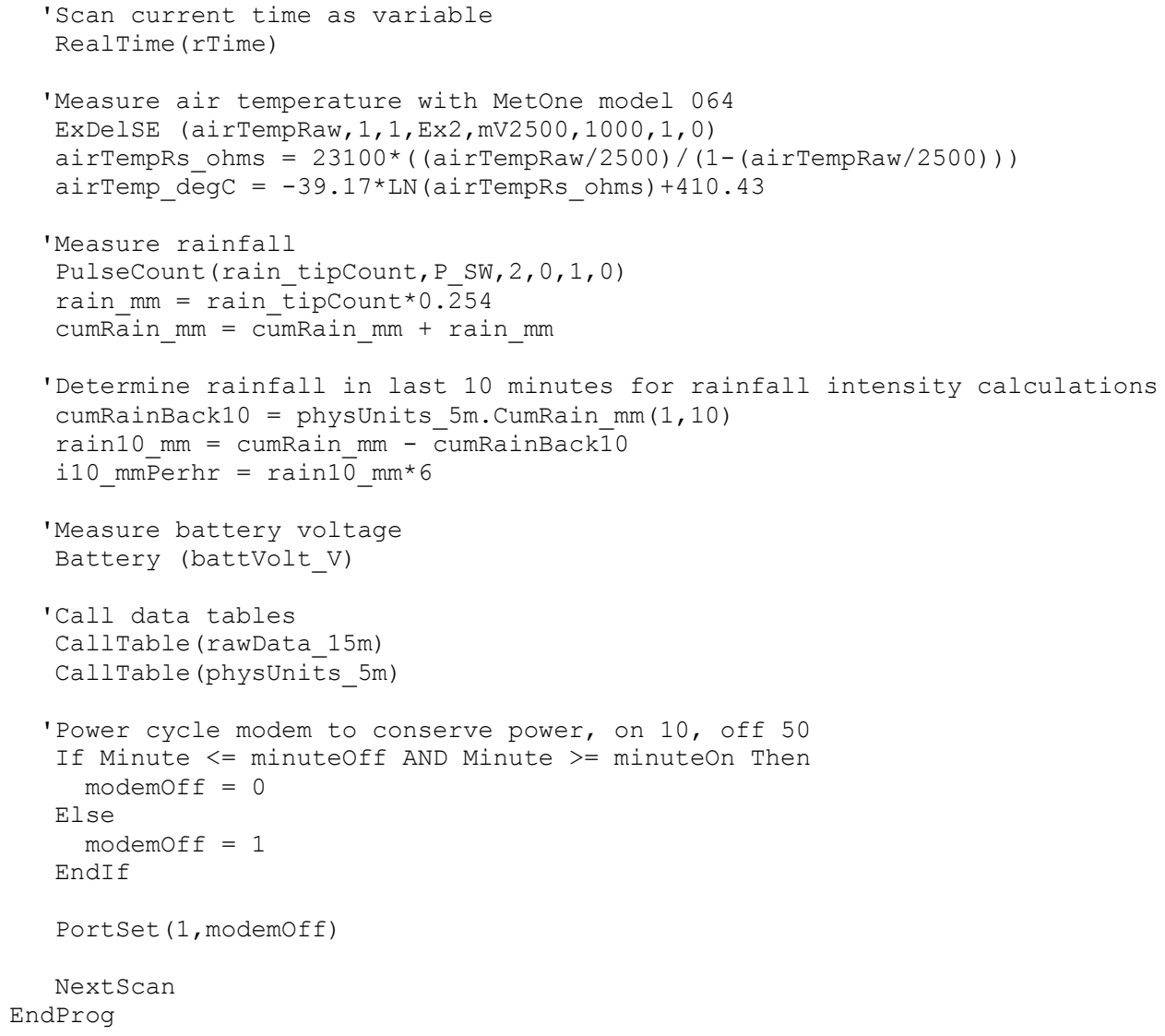


st_VH_20150817.CR1

'Program for Sound Transit hydrological monitoring sites

'Smith 20150617

'Modified by Smith on 20150706 to change modem

'Switch to "normally open" configuration

'Modified by Michel on 20150811 to update piezometer calibration

'Modified by Smith on 20150817 to change scan interval,

'and change programming to accommodate a normally open modem relay

'The underscore character ( ) at the end of a line continues a command to the following line

'The apostrophe character (') denotes comments

'Define variables

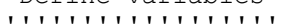

'System variables

Public battV V

Public pTemp_c

'system voltage

Const scanRate $=15 \quad$ 'minutes

'Modem switching variables

Public rTime(9)

'(1) year, (2) month, (3) day of month,

'(4) hour of day, (5) minutes, (6) seconds,

' (7) microseconds, (8) day of week

' (1-7; Sunday = 1), (9) day of year

Public modemoff

'modem is off when modemoff is true $(<>0)$

Alias rTime (4) = Hour

Alias rTime(5) = Minute

Const minuteoff $=15$

'15 minutes past the hour

Const minuteon $=0$

' 0 minutes past the hour

'Rain gage variables

Public rain tipcount

Public rain_mm

'Volumetric water content variables

'EC-5 volumetric water content sensor

'"Raw" units are voltage ratio Vin/Vexcite

Public VwCRaw1

Public vwcRaw2

'use of non-consecutive excitation ports

Public vwcRaw3

'requires explicit variable declaration

Public VwcRaw4

Public vwcRaw5

'EC-5 volumetric water content sensor, converted output

Public VwC1

Public VwC2

Public vwC3

Public vwc4

Public vwc5

Public vwcMult $=2.975 \quad$ 'generic multiplier for raw vwc to volumetric water content

Public vwcOffs $=-0.4 \quad$ 'generic offset for raw vwc to volumetric water content

'Tensiometer Serial numbers

'Tens1 = 04353, replaced with 4521 on 8/17

'Tens2 = 04342

'Tens $3=04341$

'Tensiometer variables

Public seTensPres_V(3)

Public seTenstemp $V(3)$

Public seTensGround_V(3)

Public corrTensPres_V(3)

Public corrTensTemp $\mathrm{V}(3)$

Public corrTensPres_kPa(3)

Public corrTensTemp_degC (3)

Public tensMult $(2)=\{-1 / 10,1 / 20$

'tensiometer pressure reading, raw

'tensiometer temperature reading, raw

'tensiometer ground reading, for differential correction

'differential pressure reading from tensiometer

'differential temperature reading from tensiometer

'converted pressure reading from tensiometer

'converted temperature reading from tensiometer

Public tensoffs $(2)=\{100,-30\}$

multiplier \{pressure, temperature\} for tensiometer conversion

'Air temperature variables

Public airTempRaw

Public airTempRs_ohms

'temperature probe raw measurement, $23.1 \mathrm{k}$ completion resistor

Public airTemp_dēgC

'resistance of the thermistor

'resistance reading converted to degrees Celsius 


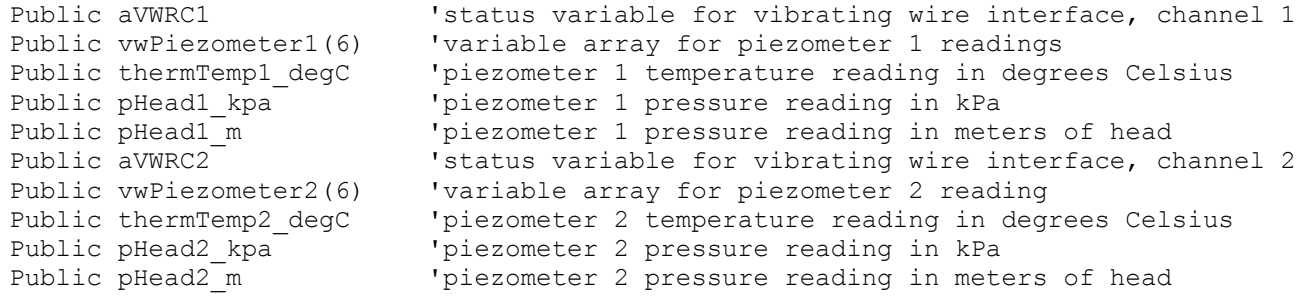




\begin{tabular}{|c|c|}
\hline 157 & Sample (1, vwc2, FP2) \\
\hline 158 & Sample $(1, \operatorname{Vwc} 3, \mathrm{FP} 2)$ \\
\hline 159 & Sample (1, Vwc4, FP2) \\
\hline 160 & Sample (1, Vwc5, FP2) \\
\hline 161 & Sample $(3$, corrTensPres_kPa (), FP2) \\
\hline 162 & Sample $(3$, corrTensTemp $\operatorname{deg}()$, FP2) \\
\hline 163 & Sample (1, pHead1 m, FP2) \\
\hline 164 & Sample (1, thermTemp1_degC, FP2) \\
\hline 165 & Sample $(1, \mathrm{pHead} 2 \mathrm{~m}, \mathrm{~F} \overline{\mathrm{P}} 2)$ \\
\hline 166 & Sample (1, thermTemp2_degC, FP2) \\
\hline 167 & Sample $(1$, battV $V$, FP $\overline{2})$ \\
\hline 168 & EndTable \\
\hline 169 & \\
\hline 170 & 'vwDiagnostics $15 \mathrm{~m}$ table provides diagnostic information for converted units \\
\hline 170 & ' for field verification of proper operation and troubleshooting, every 15 minutes \\
\hline 171 & DataTable (vwDiagnostics $15 \mathrm{~m}$, True, 1344 ) \\
\hline 172 & Sample (1, aVWRC1, FP2) \\
\hline 173 & Sample (1, freq1, FP2) \\
\hline 174 & Sample (1, amp $1, \mathrm{FP} 2)$ \\
\hline 175 & Sample (1, sNRat1, FP2) \\
\hline 176 & Sample (1, nFreq1, FP2) \\
\hline 177 & Sample (1, dRat1, FP2) \\
\hline 178 & Sample (1, thermRes 1, FP2) \\
\hline 179 & Sample (1, thermTemp1 degC, FP2) \\
\hline 180 & Sample $(1$, pHead1_m, $F \bar{P} 2)$ \\
\hline 180 & Sample $(1$, aVWRC2, FP2) \\
\hline 182 & Sample (1, freq2, FP2) \\
\hline 183 & Sample (1, amp2, FP2) \\
\hline 184 & Sample (1, sNRat2, FP2) \\
\hline 185 & Sample (1, nFreq2, FP2) \\
\hline 186 & Sample (1, dRat2, FP2) \\
\hline 187 & Sample (1, thermRes2, FP2) \\
\hline 188 & Sample (1, thermTemp2_degC, FP2) \\
\hline 189 & Sample $(1$, pHead2_m, E $\bar{P} 2)$ \\
\hline 190 & EndTable \\
\hline 191 & \\
\hline 192 & י \\
\hline 193 & (2. \\
\hline 194 & 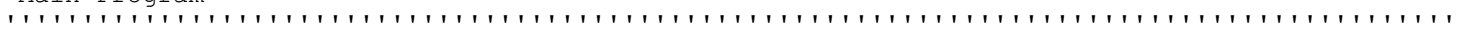 \\
\hline 195 & \\
\hline 196 & BeginProg \\
\hline 197 & 'Establish connection with AVW200 vibrating wire interface \\
\hline 198 & SerialOpen $(\mathrm{Com} 1,38400,4,0,0)$ \\
\hline 199 & \\
\hline 200 & 'Begin Scan \\
\hline 201 & Scan ( scanRate, Min, 1,0$)$ \\
\hline 202 & \\
\hline 203 & 'Battery voltage measurement \\
\hline 204 & Battery (battv_v) \\
\hline 205 & \\
\hline 206 & 'Wiring panel temperature measurement \\
\hline 207 & PanelTemp (pTemp_C, $60 \mathrm{~Hz}$ ) \\
\hline 208 & \\
\hline 209 & ' 5 Decagon EC-5 measurements: \\
\hline 210 & Dim i \\
\hline 211 & BrHalf (vwcRaw1, 1, mV2500,10,Vx1, 1,2500, False, $10000,250,1,0$ ) \\
\hline 212 & BrHalf (vwcRaw2, 1, mV2500,11,Vx1, 1, 2500, False, $10000,250,1,0$ ) \\
\hline 213 & BrHalf (vwcRaw3, 1, mV2500,12,Vx1,1,2500, False, $10000,250,1,0$ ) \\
\hline 214 & BrHalf (vwcRaw4, 1, mV2500,13, Vx3,1,2500, False, $10000,250,1,0$ ) \\
\hline 215 & BrHalf (vwcRaw5, 1, mV2500,14, Vx3, 1,2500, False, $10000,250,1,0$ ) \\
\hline 216 & \\
\hline 217 & 'Convert vwcRaw measurement to volumetric water content \\
\hline 218 & $\mathrm{vwCl}=\mathrm{vwCRaw} 1$ * $\mathrm{vwCMult}+\mathrm{vwcOffs}$ \\
\hline 219 & vwc2 $=$ vwcRaw2* vwcMult + vwcOffs \\
\hline 220 & vwc3 $=$ vwcRaw3* vwcMult+vwcoffs \\
\hline 221 & $\mathrm{Vwc} 4=\mathrm{VwcRaw} 4 * \mathrm{VwcMult}+\mathrm{VwcOffs}$ \\
\hline 222 & vwc5 $=$ vwcRaw5* vwcMult+vwcOffs \\
\hline 223 & \\
\hline 224 & 'Read three UMS T8 tensiometers \\
\hline 225 & SW12(1) 'switch on power to tensiometers \\
\hline 226 & Delay $(0,30, \mathrm{Sec})$ 'allow tensiometers to warm \\
\hline 227 & \\
\hline 228 & 'Tensiometer 04353, replaced with 4521 on 8/17 \\
\hline 229 & 'make single ended tensiometer pressure measurement \\
\hline 230 & VoltSe (seTensPres_V(1), 1, mV2500,1, True, $0,660 \mathrm{~Hz}, 1,0$ ) \\
\hline 231 & 'make single ended tensiometer temperature measuremen \\
\hline 232 & VoltSe (seTensTemp_V(1), 1, mV2500,2, False, 0, $60 \mathrm{~Hz}, 1,0$ ) \\
\hline 234 & 'make ground measurement for differential correction \\
\hline 235 & VoltSe (seTensGround V(1), 1, mV25, 3, False, $0,60 \mathrm{~Hz}, 1,0$ ) \\
\hline
\end{tabular}




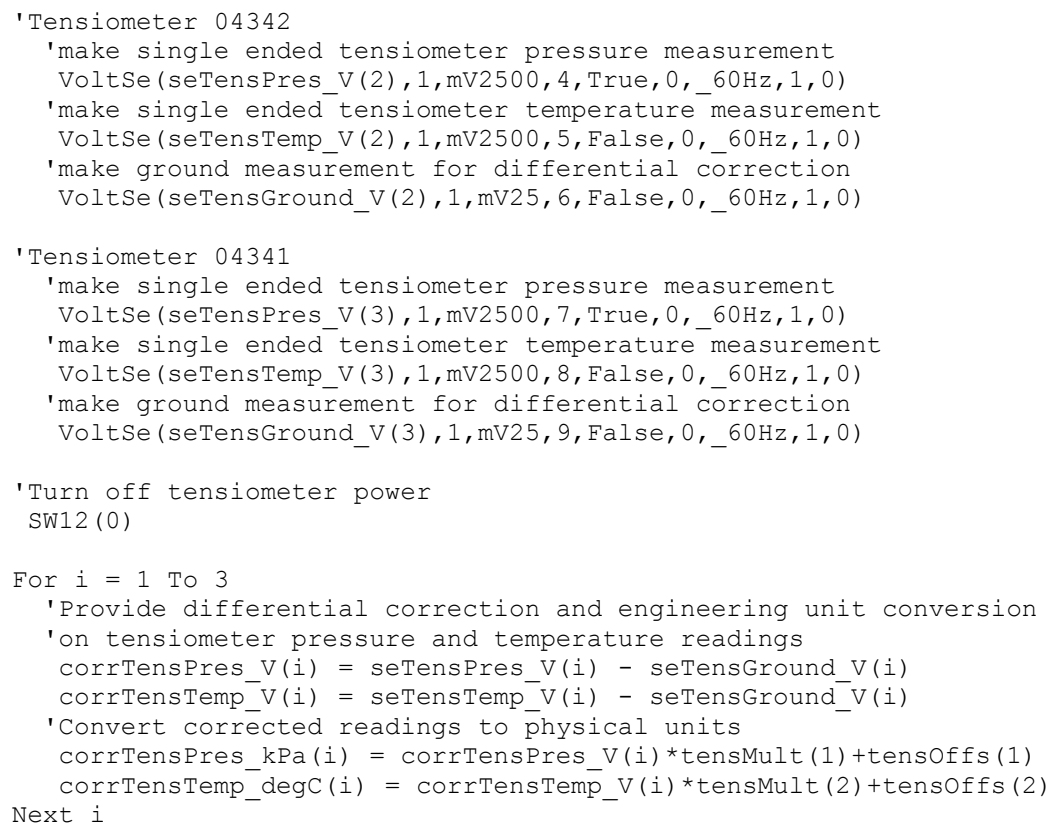

'Query AVW200 channel 1 vibrating wire interface for piezometer measurements AVW200 (aVWRC1, Com1, 0,200,vwPiezometer1 ( ) , 1, 1, 1,2000,3000,1,_60 Hz, 1, 0)

'Calculate thermistor temperature 'ThermTemp'

thermTemp1_degC $=1 /(1.4051 \mathrm{E}-3+2.369 \mathrm{E}-4 * \mathrm{LN}($ thermRes 1$)+1.019 \mathrm{E}-7$

$\star$ LN (thermRes 1$) \wedge 3$ )

'Convert 'ThermTemp' to 'degC' and add 'Tempoffset'

thermTemp1_degC $=$ thermTemp1_degC-273.15+tempoffset 1

'Calculate water level 'pHead' (kPa)

$\mathrm{pHead} 1 \mathrm{kpa}=(\mathrm{C} 1 \mathrm{~A}$ *freq1^2$)+(\mathrm{C} 1 \mathrm{~B}$ *freq1 $)+\left(\begin{array}{ll}\mathrm{C} 1 & \mathrm{C}\end{array}\right)$

'Apply temperature corrections

pHead1_kpa $=$ pHead1_kpa $+($ (tempCal1-thermTemp1_degC $) *$ tempCoeff1_m $)$ $+($ temp̄oeff1 b)

'Convert 'pHead' from kpa to $\mathrm{m}$

pHead1_m= pHead1_kpa*0.1019977334

'Query AVW200 channel 2 vibrating wire interface for piezometer measurements AVW200 (aVWRC2, Com1, 0, 200, vwPiezometer2( ), 2,1, 1,2000,3000,1, 60Hz, 1,0)

'Calculate thermistor temperature 'ThermTemp' thermTemp2_degC=1/(1.4051E-3+2.369E-4*LN (thermRes 2$)+1.019 \mathrm{E}-7$ * LN (thermRes2)^3)

'Convert 'ThermTemp' to 'degC' and add 'Tempoffset'

thermTemp2_degC=thermTemp2_degC-273.15+tempoffset2

'Calculate water level 'pHead' (kPa)

pHead2 $\mathrm{kpa}=\left(\mathrm{C} 2 \mathrm{~A}^{\star}\right.$ freq2^ 2$)+\left(\mathrm{C} 2 \mathrm{~B}^{\star}\right.$ freq2 $)+(\mathrm{C} 2 \mathrm{C})$

'Apply temperature corrections

$\mathrm{pHead2}$ _kpa $=$ pHead2_kpa +( (tempCal2-thermTemp2_degC $)$ *tempCoeff2_m $)$ $+($ tempCoeff2 b)

'Convert pressurekPA to $\mathrm{m}$

pHead2_m $=$ pHead2_kpa*0.1019977334

'Measure air temperature with Metone model 064

BrHalf (airTempRaw, 1, Autorange, 16, Vx2, 1, 1000 , True, 0, 60 Hz, 1,0)

airTempRs ohms = 23100* (airTempRaw/(1-airTempRaw))

airTemp_degC $=-39.17 *$ LN (airTempRs_ohms) +410.43

'Measure rainfall amount with TB4 rain gage

Pulsecount (rain tipCount, 1, 1,2, 0, 1, 0)

rain $m$ m = rain EipCount*0.254

'For power savings, switch modem on for first 30 minutes per hour to

'transmit data, off for 30

RealTime (rTime)

If Minute $<=$ minuteoff AND Minute $>=$ minuteon Then modemoff $=0$ 


\begin{tabular}{|c|c|}
\hline 315 & Else \\
316 & modemoff $=1$ \\
317 & EndIf \\
318 & PortSet (8, modemoff) \\
319 & \\
320 & Call data tables and store data \\
321 & CallTable rawMeasurements_15m \\
322 & CallTable physicalUnits_15m \\
323 & CallTable vwDiagnostics_15m \\
324 & \\
325 & NextScan \\
326 & EndProg \\
327 &
\end{tabular}


st LSa 20150824.CR1

'Program for Sound Transit hydrological monitoring sites

'Smith 20150617

'Modified by Smith on 20150617 for "normally open" modem switch

'Changed EC-5 excitation channels on 20150714

'Modified by Michel on 20150811 to change VW piezometer calibration

'Modified by Smith on 20150817 to change scan rate and add barometer

'Modified by Michel on 20150824 to change piezometer calibration

'The underscore character ( ) at the end of a line continues a command to the following line

'The apostrophe character (') denotes comments

'Define variables

' System variables

Public battV V

Public pTemp C

Const scanRate $=15$

system voltage

Const warmTime $=60$

' logger panel temperature

'minutes

'Modem switching variables

Public rTime(9)

' (1) year, (2) month, (3) day of month,

' (4) hour of day, (5) minutes, (6) seconds,

' (7) microseconds, (8) day of week

' (1-7; Sunday = 1), (9) day of year.

Public modemoff

Alias rTime $(4)=$ Hour

Alias rTime (5) = Minute

Const minuteoff $=15$

'modem is off when modemoff is true $(<>0)$

Const minuteon $=0$

' 10 minutes past the hour

' 0 minutes past the hour

'Rain gage variables

Public rain tipcount

Public rain_mm

'Volumetric water content variables

'EC-5 volumetric water content sensor

Public VwcRaw(5) " "Raw" units are voltage ratio Vin/Vexcite

Public VwC(5) 'EC-5 volumetric water content sensor, converted output

Public vwcMult $=2.975$ 'generic multiplier for vwc raw to volumetric water content

Public vwcOffs $=-0.4 \quad$ 'generic offset for vwc raw to volumetric water content

'Barometric pressure variables

Public barometricPressure raw

Public barometricPressure_kPa

'Tensiometer Serial numbers

'Tens1 $=04339$

'Tens2 = 04343

'Tens3 = 04338

' Tensiometer variables

Public seTensPres $V(3)$

Public seTenstemp_V(3)

Public seTensGround $V(3)$

Public corrTenspres $V(3)$

Public corrTenstemp_V(3)

Public corrTensPres_kPa (3)

Public corrTenstemp $\operatorname{deg}(3)$

'tensiometer pressure reading, raw

'tensiometer temperature reading, raw

'tensiometer ground reading, for differential correction

'differential pressure reading from tensiometer

'differential temperature reading from tensiometer

'converted pressure reading from tensiometer

'converted temperature reading from tensiometer

Public tensmult $(2)=\{-1 / 10,1 / 20\}$ 'multipliers \{pressure, temperature for tensiometer conversion

Public tensoffs $(2)=\{100,-30\}$

'offsets \{pressure, temperature\} for tensiometer conversion

'Air temperature variables

Public airTempRaw

Public airTempRs_ohms

'temperature probe raw measurement, $23.1 \mathrm{k}$ completion resistor

'resistance of the thermistor

Public airTemp_dēgC

'resistance reading converted to degrees Celsius

'Vibrating Wire Piezometer variables

'status variable for vibrating wire interface, channel 1

Public vwPiezometerl(6)

Public thermTemp1_degC

Public pHead1_m

Public aVWRC2

Public vwPiezometer2 (6)

' variable array for piezometer reading

'piezometer temperature reading in degrees Celcius

'piezometer pressure reading in meters of head

'status variable for vibrating wire interface, channel 2

Public thermTemp2 degc

'variable array for piezometer reading

'piezometer temperature reading in degrees Celcuis 


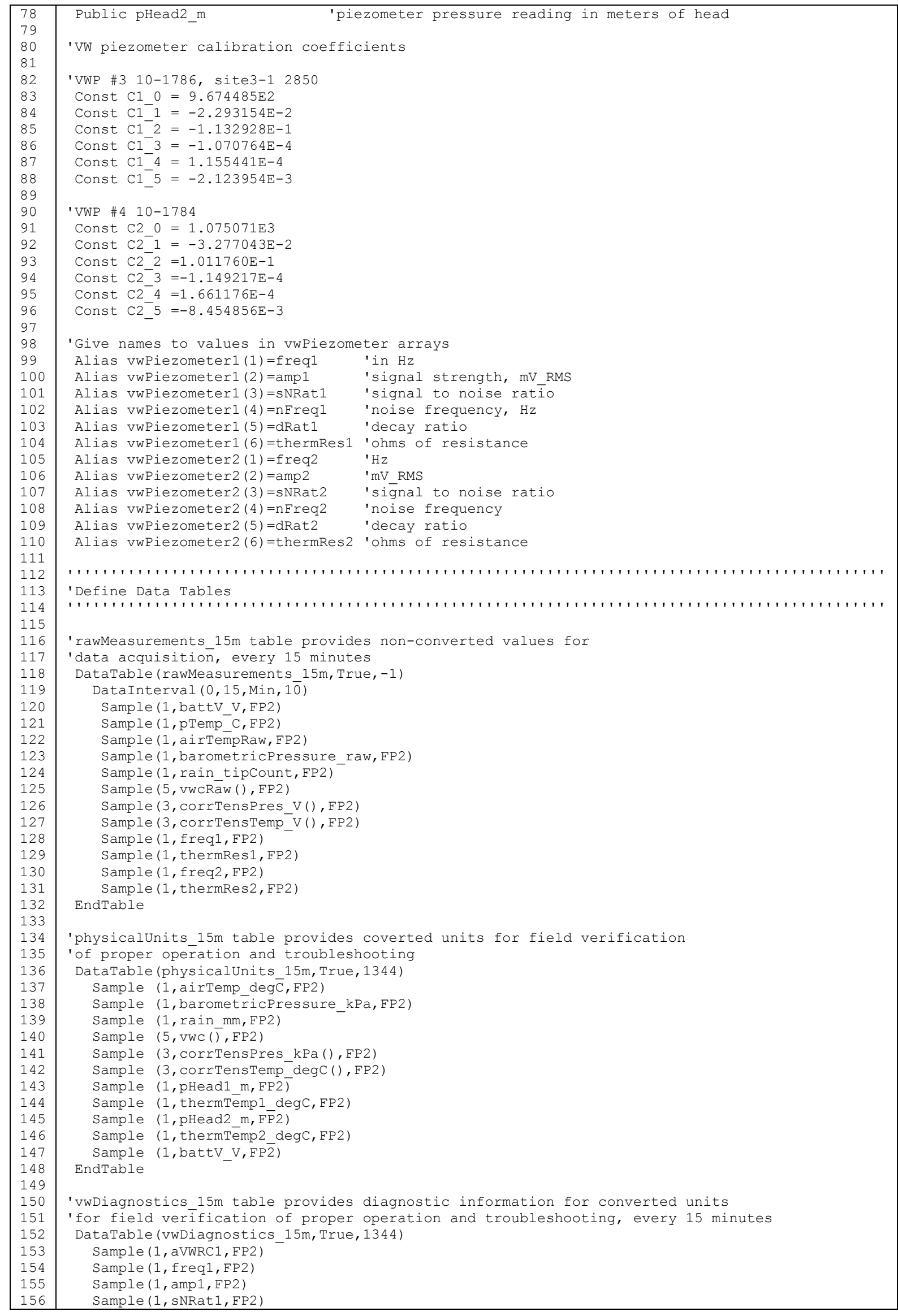


Sample $(1$, nFreq1, FP2

Sample (1, dRat1, FP2)

Sample (1, thermRes1, FP2)

Sample (1, thermTemp1_degC, FP2)

Sample (1, pHead1_m, FP 2$)$

Sample (1, aVWRC2, FP2)

Sample (1, freq2, FP2)

Sample (1, amp2, FP2)

Sample (1, sNRat2, FP2)

Sample (1, nFreq2, FP2)

Sample (1, dRat2, FP2)

Sample (1, thermRes2, FP2)

Sample (1, thermTemp2_degC,FP2)

Sample (1, pHead2 m, FP2)

EndTable

'Main Program

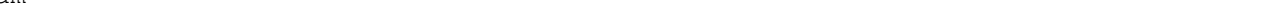

BeginProg

'Establish connection with AVW200 vibrating wire interface

Serialopen (Com1, 38400,4,0,0)

'Begin Scan

Scan (scanRate, min, 1,0)

$\operatorname{SW} 12(1)$

PortSet $(7,1)$

'switch on power to tensiometers

Delay (0, warmTime, Sec)

'allow tensiometers and barometer to warm up

'Battery voltage measurement

Battery (battV_V)

'Wiring panel temperature measurement

PanelTemp (pTemp_C, _60 Hz)

'5 Decagon EC-5 measurements:

BrHalf (VwcRaw (1) , 1, mV2500, 10, Vx1, 1,2500, False, $10000,250,1,0$ )

BrHalf (VwcRaw (2) ,1, mV2500,11,Vx1, 1,2500, False, $10000,250,1,0$ )

BrHalf (VwcRaw (3) , 1, mV2500, 12,Vx1, 1, 2500, false, $10000,250,1,0$ )

BrHalf (VwcRaw (4), 1, mV2500, 13, Vx3, 1,2500, False, $10000,250,1,0$ )

BrHalf (VwcRaw (5) , 1, mV2500, 14,Vx3, 1,2500, False, 10000 , 250, 1, 0)

'Convert vwcRaw measurement to volumetric water content

Dim i

For $i=1$ To 5

$\operatorname{Vwc}(i)=\operatorname{VwcRaw}(i) * \operatorname{VwcMult}+\operatorname{vwcOffs}$

Next i

'Read three UMS T8 tensiometers

' Tensiometer 04339

'make single ended tensiometer pressure measurement

VoltSe (seTensPres_V(1), 1, mV2500,1, True, 0, 60Hz, 1,0)

'make single ended tensiometer temperature measurement

VoltSe (seTensTemp V(1), 1, mV2500,2, False, 0, 60Hz, 1,0)

'make ground measurement for differential correction

VoltSe (seTensGround_V (1), 1, mV25, 3, False, 0,_60 Hz, 1, 0)

'Tensiometer 04343

'make single ended tensiometer pressure measurement

VoltSe (seTensPres V(2), 1, mV2500, 4, True, 0, 60Hz, 1, 0)

'make single ended tensiometer temperature measurement

VoltSe (seTensTemp V(2), 1, mV2500,5, False, 0, 60Hz, 1, 0 )

'make ground measurement for differential correction

VoltSe (seTensGround_V (2) , 1, mV25, 6, False, 0,_60 Hz, 1, 0)

'Tensiometer 04338

'make single ended tensiometer pressure measurement

VoltSe (seTensPres V(3), 1, mV2500, 7, True, 0, 60Hz, 1, 0)

'make single ended tensiometer temperature measurement

VoltSe (seTensTemp_V(3), 1, mV2500,8, False, 0,_60 Hz, 1,0)

'make ground measurement for differential correction

VoltSe (seTensGround_V(3), 1, mV25,9, False, 0,_60 Hz, 1,0)

'Turn of tensiometer power

SW12 (0) 


\begin{tabular}{|c|c|}
\hline 236 & For $i=1$ To 3 \\
\hline 237 & 'Provide differential correction and engineering unit conversion \\
\hline 238 & 'on tensiometer pressure and temperature readings \\
\hline 239 & corrTensPres_V(i) = seTensPres_V(i) - seTensGround_V(i) \\
\hline 240 & corrTensTemp_V(i) = seTensTemp_V(i) - seTensGround_V(i) \\
\hline 241 & \\
\hline 242 & 'Convert corrected readings to physical units \\
\hline 243 & corrTensPres_kPa(i) = corrTensPres_V(i) *tensMult (1) +tensoffs (1) \\
\hline 244 & corrTensTemp_degC $(i)=$ corrTensTemp_V(i) *tensMult (2) +tensoffs (2) \\
\hline 245 & Next i \\
\hline 246 & \\
\hline 247 & 'Measure barometric pressure \\
\hline 248 & Voltse (barometricPressure_raw, 1, mV2500,15, 1, 0,_60 Hz, 1, 0) \\
\hline 249 & barometricPressure_kPa $=($ bārometricPressure_raw $\bar{\star} 0.240+500) * 0.1$ \\
\hline 250 & PortSet $(7,0)$ \\
\hline 251 & \\
\hline 252 & 'Query AVW200 channel 1 vibrating wire interface for piezometer measurements \\
\hline 253 & AVW2 00 (aVWRC1, Com1,0,200, vwPiezometer1 (), 1,1,1,400,3500,1,_60Hz,1,0) \\
\hline 254 & \\
\hline 255 & 'Calculate thermistor temperature 'ThermTemp' \\
\hline 256 & thermTemp1_degC $=1 /(1.401 \mathrm{E}-3+2.377 \mathrm{E}-4 * \mathrm{LN}($ thermRes 1$) \ldots$ \\
\hline 257 & $+9.730 \mathrm{E}-8 * \overline{\mathrm{L}} \mathrm{N}($ thermRes 1$) \wedge 3)-273.15$ \\
\hline 258 & \\
\hline 259 & 'Calculate water level 'Lvl' (kPa) using TI factors and TI equation \\
\hline 260 & 'Pressure $=\mathrm{C} 0+(\mathrm{C} 1 * \mathrm{~Hz})+(\mathrm{C} 2 * \mathrm{~T})+\left(\mathrm{C} 3 * \mathrm{~Hz}^{\wedge} 2\right)+(\mathrm{C} 4 * \mathrm{~Hz} * \mathrm{~T})+\left(\mathrm{C} 5 * \mathrm{~T}^{\wedge} 2\right)$ \\
\hline 261 & pHead1_m=C1_0+(C1_1*freq1) + (C1_2*thermTemp1_degC $)+\left(\mathrm{C} 1 \_3 *\right.$ \\
\hline 262 & 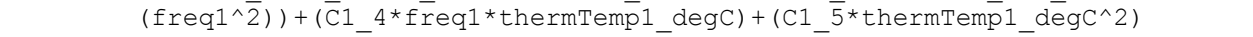 \\
\hline 263 & \\
\hline 264 & 'Convert water level 'Lvl' from PSI to $\mathrm{m}$ \\
\hline 265 & pHead1_m=pHead1_m*0.1019977334 \\
\hline 266 & \\
\hline 267 & 'Query AVW200 channel 2 vibrating wire interface for piezometer measurements \\
\hline 268 & AVW200 (aVWRC2,Com1,0,200,vwPiezometer2 ( ),2,1,1,400,3500,1,_60Hz, 1,0) \\
\hline 269 & \\
\hline 270 & 'Calculate thermistor temperature 'ThermTemp_2' \\
\hline 271 & thermTemp2_degC $=1 /(1.401 \mathrm{E}-3+2.377 \mathrm{E}-4 * \mathrm{LN}$ (thermRes2) \\
\hline 272 & $+9.730 \mathrm{E}-8 * \overline{\mathrm{L}} \mathrm{N}($ thermRes 2$) \wedge 3)-273.15$ \\
\hline 273 & \\
\hline 274 & 'Calculate water level 'LvI_2' (PSI) using TI factors and TI equation \\
\hline 275 & 'Pressure $=\mathrm{C} 0+(\mathrm{C} 1 * \mathrm{~Hz})+(\mathrm{C} 2 * \mathrm{~T}) \overline{-}\left(\mathrm{C} 3 * \mathrm{~Hz}^{\wedge} 2\right)+(\mathrm{C} 4 * \mathrm{~Hz} * \mathrm{~T})+\left(\mathrm{C} 5 * \mathrm{~T}^{\wedge} 2\right)$ \\
\hline 276 & pHead2_m=C2_0+(C2_1*freq 2$)+\left(\mathrm{C} 2 \_3 *\right.$ thermTemp $2 \_$degC $)+\left(\mathrm{C} 2 \_3 *\right.$ \\
\hline 277 & 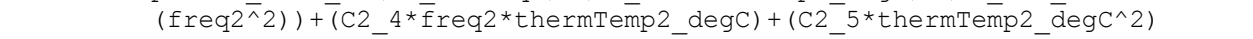 \\
\hline 278 & \\
\hline 279 & 'Convert water level 'Lv1_2' from PSI to meters \\
\hline 280 & pHead2_m=pHead2_m*0.10199̄77334 \\
\hline 281 & \\
\hline 282 & 'Measure air temperature with Metone model 064 \\
\hline 283 & BrHalf (airTempRaw, 1, Autorange, 16, Vx2, 1, 1000 , True, 0, 250, 1,0) \\
\hline 284 & airTempRs_ohms $=23100 *($ airTempRaw/(1-airTempRaw) $)$ \\
\hline 285 & airTemp_de gC $=-39.17 * \mathrm{LN}$ (airTempRs_ohms) +410.43 \\
\hline 286 & \\
\hline 287 & 'Measure rainfall amount with TB4 rain gage \\
\hline 288 & Pulsecount (rain_tipCount, $1,1,2,0,1,0$ ) \\
\hline 289 & rain_mm $=$ rain_tipCount*0.254 \\
\hline 290 & \\
\hline 291 & 'For power savings, switch modem on for first 30 minutes per hour to \\
\hline 292 & 'transmit data, off for 30 \\
\hline 293 & RealTime (rTime) \\
\hline 294 & \\
\hline 295 & If Minute $<=$ minuteoff AND Minute $>=$ minuteon Then \\
\hline 296 & modemoff $=0$ \\
\hline 297 & Else \\
\hline 298 & modemoff $=1$ \\
\hline 299 & EndIf \\
\hline 300 & \\
\hline 301 & PortSet $(8$, modemoff $)$ \\
\hline 302 & \\
\hline 303 & 'Call data tables and store data \\
\hline 304 & CallTable rawMeasurements_ $15 \mathrm{~m}$ \\
\hline 305 & CallTable physicalunits_1 $\overline{5} \mathrm{~m}$ \\
\hline 306 & CallTable vwDiagnostics_15m \\
\hline 307 & \\
\hline 308 & NextScan \\
\hline 309 & EndProg \\
\hline 310 & \\
\hline 311 & \\
\hline 312 & \\
\hline
\end{tabular}


st LSb 20150817.CR1

'Program for Sound Transit hydrological monitoring sites

'Smith 20150617

'Modified by Smith on 20150617 for "normally open" modem switch

'Changed EC-5 excitation channels on 20150714

'Modified by Michel on 20150811 to provide updated piezometer calibration

'Modified by Smith On 20150817 to change scan rate

'The underscore character (_) at the end of a line continues a command to the following line

'The apostrophe character (') denotes comments

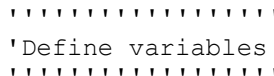

'system variables

Public battV V

Public pTemp_c

Const scanRate $=15$

'system voltage

' logger panel temperature

'minutes

'Modem switching variables

Public rTime(9)

' (1) year, (2) month, (3) day of month,

' (4) hour of day, (5) minutes, (6) seconds,

' (7) microseconds, (8) day of week

' (1-7; Sunday = 1), (9) day of year

Public modemoff

Alias rTime $(4)=$ Hour

'modem is off when modemoff is true $(<>0)$

Alias rTime (5) = Minute

Const minuteoff $=10$

'10 minutes past the hour

Const minuteon $=0$

' 0 minutes past the hour

'Rain gage variables

Public rain tipcount

Public rain_mm

'Volumetric water content variables

Public vwCRaw(5) 'EC-5 volumetric water content sensor, voltage ratio Vin/Vexcite

Public Vwc (5)

Public vwcMult $=2.975$

'EC-5 volumetric water content sensor, converted output

'generic multiplier for Vwc raw to volumetric water content

Public vwcOffs $=-0.4$

'generic offset for vwc raw to volumetric water content

'Tensiometer Serial numbers

'Tens1 = 04339

'Tens2 = 04343

'Tens3 = 0433

' Tensiometer variables

Public seTensPres V(3)

Public seTenstemp_V(3)

Public seTensGround V(3)

Public corrTenspres $V(3)$

'tensiometer temperature reading, raw

'tensiometer ground reading, for differential correction

'differential pressure reading from tensiometer

Public corrTenstemp_V(3)

Public corrTensPres_kPa (3)

'differential temperature reading from tensiometer

'converted pressure reading from tensiometer

'converted temperature reading from tensiometer

Public tensmult $(2)=\{-1 / 10,1$

Public tensoffs $(2)=\{100,-30\}$

'multipliers \{pressure, temperature\} for tensiometer conversion

'offsets \{pressure, temperature\} for tensiometer conversion

'Air temperature variables

Public airTempRaw

'temperature probe raw measurement, $23.1 \mathrm{k}$ completion resistor

Public airTempRs ohm

'resistance of the thermistor

Public airTemp_dege

'resistance reading converted to degrees Celsius

'Vibrating Wire Piezometer variables

Public aVWRC1

'status variable for vibrating wire interface, channel 1

Public vwPiezometer1(6)

Public thermTemp1_degC

Public pHeadl m

Public pHead1_kpa

Public aVWRC2

Public vwPiezometer2(6)

Public thermTemp2_degC

Public pHead2_m

Public pHead2 kpa

'variable array for piezometer 1 reading

'piezometer 1 temperature reading in degrees Celsius

'piezometer 1 pressure reading in meters of head

'piezometer 1 pressure reading in $\mathrm{kPa}$

'status variable for vibrating wire interface, channel 2

'variable array for piezometer 2 reading

'piezometer 2 temperature reading in degress Celsius

'piezometer 2 pressure reading in meters of head

'piezometer 2 pressure reading in $\mathrm{kPa}$

'VW piezometer serial numbers

'VWP \#5 = 2850

'VWP \#6 = 2851 


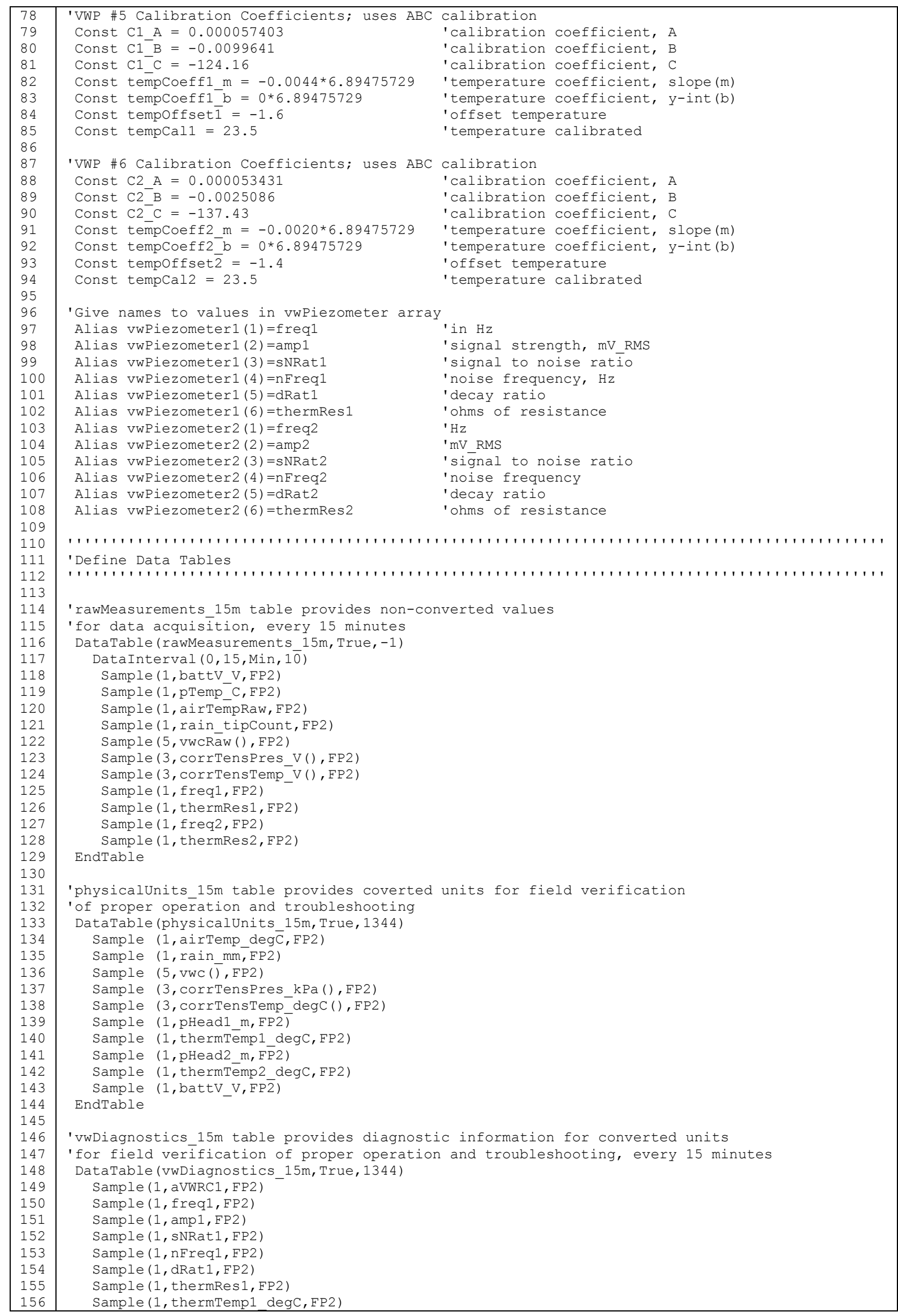




\begin{tabular}{|c|c|}
\hline 157 & Sample (1,pHead1 m, FP2) \\
\hline 158 & Sample $(1$, aVWRC2, FP2 $)$ \\
\hline 159 & Sample (1, freq2, FP2) \\
\hline 160 & Sample (1, amp2, FP2) \\
\hline 161 & Sample (1, sNRat2, FP2) \\
\hline 162 & Sample (1, nFreq2, FP2) \\
\hline 163 & Sample (1, dRat2, FP2) \\
\hline 164 & Sample (1, thermRes2, FP2) \\
\hline 165 & Sample (1, thermTemp2 degC,FP2) \\
\hline 166 & Sample $(1, \mathrm{pHead} 2 \mathrm{~m}, \mathrm{~F} \overline{\mathrm{P}} 2)$ \\
\hline 167 & EndTable \\
\hline 168 & \\
\hline 169 & 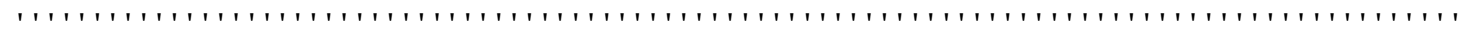 \\
\hline 170 & 'Main Program \\
\hline 170 & 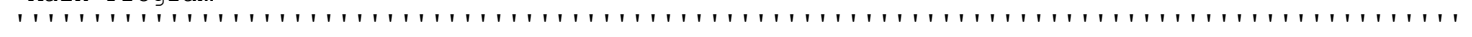 \\
\hline 171 & BeginProg \\
\hline 172 & 'Establish connection with AVW200 vibrating wire interface \\
\hline 173 & Serialopen (Com1, $38400,4,0,0)$ \\
\hline 174 & \\
\hline 175 & 'Begin Scan \\
\hline 176 & Scan (scanRate, min, 1,0) \\
\hline 177 & \\
\hline 178 & 'Battery voltage measurement \\
\hline 179 & Battery (battV_V) \\
\hline 180 & \\
\hline 180 & 'Wiring panel temperature measurement \\
\hline 182 & PanelTemp (pTemp_C,_60Hz) \\
\hline 183 & \\
\hline 184 & '5 Decagon EC-5 measurements \\
\hline 185 & BrHalf (VwcRaw (1), 1,mV2500,10,Vx1, 1,2500, False, $10000,250,1,0$ ) \\
\hline 186 & BrHalf (VwcRaw (2), 1, mV2500,11,Vx1, 1,2500, False, $10000,250,1,0$ ) \\
\hline 187 & BrHalf (VwcRaw (3), 1, mV2500,12,Vx1, 1,2500, false, $10000,250,1,0$ ) \\
\hline 188 & BrHalf (VwcRaw (4), 1, mV2500,13,Vx3,1,2500, False, $10000,250,1,0$ ) \\
\hline 189 & BrHalf (VwcRaw (5), 1, mV2500,14,Vx3,1,2500, False, $10000,250,1,0$ ) \\
\hline 190 & \\
\hline 191 & 'Convert half bridge measurement to Volumetric water content \\
\hline 192 & Dim i \\
\hline 193 & For $i=1$ To 5 \\
\hline 194 & $\operatorname{Vwc}(i)=\operatorname{vwcRaw}(i) * \operatorname{vwcMult}+\operatorname{vwcOffs}$ \\
\hline 195 & Next i \\
\hline 196 & \\
\hline 197 & 'Read three UMS T8 tensiometers \\
\hline 198 & Sw12(1) 'switch on power to tensiometers \\
\hline 199 & Delay $(0,30, \mathrm{Sec})$ 'allow tensiometers to warm \\
\hline 200 & \\
\hline 201 & 'Tensiometer 04339 \\
\hline 202 & 'make single ended tensiometer pressure measurement \\
\hline 203 & VoltSe (seTensPres_V(1), 1, mV2500,1, True, $0,60 \mathrm{~Hz}, 1,0$ ) \\
\hline 204 & 'make single ended tensiometer temperature measurement \\
\hline 205 & VoltSe (seTensTemp_V(1), 1, mV2500,2, False, 0,_60 Hz, 1,0) \\
\hline 206 & 'make ground measurement for differential correction \\
\hline 207 & VoltSe (seTensGround_V(1), $1, \mathrm{mV} 25,3$, False, $0,-60 \mathrm{~Hz}, 1,0$ ) \\
\hline 208 & \\
\hline 209 & 'Tensiometer 04343 \\
\hline 210 & 'make single ended tensiometer pressure measurement \\
\hline 211 & VoltSe (seTensPres_V(2), $1, \mathrm{mV} 2500,4$, True, $0,-60 \mathrm{~Hz}, 1,0$ ) \\
\hline 212 & 'make single ended tensiometer temperature measurement \\
\hline 213 & VoltSe (seTensTemp_V (2), 1, mV2500,5, False, 0, $60 \mathrm{~Hz}, 1,0$ ) \\
\hline 214 & 'make ground measurement for differential correction \\
\hline 215 & VoltSe (seTensGround_V(2), $1, \mathrm{mV} 25,6$, False, $0, \ldots 60 \mathrm{~Hz}, 1,0$ ) \\
\hline 216 & \\
\hline 217 & 'Tensiometer 04338 \\
\hline 218 & 'make single ended tensiometer pressure measurement \\
\hline 219 & VoltSe (seTensPres_V(3), $1, \mathrm{mV} 2500,7$, True, $0,-60 \mathrm{~Hz}, 1,0$ ) \\
\hline 220 & 'make single ended tensiometer temperature measurement \\
\hline 221 & VoltSe (seTensTemp V(3), 1, mV2500,8, False, 0, $60 \mathrm{~Hz}, 1,0$ ) \\
\hline 222 & 'make ground measurement for differential correction \\
\hline 223 & VoltSe (seTensGround_V(3), $1, \mathrm{mV} 25,9$, False, $0,660 \mathrm{~Hz}, 1,0$ ) \\
\hline 224 & \\
\hline 225 & 'Turn of tensiometer power \\
\hline 226 & SW12 (0) \\
\hline 227 & \\
\hline 228 & For $i=1$ To 3 \\
\hline 229 & 'Provide differential correction and engineering unit conversion \\
\hline 230 & 'on tensiometer pressure and temperature readings \\
\hline 231 & corrTensPres_V(i) = seTensPres_V(i) - seTensGround $V(i)$ \\
\hline 232 & corrTensTemp_V(i) = seTensTemp_V(i) - seTensGround_V(i) \\
\hline 234 & \\
\hline 235 & 'Convert corrected readings to physical units \\
\hline
\end{tabular}




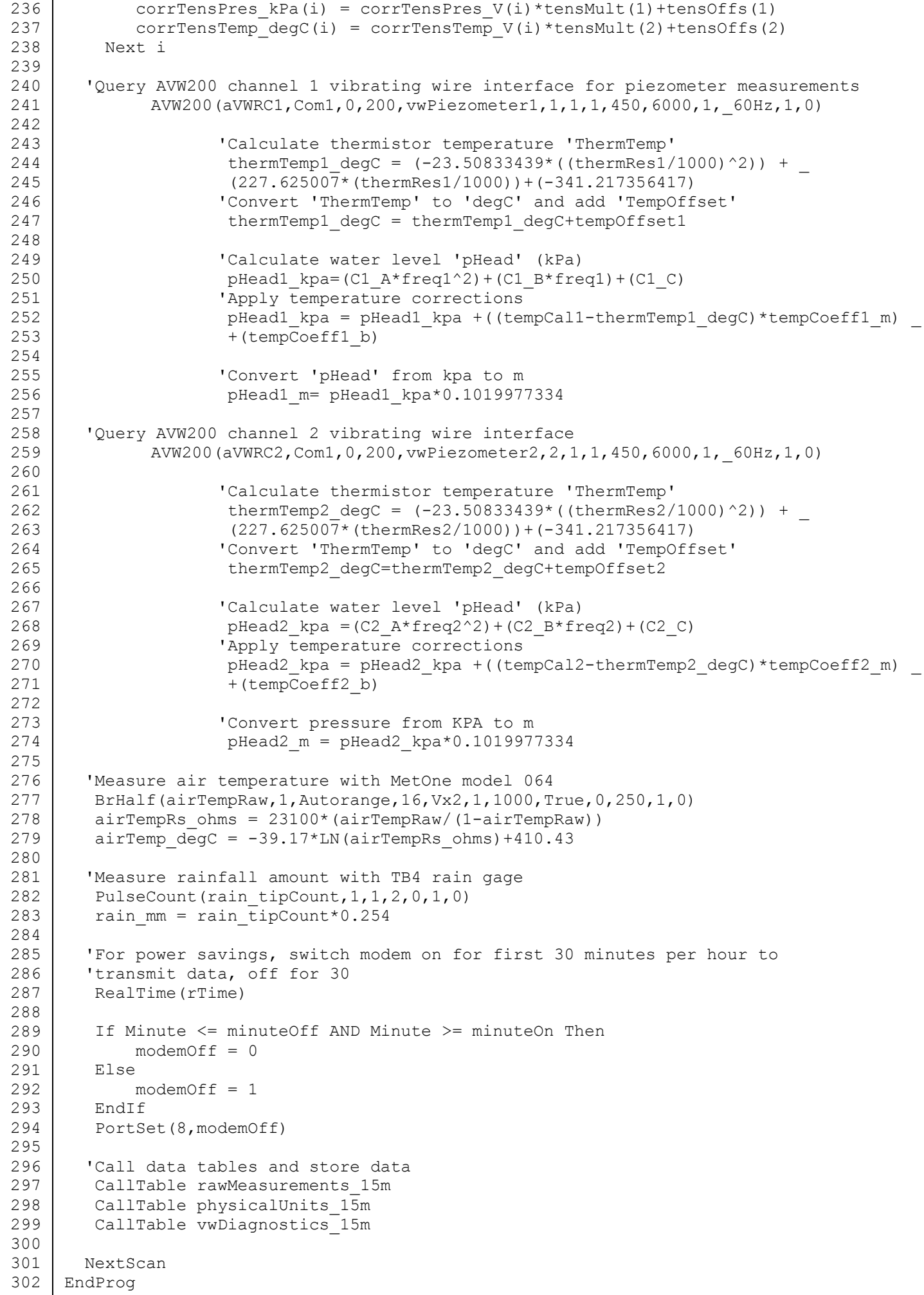


Publishing support provided by: Denver Publishing Service Center, Denver, Colorado

For more information concerning this publication, contact: Director, USGS Geologic Hazards Science Center

Box 25046, Mail Stop 966

Denver, C0 80225

(303) 273-8579

Or visit the Geologic Hazards Science Center Web site at: https://geohazards.cr.usgs.gov/

This publication is available online at: https://doi.org/10.3133/ofr20171095 


\section{$\frac{\mathbb{3}}{3}$}

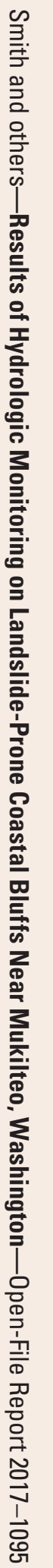

